\title{
KALEIZU TEODORO ROSA
}

Influência dos barorreceptores e da pressão arterial na resposta cardíaca à hipertensão renovascular em ratos

Tese apresentada à Faculdade de Medicina da Universidade de São Paulo para obtenção do título de Doutor em Ciências Área de concentração: Cardiologia Orientadora: Profa. Dra. Maria Cláudia Irigoyen

São Paulo 


\section{KALEIZU TEODORO ROSA}

Influência dos barorreceptores e da pressão arterial na resposta cardíaca à hipertensão renovascular em ratos

Tese apresentada à Faculdade de Medicina da Universidade de São Paulo para obtenção do título de Doutor em Ciências Área de concentração: Cardiologia Orientadora: Profa. Dra. Maria Cláudia Irigoyen

\section{São Paulo}


Dados Internacionais de Catalogação na Publicação (CIP)

Preparada pela Biblioteca da

Faculdade de Medicina da Universidade de São Paulo

Creprodução autorizada pelo autor

Rosa, Kaleizu Teodoro

Influência dos barorreceptores e da pressão arterial na resposta cardíaca à

hipertensão renovascular em ratos / Kaleizu Teodoro Rosa. -- São Paulo, 2008.

Tese(doutorado)--Faculdade de Medicina da Universidade de São Paulo.

Departamento de Cardio-Pneumologia.

Área de concentração: Cardiologia.

Orientadora: Maria Cláudia Irigoyen.

Descritores: 1.Barorreflexo 2.Ecocardiografia 3.Hipertensão 4.Hipertrofia ventricular esquerda 5. Ratos

USP/FM/SBD-239/08 
Minha MÃE, minha MÃE!

Meu orgulho, meu amor, meu TUDO...

Quantas saudades do seu abraço!

Meu PAl querido, que entre tantos ensinamentos, me mostra a cada dia a perseverança e a certeza de que DEUS é maior que tudo!

A vocês dois que ainda são UMA SÓ CARNE, onde fui concebido 


\section{AGRADECIMENTOS}

Sempre, em primeiro lugar Àquele que acredita em mim, apesar de todas as minhas fraquezas. Que me ampara, me ilumina, me governa e me chama de filho: DEUS

À minha orientadora e mestra, Prof ${ }^{a}$. Dra . Maria Cláudia, pela grande confiança e carinho; por me ouvir, me corrigir e estar sempre presente; por me incentivar, me apoiar e me mostrar o caminho

À minha co-orientadora, Prof ${ }^{\mathrm{a}}$. Dr ${ }^{\mathrm{a}}$. Kátia De Angelis, por ser para mim um grande exemplo profissional; pela amizade e respeito e, acima de tudo, pelo estímulo

À Dra . Fernanda Consolim-Colombo, pelo exemplo de devoção profissional e pela confiança em mim depositada na investigação clínica; também pela lucidez na discussão dos resultados, mostrando a importância clínica das observações experimentais aqui descritas 
Ao prezado Prof. Dr. Eduardo Moacyr Krieger, pelos momentos de cultura, filosofia e ciência compartilhados

\begin{abstract}
À Prof ${ }^{a}$. Dr ${ }^{\mathrm{a}}$. Grázia Guerra, pela amizade e momentos de aprendizado; pelo carinho e principalmente pela oportunidade a mim concedida de fazer o quê mais gosto: LECIONAR
\end{abstract}

À Prof ${ }^{a}$. Dr ${ }^{a}$. Patrícia Chakur Brum e à Prof ${ }^{a}$. Dr ${ }^{a}$. Alessandra Medeiros, cujas colaborações engrandeceram sobremaneira este projeto; pela disponibilidade e atenção

Aos queridos amigos do InCor, sem os quais este trabalho não se tornaria possível:

GEORGIA CÂNDIDO, exemplo de comprometimento, caráter e dedicação - sem sua ajuda, eu não conseguiria!

EDSON DIAS MOREIRA, amigo e colaborador, sempre CRISTIANO MOSTARDA, exemplo de perseverança;

LEANDRO EZIQUIEL, grande cirurgião BRUNO RODRIGUES, pela amizade 
Àquele colocado por DEUS em meu caminho e que, embora sem laços de sangue, tornou-se meu irmão; meu confidente, sócio e amigo; me ampara, me corrige e me dá forças. Sem você, tudo isto seria impossível, WEBEL MACHADO LEOPOLDINO

À Prof ${ }^{a}$. Eloise Vieira, pelo carinho, estímulo, incentivo e confiança; amiga de todas as horas

À MARIA LEHTO, anjo que Deus disponibilizou em minha vida para me mostrar a força da doação pessoal gratuita

Às secretárias do setor de Pós-Graduação do InCor: JULIANA, EVA e NEUSA - pela EFICIÊNCIA, CARINHO e ATENÇÃO

A todos os funcionários da EXPERIMENTAÇÃO ANIMAL do InCor, MEUS SINCEROS AGRADECIMENTOS e a certeza de minha GRATIDÃO! 


\section{"ANJA-MARIA" e ZEZINHO}

Talvez sem consciência, mas certamente não sem razão, eram assim chamados por minha MÃE.

Foram, de fato, a "anja" e seu marido - não por coincidência, mas por providência - chamado de JOSÉ, colocados por Deus em sua vida, em cujos instantes finais devotaram-lhe dedicação, conforto e segurança.

Depois de sua partida, deixou-os como substitutos, lugar que ocupam com extrema maestria.

Jamaria e Zezinho, 


\section{Palavras que edificam...}

Algumas palavras, certamente inspiradas por Deus, modificam o curso de nossas vidas. Talvez quem as diga não tenha a dimensão exata do impacto que causam, mas naturalmente quem as ouve, mantêm-nas guardadas no coração.

Se hoje me faço Doutor, muito se deve ao fato de ter escutado em certa ocasião de pessoas muito especiais:

- "Kaleizu, percebe-se em você um talento nato. Você já pensou em seguir carreira acadêmica?"

Iracema e César, grandes amigos, a quem devoto muito carinho e admiração.

Um abraço caloroso de gratidão e amizade! 


\begin{abstract}
ANJO
Anjo sem asa mandada por Deus a seu tempo. Nem cedo, nem tarde... Traz brilho, amor e paz!

Embora os laços de sangue não possam ser escolhidos, comumente Deus nos presenteia com pessoas que transformam nossa rotina num bálsamo de luz. Sentirmo-nos amados por alguém cujo amor é incondicional e gratuito, faz de nós pessoas melhores.
\end{abstract}

Alguém desprendido, devotado e dedicado; alguém que transforma as preocupações diárias em meros detalhes a serem vividos, simplesmente por sabermos de sua presença.

Assim é minha irmã querida, LEDA PAULA, a quem amarei até o último dos meus dias e, por ter plena consciência da impossibilidade de Ihe retribuir todo o conforto e segurança que sua existência me traz, 


\section{AMOR}

Àquela que, se fazendo constantemente presente em minha vida, suporta minha infinita inquietude; suportando minha inquietude, me consola; consolando-me, me mostra outros caminhos.... e me dá PAZ!

Àquela cujo ombro é meu descanso; cujos ouvidos são meu alívio; cujo silêncio me renova; e cujo coração é o meu REFÚGIO!

Àquela a quem eu, pelo fato de ser incapaz de agradecer de maneira adequada,

DIVIDO ESTE TÍTULO!

AMOR e GRATIDÃO ETERNOS,

Andréia 


\section{SUMÁRIO}

Lista de abreviaturas e siglas

Lista de figuras

Lista de tabelas

Resumo

Abstract

Anexos

1. INTRODUÇÃO

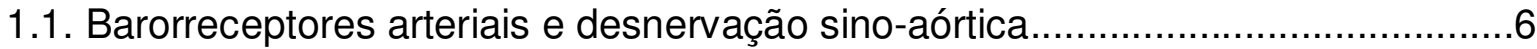

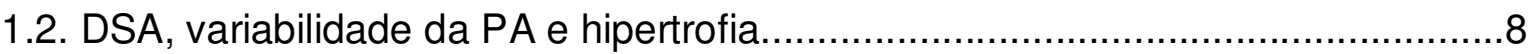

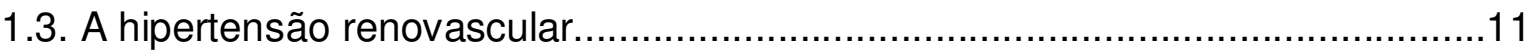

1.4. Proteínas reguladoras da homeostasia do cálcio intracelular e seu papel na

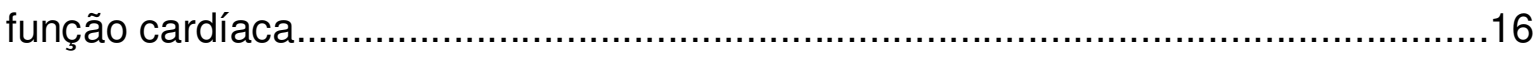

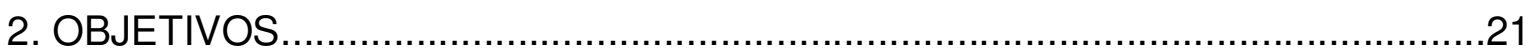

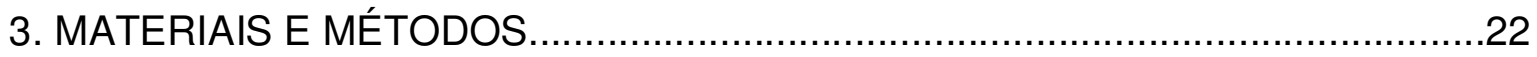

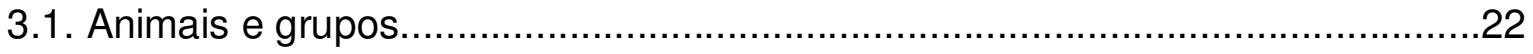

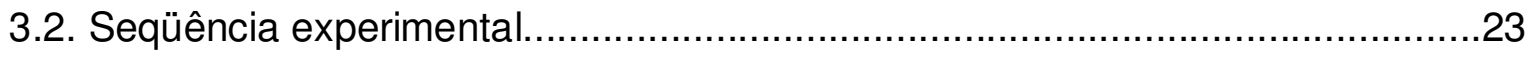

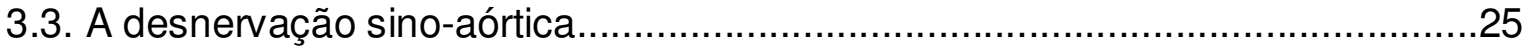

3.4. A indução da hipertensão renal crônica tipo goldblatt 2rins-1 clipe.....................30

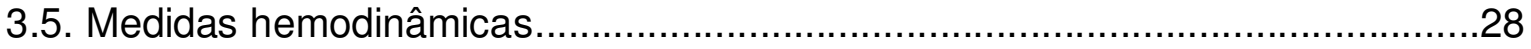

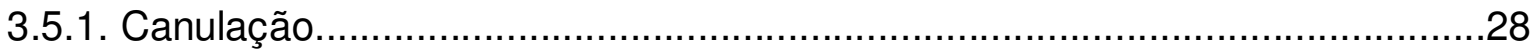

3.5.2. Medidas de pressão arterial e labilidade da PA..............................................30 
3.5.4. Variabilidade do intervalo de pulso (IP) e da pressão arterial sistólica (PAS) no domínio do tempo e da freqüência.

3.6. Ecodopplercardiograma 35

3.7. Sacrifício dos animais .45

3.8. Expressão de proteínas cardíacas. .46

3.8.1. Preparação dos homogeneizados ventriculares 47

3.8.2. Western blot. .48

3. 9. Análise estatística. .50

4. RESULTADOS 51

4.1. Efeitos do tempo de clipe na artéria renal no desenvolvimento da hipertensão e hipertrofia cardíaca. .51

4.1.1. Avaliações hemodinâmicas. 51

4.1.2. Variabilidade da freqüência cardíaca. .55

4.1.3. Variabilidade da pressão arterial sistólica. .56

4.1.4. Avaliações morfométricas. 57

4.1.5. Avaliações da função sistólica. 61

4.1.6. Avaliações da função diastólica. 64

4.1.7. Avaliações post-mortem dos tecidos. 66

4.1.8. Avaliações moleculares das proteínas da homeostase do $\mathrm{Ca}^{2+}$ 69

4.2. Efeitos da pressão arterial e da variabilidade da pressão arterial no desenvolvimento da hipertrofia cardíaca. .72

4.2.1. Avaliações hemodinâmicas. .72 
4.2.2. Variabilidade do intervalo de pulso e variabilidade da freqüência cardíaca no domínio do tempo.

4.2.3. Variabilidade da pressão arterial sistólica e variabilidade da pressão arterial no domínio da freqüência

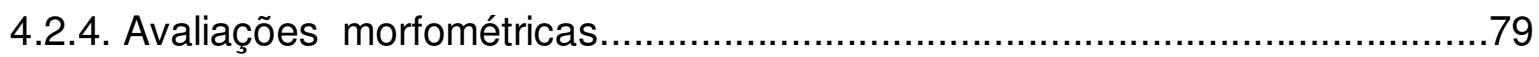

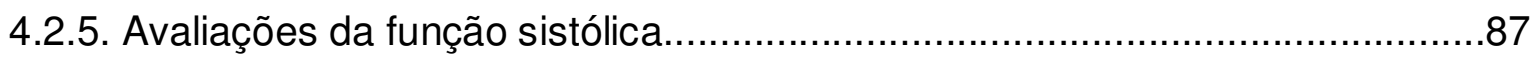

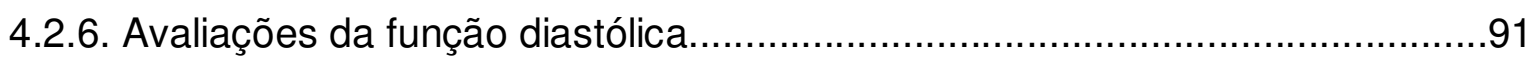

4.2.7. Avaliações post-mortem dos tecidos.................................................

4.2.8. Avaliações moleculares das proteínas da homeostase do $\mathrm{Ca}^{2+}$

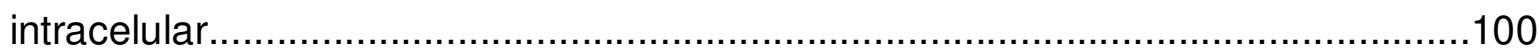

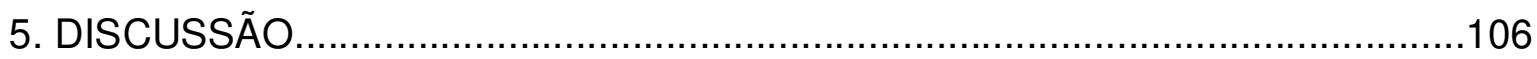

5.1. A desnervação sino-aórtica (DSA) ...........................................................107

5.2. A HIPERTENSÃO RENOVASCULAR - Efeito do tempo do clipe no desenvolvimento da hipertensão e hipertrofia cardíaca.....................................113

5.3. Associação entre DSA+2K1C.............................................................126

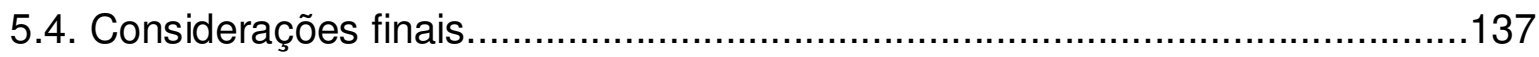

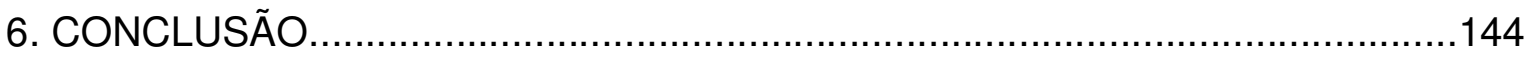

7. REFERÊNCIAS BIBLIOGRÁFICAS ......................................................... 145 


\section{LISTA DE ABREVIATURAS E SIGLAS}

1K1C: One Kidney-One Clip (Ratos 1Rim-1Clip)

2K1C: Two Kidney- One Clip (Ratos 2Rins-1Clip)

AF: Freqüência Alta (estudo da análise espectral)

ANOVA: Análise de Variância

AT: Receptor tecidual da Angiotensina

ATRAMI: Autonomic Tone and Reflexes After Myocardial Infarction (Tônus

Autonômico e Reflexos após Infarto do Miocárdio)

BF: Freqüência Baixa (estudo da análise espectral)

C: Grupo Controle

Cx SD: Coefficient of Standard Deviation (Coeficiente do Desvio Padrão )

D: Diâmetro

DC: Débito Cardíaco

DSA: Desnervação Sino-Aórtica

DSA+2K1C: Ratos com Desenervação Sino-Aórtica + 2 Rins-1Clip

E/A: Relação dos picos E e A no estudo do fluxo transmitral

E'/A': Relação dos picos E' e A' obtidos no estudo Doppler tecidual

E'/A's: Relação dos picos E' e A' obtidos no estudo Doppler tecidual com o volumeamostra posicionado na parede septal do ventrículo esquerdo

E /E ' s: Relação do pico E obtido no estudo Doppler do fluxo transmitral sobre o pico E' obtido no estudo do Doppler tecidual da parede septal do ventrículo esquerdo 
E'/A'p: Relação dos picos E' e A' obtidos no estudo Doppler tecidual com o volumeamostra posicionado na parede lateral do ventrículo esquerdo

ECA: Enzima Conversora da Angiotensina

ERP: Espessura Relativa da Parede

FC: Freqüência Cardíaca

FE: Fração de Ejeção

Fosfo-Ser ${ }^{16}$-PLB: fosfolambam fosforilado na serina- 16

Fosfo-Tre ${ }^{17}$-PLB: fosfolambam fosforilado na treonina-17

$\Delta \mathrm{D} \%$ : Fração de Encurtamento

HRC: Hipertensão Renal Crônica

IBR: Índice de Bradicardia Reflexa

IC: Índice Cardíaco (débito cardíaco corrigido pelo peso corporal)

IDM: Índice de Desempenho Miocárdico

ITR: Índice de Taquicardia Reflexa

IVS: Interventricular Septum (Septo interventricular)

LV: Left Ventricle (Ventrículo Esquerdo)

LVW: Left Ventricle Posterior Wall (Parede do Ventrículo Esquerdo)

MBF: Freqüência Muito Baixa (estudo da análise espectral)

MCT: Monocrotalina

MVE: Massa do Ventrículo Esquerdo

MVEcorr: Massa do Ventrículo Esquerdo corrigida pelo peso

NCX: trocador sódio/cálcio

NTS: Núcleo do Trato Solitário 
PA: Pressão Arterial

PAD: Pressão Arterial Diastólica

PAM: Pressão Arterial Média

PAS: Pressão Arterial Sistólica

PARDIAcorr: Espessura da Parede Posterior do Ventrículo Esquerdo na Diástole corrigida pelo peso corporal

PLB: fosfolambam

R-R: Intervalo entre as ondas $\mathrm{R}$ no traçado eletrocardiográfico

RS: Retículo Sarcoplasmático

SD: Standard Deviation (Desvio Padrão)

SHR: Spontaneously Hipertensive Rats (Ratos Espontaneamente Hipertensos)

SIVDcorr: Espessura do Septo Interventricular na Diástole corrigido pelo peso

SIVDIA: Espessura do Septo Interventricular na Diástole

SNC: Sistema Nervoso Central

SRA: Sistema Renina-Angiotensina

SRAA: Sistema Renina-Angiotensina-Aldosterona

TDE: Tempo de Desaleceração da Onda E

TDEcorr: Tempo de Desaleceração da Onda E corrigido pela freqüência cardíaca

TE: Tempo de Ejeção

TRIV: Tempo de Relaxamento Isovolumétrico

TRIVcorr: Tempo de Relaxamento Isovolumétrico corrigido pela freqüência cardíaca

V: Volume

VD: Ventrículo Direito

VDF: Volume Diastólico Final 
VE: Ventrículo Esquerdo

VEC: Velocidade de Encurtamento Circunferencial

VEDIA: Dimensão da Cavidade do Ventrículo Esquerdo

VEDIAcorr: Dimensão da Cavidade do Ventrículo Esquerdo na Diástole corrigida pelo peso

VE/PESO: Peso do Ventrículo Esquerdo corrigido pelo peso corporal

VESIS: Dimensão da Cavidade do Ventrículo Esquerdo na Sístole

VPA: Variabilidade da Pressão Arterial

VPAS: Variabilidade da Pressão Arterial Sistólica

VSF: Volume Sistólico Final

VTI: Velocity Time Integral (Integral da Velocidade do Fluxo)

WKY: Wistar Kyoto Rats (Ratos Wistar Kyoto) 


\section{LISTA DE FIGURAS}

FIGURA 1: - Determinantes primários da pressão arterial, o débito cardíaco (DC) e a resistência periférica, e a complexa série de fatores que interagem na sua determinação. Anormalidades em um ou vários desses fatores podem levar à hipertensão. SNS (sistema nervoso simpático); SRA (sistema renina angiotensina); FC (freqüência cardíaca). Modificada de Kaplan, $1998^{(2)}$

FIGURA 2: Visão ventral do animal, com incisão expondo a musculatura do pescoço. 26

FIGURA 3: Visão do feixe vásculo - nervoso, após afastamento da musculatura do pescoço 26

FIGURA 4: Inervação na região da bifurcação da carótida. A: localização do nervo laringeo superior; B: detalhe da inervação do corpo carotídeo e dos pressorreceptores carotídeos .27

FIGURA 5: Sítio de dissecção para a cateterização da artéria femoral .29

FIGURA 6: Isolamento da artéria femoral e inserção do cateter. .30

FIGURA 7: Esquema do sistema de registro de Pressão Arterial. .32

FIGURA 8: Modo-M do VE, guiado pelo modo bidimensional, com o cursor posicionado entre a válvula mitral e o músculo papilar, mostrando espessuras diastólica e sistólica do septo-interventricular (IVS), cavidade do ventrículo esquerdo 
na diástole e na sístole (LV) e espessuras diastólica e sistólica da parede posterior do ventrículo esquerdo (LVW) 40

FIGURA 9: Corte apical 4 câmaras mostrando o posicionamento do volume amostra (seta), próximo à face ventricular da válvula mitral para avaliação do fluxo transmitral no estudo do Doppler pulsátil 42

FIGURA 10: Pressão Arterial Média (PAM) nos grupos controle (C), 10 dias de clipe (CLIPE-10) e 30 dias de clipe (CLIPE-30) .53

FIGURA 11: Massa do ventrículo esquerdo obtida pelo ecocardiograma e corrigida pelo peso corporal (MVEcorr), dimensão diastólica do ventrículo esquerdo corrigida pelo peso corporal (VEDIAcorr) e espessura relativa da parede (ERP) nos grupos controle (C), 10 dias de clipe (CLIPE-10) e 30 dias de clipe (CLIPE30). .60

FIGURA 12: Modo $M$ do ventrículo esquerdo de um rato do grupo controle e de um rato do grupo clipe-10 .61

FIGURA 13: Relação E'/A' obtida ao nível do anel mitral da parede septal (E'/A's) e relação E'/A' obtida ao nível da parede lateral do ventrículo esquerdo (E'/A'p) dos grupos controle (C), 10 dias de clipe (CLIPE-10) e 30 dias de clipe (CLIPE30). .66 
FIGURA 14: Fosfolambam fosforilado no sítio de fosforilação da treonina-17 corrigido pelo fofolambam total (PPLBthr17/PLB) e fosfolambam fosforilado no sítio de fosforilação da serina-16 corrigido pelo fofolambam total (PPLBser16/PLB) dos grupos controle (C), clipe-10 e clipe-30 .71

FIGURA 15: Pressão Arterial Média (PAM) dos grupos controle (C), desnervados (DSA), 30 dias de clipe (CLIPE-30) e desnervados com hipertensão (ASSOCIAÇÃO) .74

FIGURA 16: Variabilidade da Pressão Arterial Média (SD PAM) dos grupos controle (C), desnervados (DSA), 30 dias de clipe (CLIPE-30) e desnervados com hipertensão (ASSOCIAÇÃO) 75

FIGURA 17: Massa ventricular esquerda corrigida pelo peso corporal (MVEcorr), dimensão diastólica do VE corrigida pelo peso corporal (VEDIAcorr) e espessura relativa da parede (ERP) dos grupos controle (C), desnervados (DSA), 30 dias de clipe (CLIPE-30) e desnervados com hipertensão(ASSOCIAÇÃO) 82

FIGURA 18: Modo $M$ do ventrículo esquerdo de um rato do grupo controle $(A)$, de um rato do grupo clipe-30 (B) e de um rato do grupo associação (C) .83 
FIGURA 19: Correlação entre o nível de pressão arterial média (PAM) e a espessura relativa da parede (ERP) entre os grupos controle (C), 30 dias de clipe (CLIPE-30) e

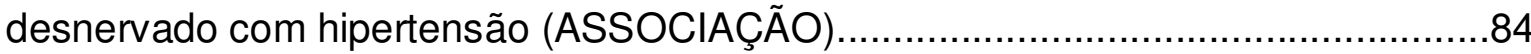

FIGURA 20: Correlação entre o índice de taquicardia reflexa (ITR) e espessura relativa da parede (ERP) entre os grupos controle (C), 30 dias de clipe (CLIPE-30) e desnervado com hipertensão (ASSOCIAÇÃO)

FIGURA 21: Correlação entre o coeficiente da variabilidade da pressão arterial média (Cx SD) e a espessura relativa da parede (ERP) entre os grupos controle (C), 30 dias de clipe (CLIPE-30) e desnervado com hipertensão

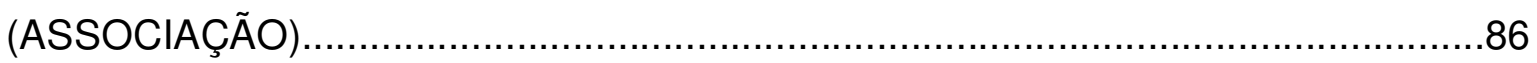

FIGURA 22: Índice de desempenho miocárdico (IDM) dos grupos controle (C), desnervado (DSA), 30 dias de clipe (clipe-30) e desnervado com hipertensão (ASSOCIAÇÃO) 89

FIGURA 23: Correlação entre o índice de desempenho miocárdico (IDM) e espessura relativa da parede (ERP) em ratos dos grupos clipe-10 e associação

FIGURA 24: Tempo de relaxamento isovolumétrico corrigido pela FC (TRIVcorr) e relação E/A no estudo Doppler dos grupos controle (C), desnervado (DSA), 30 dias de clipe (CLIPE-30) e desnervado com hipertensão (ASSOCIAÇÃO). .93 
FIGURA 25: Relações E'/A' do estudo Doppler tecidual obtidos nas paredes septal (E'/A's) e lateral (E'/A'p) do VE dos grupos controle (C), desnervado (DSA), 30 dias de clipe (CLIPE-30) e desnervado com hipertensão (ASSOCIAÇÃO) .94

FIGURA 26: Relação E'/A' obtida pelo Doppler tecidual no nível da valva mitral na parede lateral do VE do grupo controle e do grupo associação. .95

FIGURA 27: Correlação entre o peso do VE corrigido pelo peso corporal (VE/PESO) e massa ventricular esquerda corrigida pela peso corporal (MVEcorr) dos 5 grupos estudados: controle (C), desnervação sino-aórtica (DSA), 10 dias de clipe (CLIPE10), 30 dias de clipe (CLIPE-30) e desnervado com hipertensão (ASSOCIAÇÃO)...98

FIGURA 28: Correlação entre pressão arterial média (PAM) e diferença de peso entre o rim direito corrigido pelo peso corporal e rim esquerdo corrigido pelo peso corporal $(\mathrm{g} / \mathrm{Kg})$ entre os animas do grupo controle, clipe-10, clipe-30 e associação. .99

FIGURA 29: Relação SERCA2/trocador $\mathrm{Na}^{+} / \mathrm{Ca}^{2+}$ (SERCA2/NCX) nos grupos controle (C), desnervado (DSA), 30 dias de clipe (clipe-30) e associação. 102

FIGURA 30: Correlação entre a expressão do trocador sódio/cálcio (NCX) e tempo de relaxamento isovolumétrico corrigido pela freqüência cardíaca dos grupos controle (C), desnervado (DSA), clipe-10, clipe-30 e associação 103 
FIGURA 31: Correlação entre índice de bradicardia reflexa (IBR em bpm/mmHg) e SERCA-2 (em \% do controle) dos grupos controle (C), clipe-10, clipe-30 e desnervado com hipertensão (ASSOCIAÇÃO)

FIGURA 32: Correlação entre o coeficiente da variabilidade da pressão arterial média (CxSD) e a expressão da SERCA-2 nos grupos controle (C), desnervado (DSA), clipe-10, clipe-30 e associação. 


\section{LISTA DE TABELAS}

TABELA 1:. Pressão arterial sistólica (PAS), pressão arterial diastólica (PAD), pressão arterial média (PAM), variabilidade da pressão arterial média (SD PAM), coeficiente da variabilidade da pressão arterial média (Cx SD), freqüência cardíaca (FC) e intervalo de pulso (IP) dos ratos controles (C), 10 dias de clipe (CLIPE-10) e 30 dias de clipe (CLIPE-30). .52

TABELA 2: Índices de bradicardia reflexa (IBR) e taquicardia reflexa (ITR) dos ratos controles (C), 10 dias de clipe (CLIPE-10) e 30 dias de clipe (CLIPE30) 54

TABELA 3. Desvio do intervalo de pulso (SD IP), banda de baixa freqüência (LF), banda de alta freqüência (HF) do intervalo de pulso e a relação entre baixa e alta freqüências (LF/HF) do tacograma dos ratos controles (C), 10 dias de clipe (CLIPE10) e 30 dias de clipe (CLIPE-30). 56

TABELA 4. Variância da pressão arterial sistólica (VPAS) e componente de baixa freqüência (LF) do sistograma dos ratos controles (C), 10 dias de clipe (CLIPE-10) e 30 dias de clipe (CLIPE-30) .57

TABELA 5. Parâmetros ecocardiográficos de morfometria cardíaca dos ratos controles (C), 10 dias de clipe (CLIPE-10) e 30 dias de clipe (CLIPE-30). .59 
TABELA 6. Parâmetros ecocardiográficos de função sistólica dos ratos controles (C) , 10 dias de clipe (CLIPE-10) e 30 dias de clipe (CLIPE-30). 63

TABELA 7. Parâmetros ecocardiográficos da função diastólica dos ratos controles (C) , 10 dias de clipe (CLIPE-10) e 30 dias de clipe (CLIPE-30). .65

TABELA 8. Peso dos tecidos corrigidos pelo peso corporal dos ratos controle (C), 10 dias de clipe (CLIPE-10) e 30 dias de clipe (CLIPE-30).... .68

TABELA 9. Expressões da SERCA-2, trocador sódio-cálcio (NCX), relação serca-2 pelo trocador sódio-cálcio (SERCA-2/NCX), fosfolambam (PLB), relação serca-2 pelo fosfolambam (SERCA-2/PLB), fosfolambam fosforilado no sítio de fosforilação da treonina-17 corrigido pelo fosfolambam total (PPLBthr17/PLB) e fosfolambam fosforilado no sítio de fosforilação da serina-16 corrigido pelo fosfolambam total (PPLBser16/PLB) dos ratos controles (C), 10 dias de clipe (CLIPE-10) e 30 dias de clipe (CLIPE-30) .70

TABELA 10. Pressão arterial sistólica (PAS), pressão arterial diastólica (PAD), pressão arterial média (PAM), variabilidade da pressão arterial média (SD PAM), coeficiente da variabilidade da pressão arterial média (Cx SD), freqüência cardíaca (FC) e intervalo de pulso (IP) dos ratos controles (C), desnervados (DSA), 30 dias de clipe (CLIPE-30) e desnervados com hipertensão (ASSOCIAÇÃO) .73 
TABELA 11. Índices de bradicardia reflexa (IBR) e taquicardia reflexa (ITR) dos ratos controles (C), desnervados (DSA), 30 dias de clipe (CLIPE-30) e desnervados com hipertensão (ASSOCIAÇÃO) .76

TABELA 12. Desvio do intervalo de pulso (SD IP), banda e baixa freqüência (LF), banda alta freqüência $(H F)$ e a relação $L F / H F$ do intervalo de pulso dos ratos controles (C), desnervados (DSA), 30 dias de clipe (CLIPE-30) e desnervados com hipertensão (ASSOCIAÇÃO) .78

TABELA 13. Variância pressão arterial sistólica (VPAS) e componente de baixa freqüência (LF) da pressão arterial sistólica dos ratos controles (C), desnervados (DSA), 30 dias de clipe (CLIPE-30) e desnervados com hipertensão (ASSOCIAÇÃO). 79

TABELA 14. Parâmetros ecocardiográficos de morfometria cardíaca dos ratos controles (C), desenervados (DSA), 30 dias de clipe (CLIPE-30) e desnervados com hipertensão (ASSOCIAÇÃO) .81

TABELA 15. Parâmetros ecocardiográficos de função sistólica dos ratos controles (C), desnervados (DSA), 30 dias de clipe (CLIPE-30) e desnervados com hipertensão (ASSOCIAÇÃO) .88 
TABELA 16. Parâmetros ecocardiográficos da função diastólica dos ratos controles (C), desnervados (DSA), 30 dias de clipe (CLIPE-30) e desnervados com hipertensão (ASSOCIAÇÃO). .92

TABELA 17. Peso dos tecidos corrigidos pelo peso corporal dos ratos controles (C), desnervados (DSA), 30 dias de clipe (CLIPE-30) e desnervados com hipertensão (ASSOCIAÇÃO). .97

TABELA 18. Expressões da SERCA-2, trocador sódio-cálcio (NCX), relação SERCA-2 pelo trocador sódio-cálcio (SERCA-2/NCX), fosfolambam (PLB), relação SERCA-2 pelo fosfolambam (SERCA-2/PLB), fosfolambam fosforilado no sítio de fosforilação da treonina-17 corrigido pelo fosfolambam total (PPLBthr17/PLB) e fosfolambam fosforilado no sítio de fosforilação da serina-16 corrigido pelo fosfolambam total (PPLBser16/PLB) dos ratos controles (C), desnervados (DSA), 30 dias de clipe (CLIPE-30) e desnervados com hipertensão (ASSOCIAÇÃO). 101

TABELA 19 - Sumário dos efeitos do tempo de clipe na artéria renal. 142

TABELA 20 - Sumário dos efeitos da pressão arterial e da variabilidade da pressão arterial. 143 


\section{RESUMO}

Rosa, KT. Influência dos barorreceptores e da pressão arterial na resposta cardíaca à hipertensão renovascular em ratos [tese]. São Paulo. Faculdade de Medicina, Universidade de São Paulo; 2008.

No presente estudo, duas importantes situações foram abordadas no intuito de se melhor entender os mecanismos homeostáticos dos pressorreceptores na gênese da hipertrofia cardíaca em resposta à hipertensão renovascular: o efeito do tempo de clipe na artéria renal e o efeito dos níveis pressóricos e da variabilidade da pressão arterial.

O curso temporal mostrou que, antes mesmo da instalação da hipertensão, há alteração da morfologia cardíaca, qual seja o desenvolvimento de uma hipertrofia ventricular excêntrica e, como forma de mecanismo compensatório, um aumento da expressão de algumas proteínas da homeostase do cálcio (fosfolambam fosforilada pela serina-16 e corrigido pelo fosfolambam total em 100\% e fosfolambam fosforilado pela treonina-17 e corrigido pelo fosfolambam total em $54 \%$ ). Uma vez instalada a hipertensão, observou-se um remodelamento ventricular esquerdo para o tipo concêntrico, com prejuízo da função diastólica e um desbalanço do sistema nervoso autonômico, com aumento da atividade simpática, observado pelo aumento da razão dos componentes de baixa freqüência (LF) e alta freqüência (HF) no tacograma $(0,44 \pm 0,10$ vs. $0,20 \pm 0,03$ nos controles $)$. A análise do efeito da pressão 
arterial e da variabilidade da pressão arterial mostrou uma correlação positiva com o grau de hipertrofia ventricular esquerda $(r=0,76, p<0,01)$.

A secção cirúrgica dos pressorreceptores somada à implantação do clipe na artéria renal mostrou adaptações cardiovasculares em níveis semelhantes (mesmo nível de hipertensão) e, por vezes maiores (modulação simpática para o coração e para os vasos, hipertrofia ventricular esquerda e disfunção diastólica), ao grupo cuja artéria renal foi estenosada e que permaneceu com os barorreceptores intactos. Estas respostas aconteceram num período de tempo três vezes menor na ausência do barorreflexo.

Tais observações ressaltam o importante efeito homeostático do barorreflexo na gênese das respostas cardíacas adaptativas à hipertensão arterial.

Descritores: 1.Barorreflexo 2.Ecocardiografia 3.Hipertensão 4.Hipertrofia ventricular esquerda 5.Ratos 


\section{ABSTRACT}

Rosa, KT. Influence of baroreceptors and of arterial blood pressure in cardiac responses to renovascular hypertension in rats [thesis]. São Paulo: Faculty of Medicine, University of São Paulo (Brazil); 2008.

In the present study, two important situations were observed to evaluate the role of the baroreceptors in the genesis of cardiac hypertrophy in response to hypertension: the effect of the time-course of the clip in the renal artery and the effect of the level of arterial blood pressure (ABP) and blood pressure variability (ABPV).

The time-course evaluation showed that even before hypertension was installed, cardiac alterations could be observed, as a left ventricular eccentric hypertrophy. Compensatory mechanisms, such as an increase in some calcium homeosthatic proteins, could also be noticed (increase in phosphorilated phospholmaban at threonin-17 corrected by total phospholamban in $54 \%$ and increase in phosphorilated phospholmaban at serine-16 corrected by total phospholamban in $100 \%)$. However, once hypertension was established, left ventricle morphology changed to a concentric hypertrophy, accompanied by a diastolic dysfunction and enhanced sympathetic modulation, observed by relation between low-frequency component (LF) and high-frequency component (HF) at tachogram $(0,44 \pm 0,10$ vs. $0,20 \pm 0,03$ in control group).

ABP and ABPV analyses showed an important positive correlation with the degree of left ventricular hypertrophy $(r=0,76, p<0,01)$. However, the absence of baroreceptors in one of the hypertensive groups, evoked the same cardiovascular alterations (same 
level of hypertension) or even worse (sympathetic modulation for heart and vessels, left ventricular hypertrophy and diastolic dysfunction) reached by the hypertensive baroreceptors-preserved group. These cardiovascular responses were observed in a period that correspond one third of time to the group with intact baroreflex.

These observations lead us to conclude the importance of homeosthatic effects of the baroreflex in the genesis of cardiac responses to hypertension.

Descriptors: 1.Baroreflex 2.Echocardiograhy 3.Hypertension 4.Left Ventricular Hypertrophy 5.Rats 
INTRODUÇÃO 


\section{INTRODUÇÃO}

A perfusão tecidual adequada é garantida pela manutenção da força motriz da circulação - a pressão sanguínea - em níveis adequados e razoavelmente constantes, esteja o indivíduo em repouso ou desenvolvendo diferentes atividades. A pressão, definida como força/unidade de área, é uma entidade física. A pressão arterial (PA), portanto, depende de fatores físicos como o volume sangüíneo e a capacitância da circulação, sendo resultante da combinação instantânea entre o volume minuto cardíaco (ou débito cardíaco = freqüência cardíaca x volume sistólico), a resistência periférica e a capacitância venosa, que condiciona a pré-carga e, portanto, o volume sistólico. Cada um destes determinantes primários da PA, é por sua vez determinado por uma série de fatores (Figura 1) (Michelini, 1999; Kaplan, 1998). A manutenção (componente tônico), bem como a variação momento a momento da PA (componente fásico) dependem de mecanismos complexos e redundantes que determinam ajustes apropriados da freqüência e contratilidade cardíacas, do estado contrátil dos vasos de resistência e de capacitância e da distribuição de fluído dentro e fora dos vasos. 


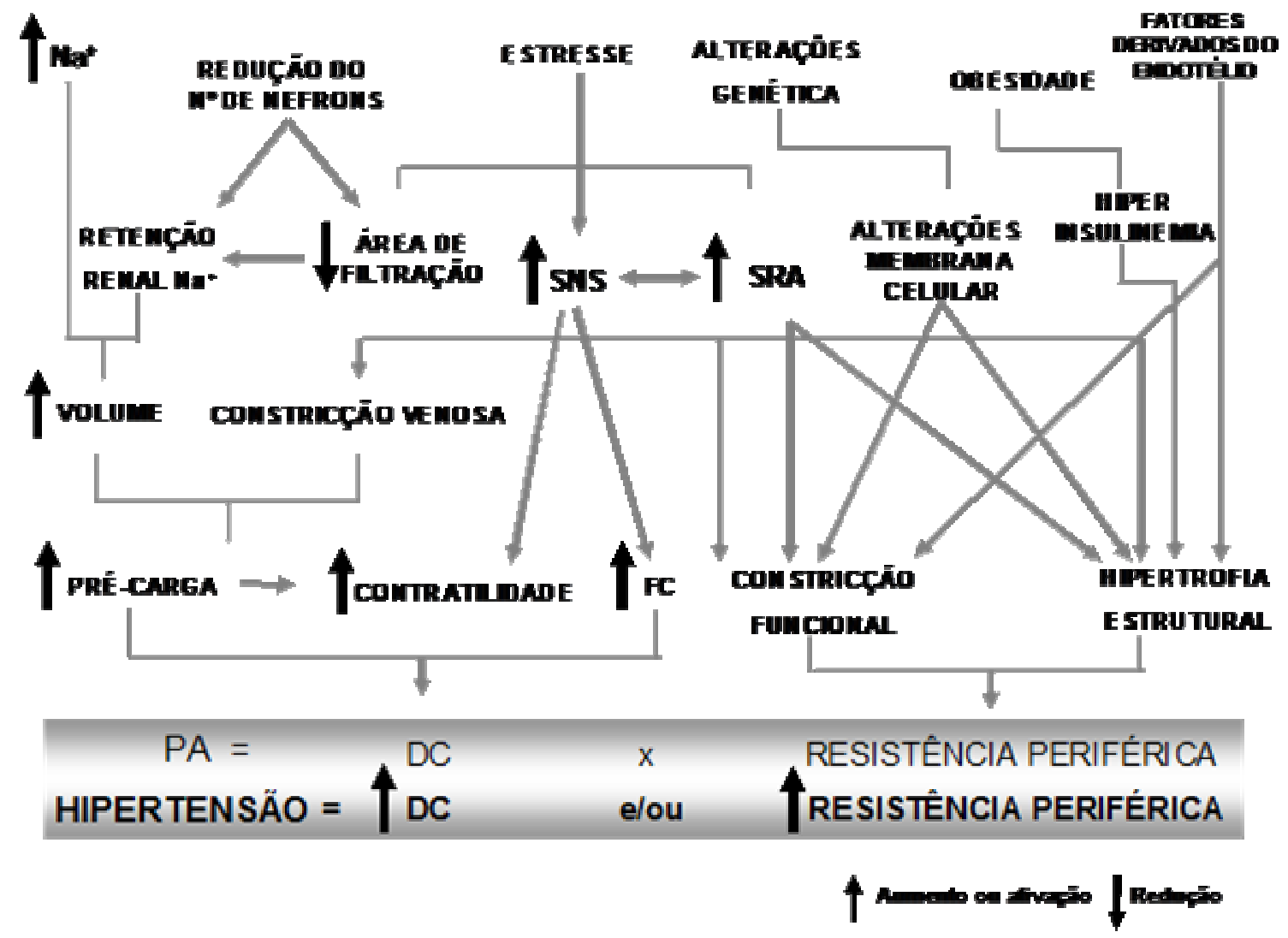

Figura 1 - Determinantes primários da pressão arterial, o débito cardíaco (DC) e a resistência periférica, e a complexa série de fatores que interagem na sua determinação. Anormalidades em um ou vários desses fatores podem levar à hipertensão. SNS (sistema nervoso simpático); SRA (sistema renina angiotensina); FC (freqüência cardíaca). Modificada de Kaplan, $1998^{(2)}$.

$\mathrm{Na}$ hipertensão estabelecida, existem alterações em praticamente todos esses controladores, sendo difícil estabelecer quais os que tiveram papel 
preponderante no desencadeamento e mesmo na manutenção de valores elevados de PA. Embora seja improvável que todos esses fatores estejam alterados ao mesmo tempo num dado paciente, arranjos múltiplos podem ser encontrados, uma vez que o marcador hemodinâmico da hipertensão primária é o aumento persistente da resistência vascular periférica, o qual pode ser determinado através de diferentes associações desses fatores determinantes. Dessa forma, os mecanismos que promovem desequilíbrio entre os fatores pressores e depressores e induzem alteração do calibre das arteríolas merecem especial atenção. Eles atuam basicamente na contração da musculatura que regula a luz do vaso ou na espessura da musculatura, ocupando maior ou menor parte do lúmen, ou em ambos (Michelini, 1999; Krieger e cols., 1999).

A variação do tônus vascular depende de diferentes fatores funcionais. Dentre eles, destaca-se a atividade simpática gerada centralmente e modulada por aferências de diferentes reflexos e por substâncias vasopressoras ou vasodepressoras circulantes ou produzidas pelas células da musculatura lisa ou endoteliais. Um considerável número de evidências dá suporte ao aumento da atividade simpática precocemente na hipertensão (Dequattro e Feng, 2002; Irigoyen e cols., 2001). Sabe-se que embora muitos reflexos estejam envolvidos na modulação da atividade simpática, os barorreceptores arteriais (alta pressão) 
são considerados o mais importante mecanismo de controle reflexo da PA, momento a momento. Tais receptores são, na verdade, mecanorreceptores posicionados estrategicamente na crossa da aorta e no seio carotídeo, que são sensíveis a variações pressóricas, enviando informações de alteração da PA ao sistema nervoso central via nervos vago e glossofaríngeo. A deformação da parede dos vasos induzida por aumentos da PA gera potenciais de ação que são conduzidos ao núcleo do trato solitário (NTS), no sistema nervoso central. A partir daí, são produzidas respostas de aumento da atividade vagal e queda da freqüência cardíaca bem como de redução da atividade simpática para o coração e os vasos, contribuindo para a bradicardia, reduzindo a contratilidade cardíaca e a resistência vascular periférica e aumentando a capacitância venosa. $\mathrm{Na}$ hipertensão sustentada, esses mecanorreceptores sofrem adaptação, deslocando sua faixa de funcionamento para um novo nível de PA, que normalmente é acompanhada de redução da sensibilidade dos pressorreceptores (Krieger e cols., 1982). Isso determina que, para uma igual variação da $\mathrm{PA}$, os hipertensos tenham uma menor quantidade de informações e conseqüentemente uma deficiência na regulação reflexa da PA. A menor sensibilidade dos barorreceptores é provavelmente o maior determinante do aumento da variabilidade da PA (Irigoyen e Krieger, 1998; Floras e cols., 1988) em indivíduos hipertensos, e de forma indireta associada às conseqüentes 
lesões dos órgãos-alvo (Floras e cols., 1988). A disfunção barorreflexa tem sido demonstrada em várias doenças cardiovasculares (La Rovere e cols., 1998) e na hipertensão clínica e experimental (Irigoyen e Krieger, 1998; Mancia e cols., 1997). Dados obtidos em nosso laboratório demonstram que jovens normotensos, filhos de hipertensos, apresentam aumento da PA, dos níveis séricos de catecolaminas e redução da resposta barorreflexa da freqüência cardíaca, quando comparados a jovens filhos de normotensos (Lopes e cols., 1997). Esses dados apontam para o envolvimento precoce do sistema nervoso autônomo na gênese da hipertensão arterial bem como indicam que a predisposição genética para a hipertensão pode cursar com a redução da sensibilidade desse importante mecanismo de controle reflexo momento a momento.

O controle reflexo da circulação comandado pelos barorreceptores tem sido reconhecido também como um importante preditor de risco após evento cardiovascular. De fato, o estudo ATRAMI (Autonomic Tone and Reflexes After Myocardial Infarction) forneceu evidências clínicas do valor prognóstico da sensibilidade do barorreflexo e da variabilidade da freqüência cardíaca na mortalidade cardíaca pós infarto do miocárdio, independente da fração de ejeção do ventrículo esquerdo e de arritmias ventriculares (La Rovere e cols., 1998). 
Desta forma, iniciativas no sentido de melhor entender as repercussões funcionais e/ou estruturais associadas à disfunção barorreflexa abrem novas possibilidades de intervenções que possam contribuir no manejo das lesões de órgãos alvo na hipertensão em geral e nas doenças cardiovasculares em particular.

\subsection{BARORRECEPTORES ARTERIAIS E DESNERVAÇÃO SINO-} AÓRTICA

Os pressorreceptores aórticos e carotídeos constituem-se em terminações nervosas livres na parede do vaso e são considerados o mais importante mecanismo de controle momento-a-momento da pressão arterial (PA). Os pressorreceptores exercem ação no controle reflexo sobre o débito cardíaco e a resistência periférica, graças às múltiplas conexões no sistema nervoso central.

A comprovação da ação inibitória dos pressorreceptores sobre a atividade simpática é dada pelo efeito hipertensor agudo após sua a retirada. A secção cirúrgica das fibras aferentes dos pressorreceptores é denominada desnervação sino-aórtica (DSA) e foi descrita no rato por Krieger (1964). A DSA leva a uma conseqüente ativação de vias simpáticas principalmente para o 
coração, rins e vasos de resistência, provocando elevação da PA e aumento de sua labilidade (Krieger, 1970).

Na fase inicial da DSA, o aumento da atividade simpática e da PA é predominante (Irigoyen e cols., 1988); já na fase crônica, a normalização da PA e atividade nervosa simpática renal refletem o balanço entre efeitos opostos dos presso e quimiorreceptores (Irigoyen e cols.,1995). Uma característica importante deste modelo é o aumento da labilidade da pressão, que se mantém mesmo após a normalização desta (Barres e cols., 1992).

No início da década de 1980, Lundin e colaboradores (1982) demonstraram que a variabilidade da PA (VPA) estava aumentada em ratos espontaneamente hipertensos (SHR), se comparados a linhagens de ratos normotensos. No ano seguinte, Mancia e colaboradores (1983), estudando grupos de pacientes normotensos, com hipertensão moderada e hipertensão severa, demonstraram que havia um aumento da VPA quanto mais grave a hipertensão. Estes e outros estudos abriram caminho para o uso de um modelo de alta VPA e sem hipertensão, consistindo na DSA crônica (Su e Miao, 2001). Além disso, diversos estudos demonstraram que a DSA induz alterações estruturais cardiovasculares e hipertensão, incluindo hipertrofia do coração, arteriosclerose, hipertrofia vascular e lesões renais severas (Su e Miao, 2001; Van Vliet e cols., 1996) 


\subsection{DSA, VARIABILIDADE DA PA E HIPERTROFIA}

A DSA, com a interrupção das vias aferentes que sinalizam a atividade dos pressorreceptores para o sistema nervoso central, tem sido utilizada como um modelo para o estudo da influência do reflexo comandado por estes receptores (barorreflexo) no controle da circulação (Su e cols., 2002). Embora no passado a DSA tenha sido usada como um modelo de hipertensão neurogênica, (Krieger 1964) sabe-se atualmente que a hipertensão é temporária e restringe-se à fase aguda.(Franchini e Krieger, 1992; Irigoyen e cols., 1995) e que, na realidade, a lesão de órgãos-alvo nesse modelo cronicamente, pode estar mais relacionada a labilidade da PA, que permanece, do que aos níveis de PA propriamente ditos, que retornam aos valores de normalidade (Norman e cols., 1981). Existem evidências de que a hipertrofia ventricular esquerda é modesta em ratos com DSA, com índices entre $11 \%$ e $16 \%$ de aumento do ventrículo esquerdo observados 6, 10 e 16 semanas após a cirurgia de desnervação (Miao e Su, 2002), quando comparados esses índices com aqueles observados em SHR (30\%) (Lo e cols., 1990) e na hipertensão renal, 2K1C e 1K1C (32\%) (Jones e Floras, 1980). Esses dados parecem indicar que a hipertensão mais do que a labilidade é o fator crítico para

o desenvolvimento da hipertrofia ventricular esquerda. Alternativamente, a 
hipertrofia ventricular esquerda poderia também ser causada pela associação de hipertensão e labilidade da PA, uma vez que na hipertensão espontânea em ratos existe aumento da variabilidade da PA (Dias e cols., 2002).

Vários trabalhos ressaltam o desenvolvimento de hipertrofia de ventrículo direito (VD) induzida pela DSA e que estaria relacionada ao desenvolvimento de hipertensão pulmonar (Van Vliet e cols.,1996; Ou e Smith, 1983; Krishnan, 2000). Neste sentido, Galinier e colaboradores (1995) demonstraram que em cães, a desnervação sino-aórtica causa hipertensão pulmonar transitória e aguda, devido a dois mecanismos: hipertensão pós - capilar secundária e aumento da pós - carga no ventrículo esquerdo devido à hipertensão sistêmica e à hipertensão pré - capilar.

A hipertensão pulmonar é uma doença caracterizada pelo remodelamento vascular progressivo, produzindo insuficiência do ventrículo direito (Setoguchi e Fukuchi, 2001). Com o intuito de melhor entender os processos envolvidos na fisiopatologia da hipertensão pulmonar, foram desenvolvidos modelos animais de hipertensão pulmonar. Em ratos, os modelos mais utilizados são os da hipóxia e o da injeção de monocrotalina (MCT). A exposição prolongada à hipóxia induz mudanças fisiológicas nos vasos pulmonares e aumento no tônus vasomotor. Já as mudanças patológicas por MCT incluem lesão no endotélio arterial pulmonar e infiltrado inflamatório alveolar, e o espaço sub - endotelial 
apresenta aberturas na lâmina elástica interna se comparada com as artérias pulmonares normais (Tanaka e cols., 1996).

Existem poucos modelos para estudo da hipertrofia ventricular direita e sua possível influência no sistema pulmonar. Neste sentido, um modelo que parece se prestar bem a este estudo é o da desnervação sino-aórtica, já que mostra agudamente hipertensão pulmonar e cronicamente hipertrofia de ventrículo direito.

Sobre este assunto, existe um trabalho na literatura que demonstrou que a hipertrofia de VD na DSA é conseqüência da desnervação carotídea produzida pela DSA, reforçando a idéia de que esse processo pudesse estar associado a alterações na circulação pulmonar (Van Vliet e cols., 1999). A ocorrência de hipertrofia ventricular direita na DSA foi demonstrada pela primeira vez por Van Vliet e colaboradores em 1996. Entretanto, dados sobre peso corporal e diferentes espécies de ratos utilizados ainda levantam dúvidas quanto aos resultados de hipertrofia direita nesse animais, em períodos de um a dois meses após a DSA (Miao e cols., 2003).

Embora este modelo tenha sido muito bem caracterizado quanto ao controle autonômico da pressão arterial e à regulação do sistema reninaangiotensina (Shan e cols., 2003) mostra-se um campo pouco explorado no que diz respeito à regulação das câmaras cardíacas e ao papel da variabilidade da 
pressão arterial sobre a estrutura do sistema cardiovascular. Além disso, a relação entre a variabilidade da pressão arterial e os mecanismos envolvidos na hipertrofia cardíaca em diferentes modelos de hipertensão estão pouco estudados.

\subsection{A HIPERTENSÃO RENOVASCULAR}

Richard Bright, em 1836, foi o primeiro a reconhecer a associação entre doença renal e hipertensão. Em um estudo de patologia post-mortem, ele constatou que 100 pacientes com urina albuminosa apresentavam paralelamente às lesões renais, hipertrofia do VE. Ele concluiu que o espessamento do VE estava associado com um esforço não usual ao qual o coração estava submetido para impelir o sangue. Essas observações estimularam a busca de mecanismos pelos quais o rim pudesse produzir esses efeitos e em 1898, Tigerstedt e Bergmann demonstraram que um extrato de córtex renal de coelho produzia uma prolongada resposta pressora após administração intravenosa. Eles sugeriram que uma substância vasoativa, sensível ao calor, que eles chamaram de hipertensina, "passa pelos rins através do sangue, e exerce de alguma forma, um efeito de aumentar a pressão". Posteriormente, tal substância, a hipertensina, passou a ser chamada então, de 
renina. A importância desse estudo, entretanto, ficou ignorada devido aos efeitos variáveis pressores e vasodilatadores dos extratos renais (Goldblatt e cols., 1934) e `a falta de um modelo experimental reprodutível de hipertensão renal.

Nesse sentido, várias tentativas foram feitas para induzir hipertensão renal (nefrectomia parcial, irradiação dos rins, bandeamento da veia renal em combinação com o envolvimento do rim com uma membrana de celofane (Cash, 1924; Chautin e Ferris, 1932; Hartman e cols., 1926; Pederson, 1927). Mas foram Goldblatt e seus colaboradores que conseguiram produzir um modelo de hipertensão renal pela constrição das artérias renais de um cão com clipes de prata ajustáveis (Goldblatt, 1934). Eles demonstraram que a constrição bilateral da artéria renal ou a constrição mais a nefrectomia unilateral, produziam hipertensão. Este foi um trabalho pioneiro pois produziu um modelo experimental para investigar os mecanismos da hipertensão, e também estimulou estudos bioquímicos detalhados sobre a natureza do sistema renina-angiotensina (Braun-Menendez e cols., 1940; Skeggs e cols., 1954). Em seqüência, outros pesquisadores buscaram diferentes técnicas de induzir a isquemia renal em diferentes espécies (Rytand, 1938; Page, 1939).

Os modelos de Goldblatt foram usados e logo ficou claro que a constrição de uma artéria renal, permanecendo o outro rim intacto, levava a uma 
hipertensão temporária de poucos dias de duração no cão (Goldblatt, 1943) e no coelho (Pickering e Prinzmetal, 1938). Em 1939, Wilson e Byrom adaptaram o clipe de prata para o rato e produziram, com sucesso, hipertensão sustentada pela oclusão parcial de uma artéria renal, deixando o outro rim intacto. As mudanças entre as espécies, parecem ser devidas a respostas peculiares como o desenvolvimento de uma circulação colateral efetiva no cão, com vasos crescendo no rim a partir de tecidos perivasculares (Cerqua e Samaan, 1939). Essa peculiaridade de resposta foi suplantada com o estabelecimento da cirurgia em dois estágios (oclusão parcial no primeiro e oclusão total no segundo, uma semana depois) (Massaki e cols., 1977), garantindo no cão o estabelecimento da hipertensão pelo uso do modelo de 2K1C. No rato, tanto este quanto o modelo $1 \mathrm{~K} 1 \mathrm{C}$ são efetivos em produzir uma hipertensão estável (revisado por Swales e cols., 1971).

Em ambos os modelos, a fase inicial de estabelecimento da hipertensão é caracterizada por um rápido aumento da renina plasmática em resposta a reduzida pressão na artéria renal e pelo conseqüente aumento da Angiotensina II circulante. Entretanto, os mecanismos envolvidos na fase crônica de manutenção da hipertensão diferem. No modelo $2 \mathrm{~K} 1 \mathrm{C}$, a hipertensão é sustentada por um sistema renina-angiotensina continuamente ativado porque a diurese do rim contralateral normal, previne a hipervolemia. Em contraste, a 
retenção de volume pelo único rim estenótico do animal 1K1C, inibe a secreção de renina, levando a um modelo de hipertensão com renina baixa e dependente de volume. Entretanto, ambos os modelos desenvolvem hipertrofia cardiovascular (De Simone, 1992).

Em 2K1C, a hipertensão é mantida por um aumento na resistência periférica, associada com uma redução no índice cardíaco tanto aguda, como cronicamente (Russel e cols., 1983). A capacidade vascular está reduzida, embora não pareça haver alteração da complacência (Edmunds e cols., 1989; Yamamoto e Ogino, 1982). O aumento da resistência vascular periférica na fase aguda deve estar associado a fatores neuro-humorais, enquanto na fase crônica existe um reforço produzido pelas alterações estruturais dos vasos. (Folkow e cols., 1973).

Em relação ao coração, a hipertrofia pode ser demonstrada tão cedo quanto 7 dias após a colocação do clipe (Lundgren e Weiss, 1979), embora estudos em animais com mais do que 6 a 8 semanas de cirurgia tenham demonstrado aumento no volume dos cardiomiócitos, da flbrose cardíaca intersticial e espessamento das paredes dos vasos miocárdicos (Hocher e cols., 1999; Smith e cols., 1988; Mall e cols., 1989; Fischer e cols., 1992), consistentes com a visão de que este tipo de hipertensão induz um progressivo e lento remodelamento cardíaco. Parece, entretanto, que observações recentes 
de alterações rápidas e substanciais no peso do VE associadas com reexpressão do gene do peptídeo natriurético atrial (um marcador molecular de hipertrofia patológica do VE) 1 ou 2 semanas após a colocação do clipe, tem modificado essa visão. (Ehmke e cols., 1999; Ito e cols., 1994).

Embora reconhecido como uma marcador de prognóstico frente a diferentes patologias do sistema cardiovascular (La Rovere, 1998), a sensibilidade do barorreflexo tem sido pouco estudada com relação à evolução das alterações estruturais do miocárdio frente a sobrecarga de pressão ou volume. Trabalhos de Miao e Su $(2002 ; 2003)$ utilizando o modelo da DSA têm demonstrado repetidamente a importância desse mecanismo homeostático na resposta adaptativa do sistema cardiovascular, independentemente do nível da PA, ao comparar ratos desnervados normotensos e ratos SHR. Com relação à hipertensão renovascular, embora existam dados de comprometimento do barorreflexo (Farah e cols., 2001; Sumitani e Krieger, 1981) não existem informações sobre o papel do barorreflexo nas respostas dos diferentes órgãos nesse tipo de hipertensão. Um trabalho pioneiro de Masson e colaboradores (1966) demonstrou uma potenciação dos efeitos pressores da hipertensão renal moderada após a retirada dos aferentes aórticos e carotídeos, indicando ainda um papel preponderante dos primeiros sobre os carotídeos nesse efeitos. Embora os autores discutissem a diferença de efeitos das duas intervenções 
(desnervação e colocação do clipe) sobre o miocárdio não foram analisados os efeitos associados.

\subsection{PRoteínAs REguladoras dA homeostasia do cálcio INTRACELULAR E SEU PAPEL NA FUNÇÃO CARDÍACA}

Embora $\circ \mathrm{Ca}^{2+}$ represente $\circ$ maior mensageiro intra-celular, regulando diversas atividades como contratilidade, metabolismo, transporte, secreção e transcrição (Zaugg e Schaub, 2004), ele é altamente tóxico para quaquer célula. A sinalização do $\mathrm{Ca}^{2+}$ para diferentes respostas celulares depende da manutenção da homeostasia do $\mathrm{Ca}^{2+}$ intracelular, a qual é fortemente controlada pela cascata de sinalização adrenérgica. Vários canais, bombas e trocadores são responsáveis pela manutenção de altas concentrações de $\mathrm{Ca}^{2+}$ intracelular durante a sístole e baixas concentrações de $\mathrm{Ca}^{2+}$ durante a diástole.

Para que ocorra o processo de excitação-contração, primeiramente ocorre a entrada de $\mathrm{Ca}^{2+}$, principalmente via canais de $\mathrm{Ca}^{2+}$ voltagem-dependentes (tipo L), presentes no sarcolema da célula, na região dos túbulos-T. Em seguida, a entrada de $\mathrm{Ca}^{2+}$ na célula induz a liberação de $\mathrm{Ca}^{2+}$ pelos canais de rianodina, presentes no retículo sarcoplasmático, processo este chamado de liberação $\mathrm{Ca}^{2+} \mathrm{Ca}^{2+}$ induzido (Berridge, 1997; Carafoli, 2002). 
O decréscimo do desempenho do cardiomiócito é determinado por alterações bioquímicas decorrentes de modificações na expressão de proteínas intracardiomiócito que participam da regulação do processo excitaçãocontração e de relaxamento do miócito (Balke e Shorofsky, 1998). O exemplo mais marcante dessa modificação é a redução de RNAm para proteínas formadoras das bombas SERCA-2 no miócito hipertrofiado de pacientes com disfunção ventricular (Colucci, 1997). A SERCA-2 é uma $\mathrm{Ca}^{2+}$ ATPase do retículo sarcoplasmático responsável pela recaptação de $\mathrm{Ca}^{2+}$ pelo retículo sarcoplasmático. A diminuição do número dessas bombas, portanto, reduz a captação de $\mathrm{Ca}^{2+}$ citosólico pelo retículo sarcoplasmático, aumentando a ligação de $\mathrm{Ca}^{2+}$-troponina, o quê dificulta 0 fenômeno de relaxamento miocárdico. No miocárdio de pacientes com insuficiência cardíaca, há diminuição da atividade e expressão da SERCA-2, o quê resulta numa menor recaptação de $\mathrm{Ca}^{2+}$ citosólico para o retículo sarcoplasmático (Hajjar e cols., 1998; Meyer e cols., 1995; Schwinger e cols., 1999). A SERCA-2 é uma proteína de $110 \mathrm{kDa}$ e encontra-se sob controle direto do fosfolambam, que por sua vez, é uma proteína de $25 \mathrm{kDa}$ (na forma de pentâmero) controlada diretamente pela proteína quinase A e pela proteína quinase dependente de $\mathrm{Ca}^{2+}$-calmodulina. Portanto, outro mecanismo que poderia estar envolvido na menor recaptação de $\mathrm{Ca}^{2+}$ pelo retículo sarcoplasmático no miocárdio de 
indivíduos com insuficiência cardíaca seria o aumento da expressão ou diminuição da fosforilação do fosfolambam. O fosfolambam, quando defosforilado, inibe a atividade da SERCA-2 diminuindo sua atividade por $\mathrm{Ca}^{2+}$. Mediante a estimulação das vias adrenérgicas, a proteína quinase $A$ fosforila 0 fosfolambam no resíduo da serina-16, e a proteína quinase $\mathrm{Ca}^{2+}$-calmodulina fosforila o fosfolambam no resíduo da treonina-17. Quando fosforilado, o fosfolambam deixa de inibir a SERCA-2. Alguns estudos têm demonstrado diminuição na expressão (Kiss e cols., 1995) e outros, aumento na atividade (Meyer e cols., 1995; Schwinger e cols., 1999) de fosfolambam na insuficiência cardíaca. Esta controvérsia parece estar relacionada às diferentes etiologias da insuficiência cardíaca. Camundongos com aumento na expressão de receptores $\beta$-adrenérgicos (Engelhardt e cols., 1999; Liggett e cols., 2000) ou de fosfolambam (Dash e cols., 2001) apresentam a médio-longo prazo, anormalidades na recaptação de $\mathrm{Ca}^{2+}$ citoplasmático para o retículo sarcoplasmático.

Outra importante proteína para a redução do $\mathrm{Ca}^{2+}$ do citosol é o trocador $\mathrm{Na}^{+} / \mathrm{Ca}^{2+}$. O Ca ${ }^{2+}$ do meio intracelular precisa ser reduzido para que o processo de relaxamento ocorra adequadamente e há dois mecanismos conhecidos de redução do $\mathrm{Ca}^{2+}$ : a recaptação pelo retículo sarcoplasmático através da SERCA-2 e sua extrusão da célula através do trocador $\mathrm{Na}^{+} / \mathrm{Ca}^{2+}$. Este último 
parece ser o mecanismo mais importante da extrusão do $\mathrm{Ca}^{2+}$ pelo sarcolema (Lu e cols., 2002; Mace e cols., 2003).

Diversos trabalhos têm demonstrado alterações na expressão dessa proteína na insuficiência cardíaca (Hatem e cols., 1994; Lu e cols., 2002). Fowler e cols. (2007) demonstraram aumento da expressão dessa proteína aos 8 meses de idade em ratos SHR, quando comparados a seus controles, WistarKyoto, como mecanismo compensatório ao déficit de relaxamento. $\mathrm{Na}$ hipertrofia cardíaca induzida pela hipertensão renovascular em ratos, também parece haver evidências do aumento na expressão do trocador $\mathrm{Na}^{+} / \mathrm{Ca}^{2+}(\mathrm{Lu} \mathrm{e}$ cols., 1999).

Assim, a homeostasia do $\mathrm{Ca}^{2+}$ intracelular nas mais diversas patologias cardiovasculares, têm sido objeto de vários estudos na literatura e o sistema nervoso simpático parece estar envolvido tanto no aumento na concentração do $\mathrm{Ca}^{2+}$ intracelular na diástole (Hajjar e cols., 1998; Kiss e cols., 1995), como na redução de sua liberação durante a sístole (Marks, 2000).

Não existem dados, entretanto, que informem sobre a homeostasia do $\mathrm{Ca}^{2+}$ intracelular na desnervação sinoaórtica ou disfunção barorreflexa completa, quando tanto aguda como cronicamente existe desregulação do controle da atividade simpática peroférica. Adicionalmente, na hipertensão crônica não se conhece se o grau de disfunção do barorreflexo pode ou não 
contribuir para as alterações da função contrátil cardíaca e quanto essas alterações podem estar associadas a mudanças na homeostasia do $\mathrm{Ca}^{2+}$ intracelular.

Após essa breve revisão da literatura, constatmos a ausência de informações consistentes sobre o papel dos barorreceptores nas adaptações morfo-funcionais do coração à hipertensão. Portanto, nesse estudo testaremos a hipótese de que a denservação sino-aórtica modifica a resposta temporal das adaptações cardíacas na hipertensão $2 \mathrm{~K} 1 \mathrm{C}$. 
OBJETIVOS 


\section{OBJETIVOS}

O objetivo deste trabalho é avaliar a importância do barorreflexo nas adaptações cardíacas e hemodinâmicas à hipertensão renovascular em ratos, levando-se em conta os efeitos do curso-temporal e da variabilidade da pressão arterial. 
MATERIAIS E MÉTODOS 


\section{MATERIAIS E MÉTODOS}

\subsection{ANIMAIS E GRUPOS}

Foram utilizados ratos machos Wistar provenientes do Biotério Central da Faculdade de Medicina da USP, com idade entre 8 a 9 semanas de vida e peso aproximado de 170 - 200 gramas (g). Os grupos foram divididos conforme se segue:

1) Grupo controle - $\mathbf{3 0}$ dias ( $C, n=6)$ : acompanhados por 30 dias

2) Grupo desnervado - $\mathbf{3 0}$ dias (DSA, $n=6$ ): submetidos a cirurgia de desnervação sino-aórtica no $1^{\circ}$ dia de protocolo, sendo acompanhados até o $30^{\circ}$ dia de estudo.

3) Grupo clipe - $\mathbf{3 0}$ dias (CLIPE-30, $n=6$ ): submetidos à cirurgia de dois rins - um clipe no $1^{\circ}$ dia de protocolo, sendo acompanhados até $030^{\circ}$ dia de experimento.

4) Grupo clipe- 10 dias (CLIPE-10, $n=6$ ): submetidos à cirurgia de dois rins - um clipe no $20^{\circ}$ dia de protocolo, sendo acompanhado até o $30^{\circ}$ dia de protocolo.

5) Grupo desnervado com hipertensão - $\mathbf{3 0}$ dias (ASSOCIAÇÃO, $n=6$ ): submetidos à cirurgia de desnervação sino-aórtica no $1^{\circ}$ dia de protocolo e à 
cirurgia de dois rins - um clipe no $20^{\circ}$ dia de protocolo, sendo acompanhados até o $30^{\circ}$ dia de protocolo.

\subsection{SEQÜÊNCIA EXPERIMENTAL}

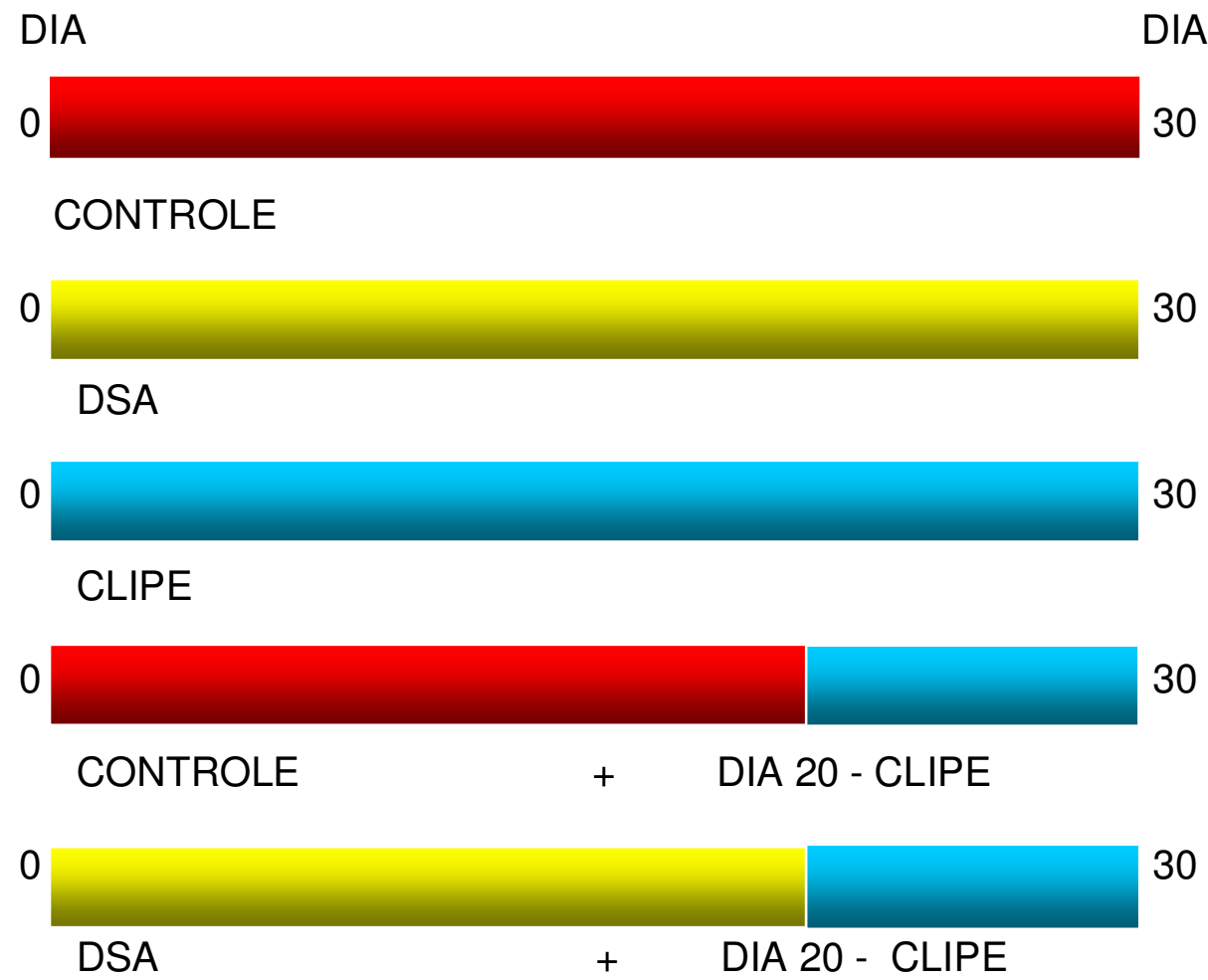


Os grupos foram divididos de maneira a fornecer informações quanto à importância do tempo de clipe na artéria renal no desenvolvimento da hipertensão e hipertrofia cardíaca (controle, clipe-10 e clipe-30) e a fornecer informações quanto à importância da pressão arterial e variabilidade da pressão arterial no desenvolvimento da hipertrofia cardíaca (controle, desnervação sinoaórtica, clipe-30 e associação).

O grupo associação passou pela cirurgia da desnervação sino-aórtica no dia 0 do experimento e pela implantação do clipe na artéria renal esquerda no dia 20. Portanto, no final do protocolo experimental, estes animais estavam com 30 dias de DSA e com 10 dias de clipe.

Os animais do grupo clipe-10 permaneceram intactos durante os primeiros 20 dias de experimento, quando então, receberam o clipe de prata na artéria renal esquerda, chegando ao final do protocolo com 10 dias de clipe. Este grupo foi incluído na seqüência experimental por entendermos que a diferença de peso dos animais e, portanto do calibre da artéria renal, possa representar um viés na interpretação dos resultados. 


\subsection{A DESNERVAÇÃO SINO-AÓRTICA}

Foi utilizado o método de desnervação sino-aórtica (DSA) descrito para o rato por Krieger (1964), que consiste em uma incisão mediana na região cervical anterior (Figura 2), separação dos músculos pré-traqueais e localização bilateral do feixe vásculo nervoso (Figura 3), constituído pela artéria carótida, nervo vago e tronco simpático. As fibras pressorreceptoras aórticas que trafegam junto ao tronco simpático ou como nervo isolado foram secionadas. $\mathrm{O}$ outro contingente de fibras aórticas que situava-se junto ao laringeo inferior foi interrompido quando seccionou-se o laringeo superior ou como fibras isoladas junto ao laríngeo inferior (Krieger e Marseillan, 1963). Em um plano superior, a bifurcação da carótida comum foi localizada (Figura 4, A e B), exposta e dissecada completamente nos dois lados (seccionando-se as fibras carotídeas e destruindo-se o corpúsculo carotídeo). Logo após, o nervo laringeo superior foi seccionado bilateralmente. O procedimento cirúrgico foi realizado mediante a um protocolo anestésico que consistiu de ketamina $(50 \mathrm{mg} / \mathrm{Kg})$ e xilazina $(10$ $\mathrm{mg} / \mathrm{Kg}$ ), administrados por via intra-peritoneal. Após a cirurgia os animais receberam 0,2 $\mathrm{ml}$ de antibiótico intramuscular (Benzetacil, Fontoura-Wyeth, Brasil). 


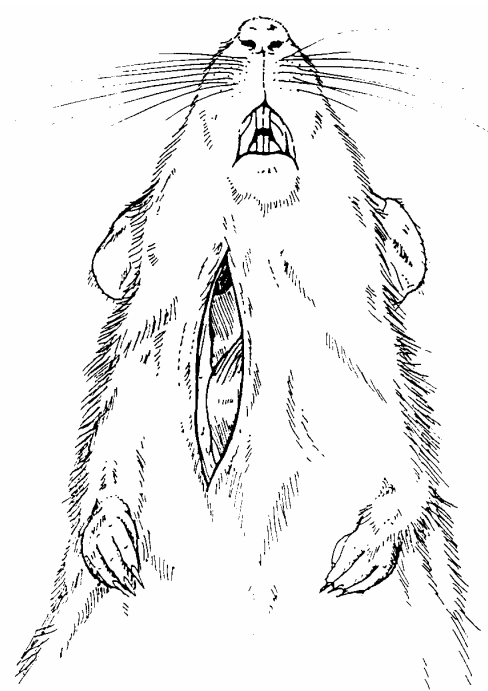

Figura 2 - Visão ventral do animal, com incisão expondo a musculatura do pescoço (Desenho: S. Lacchini).

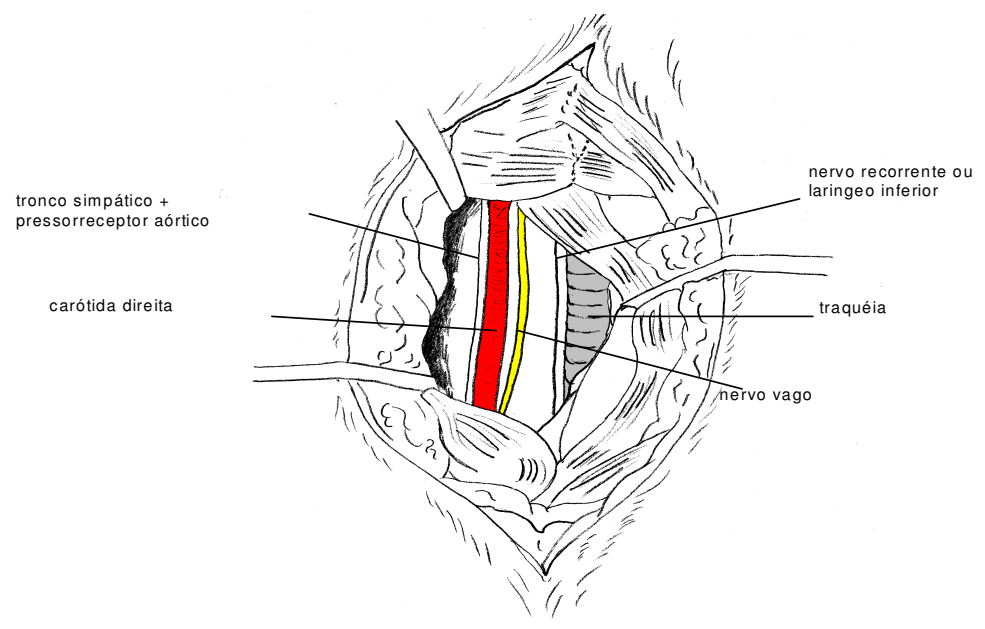

Figura 3 - Visão do feixe vásculo - nervoso, após afastamento da musculatura do pescoço (Desenho: S. Lacchini). 


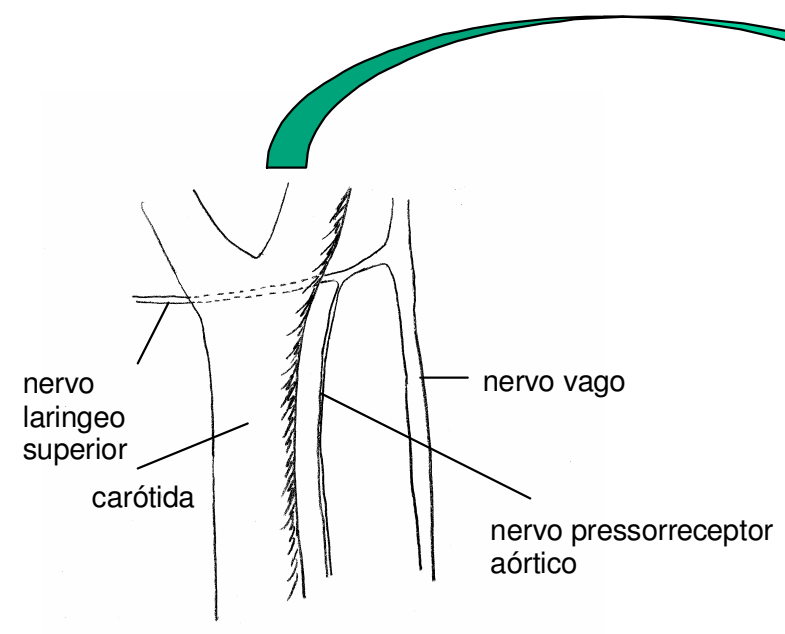

A

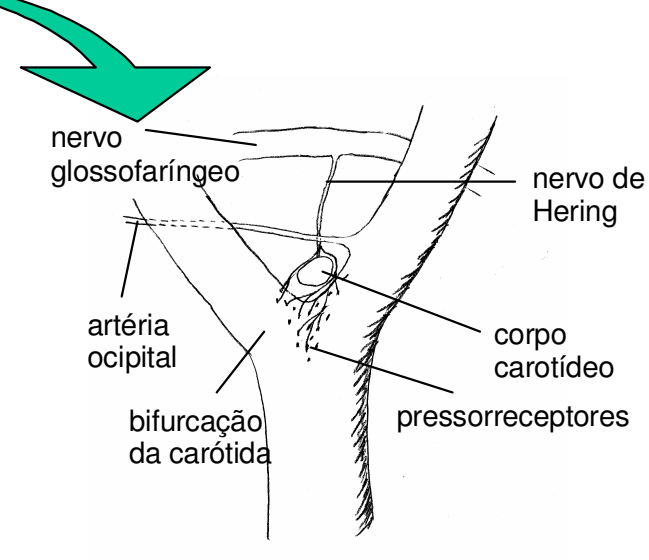

B

Figura 4 - Inervação na região da bifurcação da carótida. A: localização do nervo laringeo superior; B: detalhe da inervação do corpo carotídeo e dos pressorreceptores carotídeos (Desenho: S. Lacchini).

\subsection{A INDUÇÃO DA HIPERTENSÃo RENAL CRÔNICA TIPO} GOLDBLATT 2RINS-1CLIPE

Para a cirurgia de indução de hipertensão renal crônica (HRC) do tipo 2Rins-1Clipe, segundo o método de Goldblatt, os animais foram anestesiados com uma solução intra-peritoneal de ketamina $(50 \mathrm{mg} / \mathrm{Kg})$ e xilazina $(10 \mathrm{mg} / \mathrm{Kg})$ O procedimento cirúrgico foi realizado através de uma incisão mediana no flanco esquerdo do animal com subseqüente exposição do pedículo renal e 
colocação de um clipe de prata de abertura de $0,25 \mathrm{~mm}$ na artéria renal esquerda, tomados os devidos cuidados de assepsia para a preparação do mesmo. Após a realização da cirurgia, os animais receberam $0,2 \mathrm{ml}$ de antibiótico intramuscular (Benzetacil, Fontoura-Wyeth, Brasil).

\subsection{MEDIDAS HEMODINÂMICAS}

\subsubsection{Canulação}

No dia seguinte à avaliação ecocardiográfica, os animais foram anestesiados com ketamina $(50 \mathrm{mg} / \mathrm{Kg})$ e xilazina $(10 \mathrm{mg} / \mathrm{Kg})$ para colocação de cânulas de polietileno ( $\mathrm{PE}-10$, com diâmetro interno de 0,01 mm conectadas a uma peça de PE-50, com diâmetro interno de 0,05 mm). As cânulas foram preenchidas com soro fisiológico, e posicionadas no interior da artéria e veia femorais esquerdas para registro da PA, freqüência cardíaca e administração de drogas, respectivamente. A extremidade a ser conectada ao transdutor de pressão foi fechada com pinos de aço inoxidável. As cânulas foram introduzidas a partir de uma pequena incisão inguinal esquerda em direção ao feixe vásculo-nervoso, as extremidades das cânulas de menor 
calibre (PE-10) foram introduzidas na luz das artéria e veia femorais (Figuras 5 e 6). As cânulas foram fixadas com fio de algodão, na artéria e na veia e suas extremidades mais calibrosas foram passadas subcutâneamente, exteriorizadas no dorso da região cervical, fixadas com fio de algodão na pele. Após o término da cirurgia os animais foram tratados com um única injeção de penicilina (Benzetacil ${ }^{\circledR}$, Fontoura-Wyeth, $\left.60.000 \mathrm{U}\right)$.

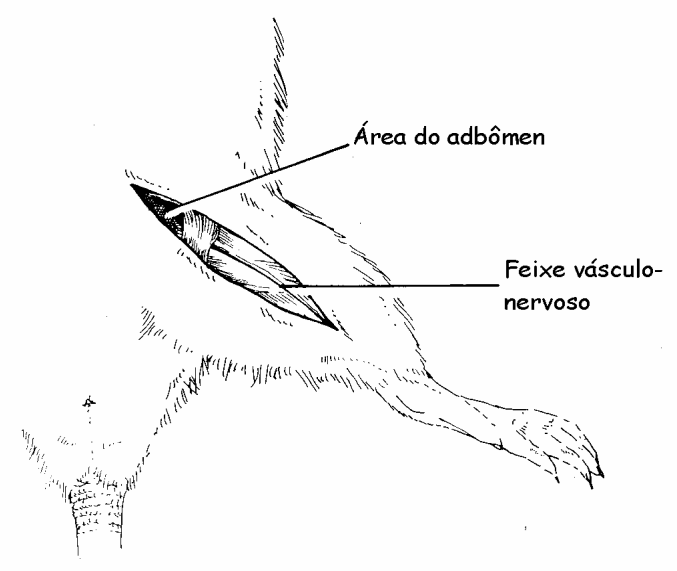

Figura 5 - Sítio de dissecção para a cateterização da artéria femoral (Desenho: S. Lacchini). 

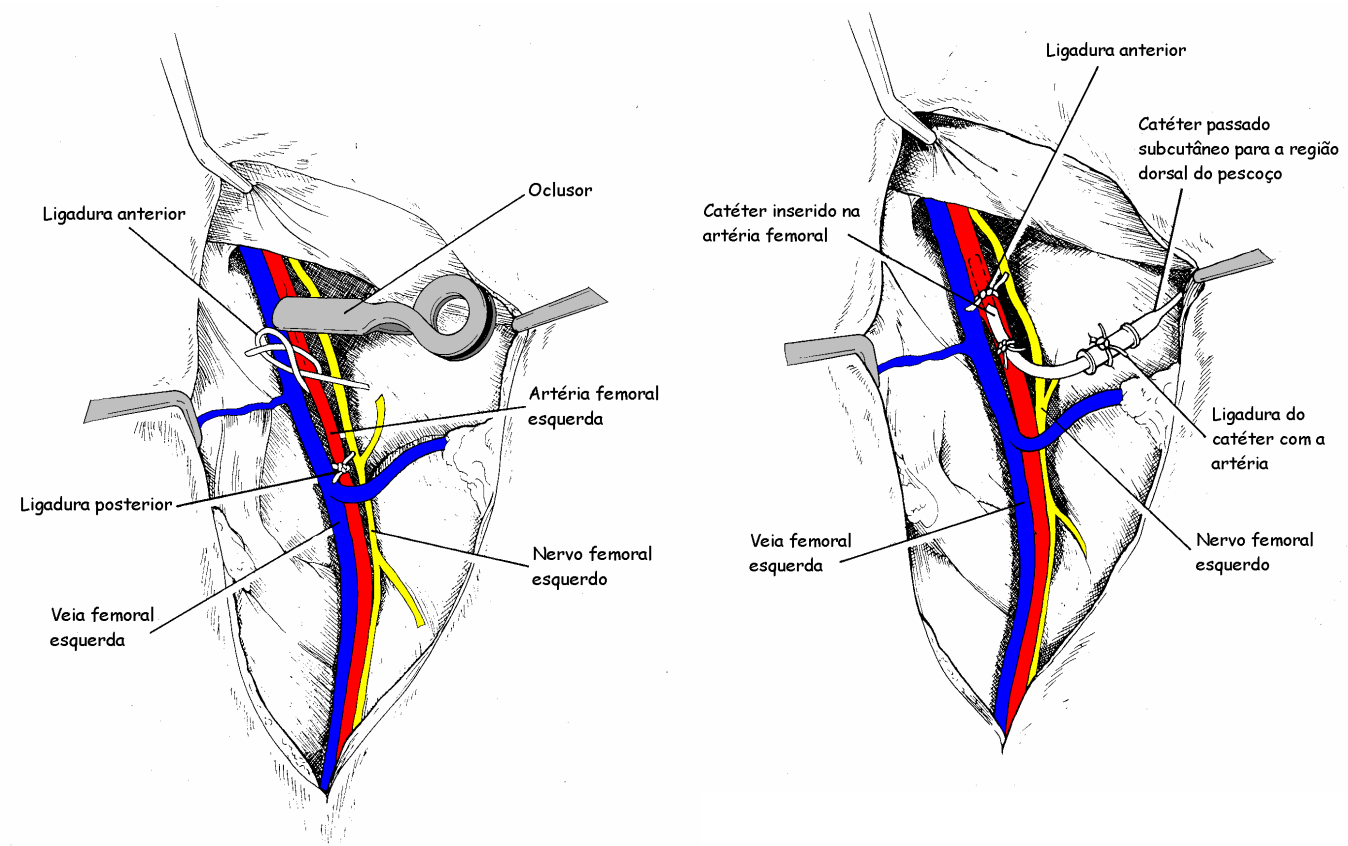

Figura 6 - Isolamento da artéria femoral e inserção do cateter (Desenho: S. Lacchini).

\subsubsection{Medidas de pressão arterial e labilidade da PA}

Vinte e quatro horas após a cirurgia de canulação, os registros de pressão pulsátil forneceram valores diretos da pressão arterial em todos os grupos experimentais. A cânula arterial foi conectada a um tubo de polietileno (PE 50) e este a um transdutor (P23 Db; Gould-Statham) que por sua vez, foi conectado a um amplificador (General Purpose Amplifier-Stemtech, Inc.). O sinal analógico 
da pressão arterial foi convertido para digital (Stemtech,Inc.), registrado em tempo real em microcomputador com sistema CODAS, com freqüência de amostragem de $2000 \mathrm{~Hz}$ por canal.

A análise dos sinais de pressão foram realizados utilizando-se um programa comercial associado ao sistema de aquisição (Figura 7). Este programa permitiu a detecção de máximos e mínimos da curva de pressão batimento a batimento, fornecendo os valores de pressão arterial sistólica (PAS) e diastólica (PAD) pela integral da área sob a curva no tempo. A freqüência cardíaca $(\mathrm{FC})$ foi determinada a partir do intervalo entre dois picos sistólicos. Os resultados foram apresentados em valores médios e desvios padrões dos períodos em que os dados fora analisados para PA e FC. As planilhas de dados obtidas foram analisadas em programa comercial para análise (Excel 5.0), onde se calcularam a média e desvio padrão da PAM, PAS, PAD e FC para cada animal. A variabilidade da PAM foi calculada, utilizando-se a média dos desvios padrões de cada animal estudado. O coeficiente da variabilidade da pressão arterial média foi conseguido por meio da razão da variabilidade da PAM pelo valor da pressão arterial média da cada animal em estudo. 


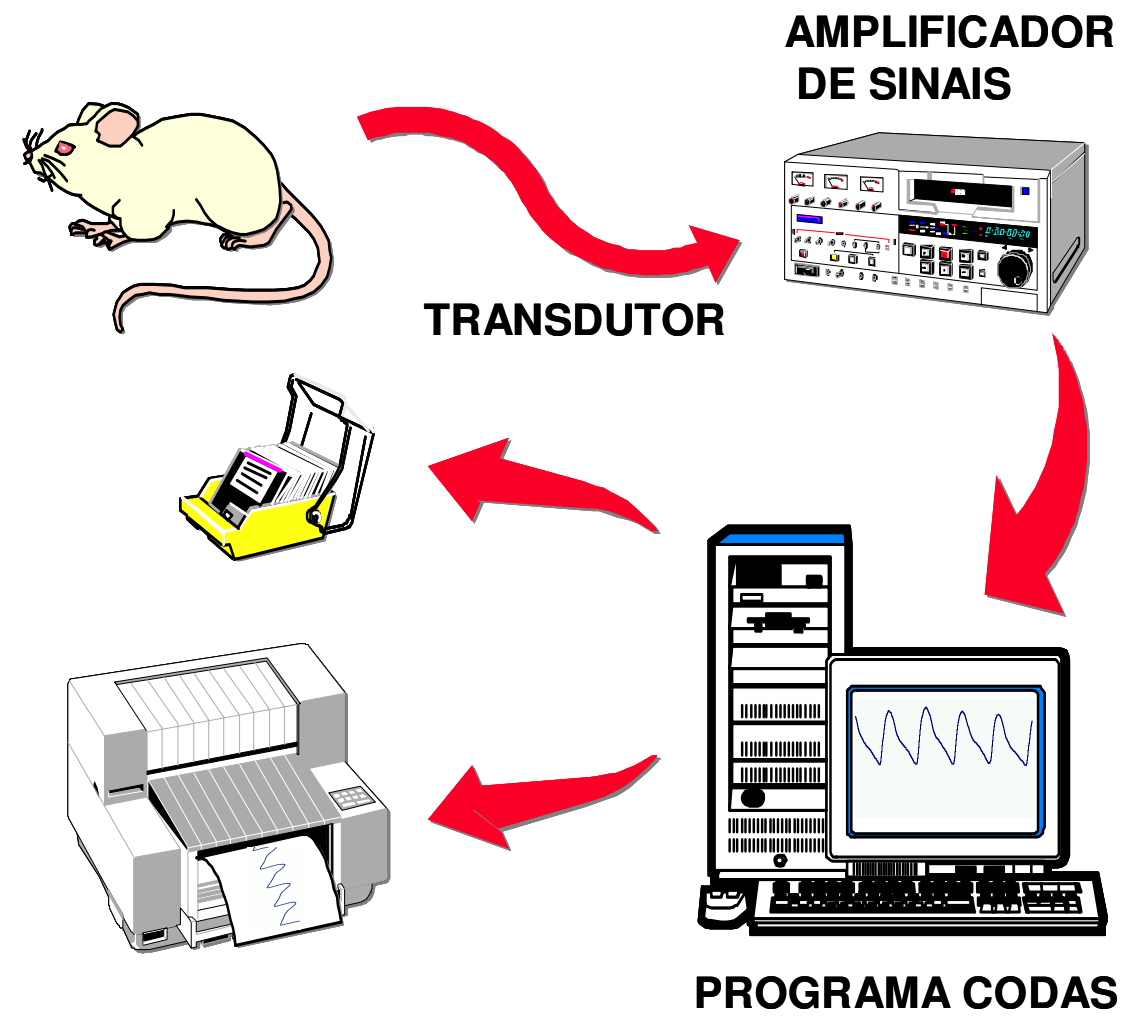

Figura 7 - Esquema do sistema de registro de Pressão Arterial (Desenho: S. Lacchini). 


\subsubsection{Avaliação do reflexo pressorreceptor}

Após o registro de PA e os animais terem permanecido em condições de repouso por 15 minutos, a sensibilidade dos pressorreceptores foi testada através da infusão de fenilefrina e logo após, nitroprussiato de sódio.

A fenilefrina (Sigma Chemical Company, St. Louis, MO, EUA), um potente estimulador a1, cuja ação predominante se dá nas arteríolas periféricas causando vasoconstrição foi injetada em doses crescentes na cânula da veia femoral. Tal fármaco foi utilizado, portanto, para causar aumento da pressão arterial, efeito que provoca bradicardia reflexa subseqüente, comandada pelos pressorreceptores.

Efeito contrário, qual seja, redução da pressão arterial com resposta taquicárdica, também comandada pelos pressorreceptores, foi provocado pela injeção doses crescentes de nitroprussiato de sódio (Sigma Chemical Company, St. Louis, MO, EUA), um potente vasodilatador tanto de arteríolas como de veias, cuja ação se dá por meio da ativação da guanilato ciclase e aumento da síntese de 3', 5'- guanosina monofosfato (GMP cíclico) na musculatura lisa dos vasos e outros tecidos.

Para avaliação da sensibilidade dos pressorreceptores, o pico máximo ou mínimo da PAM foi reduzido dos valores de PAM do período controle. Da 
mesma forma, a variação máxima da freqüência cardíaca foi reduzida dos valores de freqüência cardíaca do período controle, imediatamente antes da infusão das drogas, para posterior quantificação das respostas. A sensibilidade barorreflexa foi avaliada pelo índice calculado através divisão da variação da FC pela variação da PAM.

\subsubsection{Variabilidade do intervalo de pulso (IP) e da pressão arterial} sistólica (PAS) no domínio do tempo e da freqüência

Os parâmetros para análise no domínio do tempo consistiram em calcular os valores médios do intervalo de pulso, freqüência cardíaca, pressão arterial sistólica e pressão arterial diastólica e as variabilidades dos intervalo de pulso, da pressão arterial sistólica e da pressão arterial diastólica foram quantificadas pelo desvio padrão (IP.dp, FC.dp, PAS.dp e PAD.dp, respectivamente).

Para a análise no domínio da freqüência, a potência foi obtida usando-se o Método do Periodograma de Welch em séries de 16384 pontos das séries temporais decimadas de intervalo de pulso e pressão arterial, com uma janela Hanning de 512 pontos e com 50\% de sobre-posição (MATLAB 6.0, Mathworks, Inc). As potências para as bandas de muito baixa (VLF, 0,0-0,20 Hz; modulação humoral), baixa (LF, 0,20-0,75 Hz; modulação simpática) e alta (HF, 0,75-4,0 
Hz; modulação parassimpática) freqüências foram calculadas pela integração da potência nas bandas de interesse e apresentadas como valores absolutos e normalizados. Para a normalização, as potências das bandas de LF e HF foram divididas pela variância subtraída da potência na banda VLF (Pagani e cols., 1986). O acoplamento entre intervalo de pulso e pressão arterial sistólica é estimado pela função de coerência. Um valor de coerência (K) maior que 0,5 foi considerado significativo.

\subsection{ECODOPPLERCARDIOGRAMA}

A imagem ultra-sonográfica das estruturas cardíacas e velocidade do fluxo sangüíneo pelo ecodopplercardiograma, é largamente reconhecida por proporcionar uma das mais acuradas medidas não invasivas para caracterização da massa ventricular e análise das funções sistólica e diastólica em humanos (Devereux, 1987; Devereux e cols., 1986; Devereux e Reichek, 1977). Em animais de experimentação, o uso do ecocardiograma como metodologia não invasiva da análise da função e estrutura cardíacas, também vem se tornando rotina graças ao avanço tecnológico e desenvolvimento de transdutores ultra-sonográficos com freqüências maiores, que proporcionam uma resolução adequada a pequenas estruturas (Pawlush e cols., 1993). Essa 
prática vem sendo amplamente utilizada em estudos que requeiram análise anátomo-funcional do sistema cardiovascular no curso temporal de determinada patologia, exatamente por permitir a sobrevivência do animal até o final do experimento.

Além disso, a associação dos estudos ecocardiográficos aos celulares e moleculares tem permitido o melhor entendimento do processo patológico de hipertrofia do ventrículo esquerdo em ratos (Kagaya e cols., 1996).

O ecodopplercardiograma foi realizado nos grupos estudados no $30^{\circ}$ dia de protocolo, enfocando-se a avaliação dos seguintes parâmetros:

\section{$\checkmark$ Morfologia:}

- cavidade diastólica do VE corrigida pelo peso coporal (VEDIAcorr);

- parede posterior do VE corrigida pelo peso corporal (PARcorr);

- espessura relativa da parede (ERP);

- massa ventricular esquerda corrigida pelo peso corporal (MVEcorr).

\section{$\checkmark$ Função Sistólica:}

- fração de ejeção do VE (FE\%);

- fração de encurtamento do VE $(\Delta \mathrm{D} \%)$;

- velocidade de encurtamento circunferencial do VE (VEC);

- índice cardíaco (IC). 


\section{$\checkmark$ Função Diastólica:}

- relação dos picos E e A do fluxo transmitral (E/A);

- tempo de relaxamento isovolumétrico corrigido pela freqüência cardíaca (TRIVcorr);

- tempo de desaceleração do pico E corrigido pela freqüência cardíaca (TDEcorr);

- relação dos picos E'e A' do Doppler tecidual obtido no nível do anel mitral da parede septal do VE (E'/A's);

- relação dos picos E’e A' do Doppler tecidual obtido no nível do anel mitral da parede lateral do VE (E'/A'p);

- relação dos picos E e do pico E's (E/E’s).

\section{$\checkmark$ Função Cardíaca Global:}

- índice de desempenho miocárdico (IDM).

Após anestesia com uma solução intra-peritoneal de ketamina (50 mg/Kg) e xilazina $(10 \mathrm{mg} / \mathrm{Kg})$ os animais tiveram a região torácica devidamente tricotomizada e foram mantidos em decúbito lateral para a realização do exame no aparelho SEQUOIA 512 (ACUSON, Corporation, Mountain View, CA- EUA), com transdutor linear multifreqüencial $(10-14 \mathrm{mHz})$, que permite imagens bidimensional e monodimensional simultâneas, além da análise de fluxo por 
efeito Doppler espectral e registro eletrocardiográfico, pela colocação de três eletrodos para a derivação DII. O estudo do Doppler tecidual para análise da velocidade diastólica das paredes do VE também foi realizado, pela colocação do volume-amostra no nível do anel mitral das paredes septal e lateral do VE. A profundidade de imagem trabalhada foi de $2 \mathrm{~cm}$.

Foram utilizadas as janelas longitudinal paraesternal direita para a obtenção dos cortes longitudinal e transversal e a longitudinal paraesternal esquerda para a obtenção dos cortes apical (quatro e cinco câmaras). As medidas lineares foram realizadas nas imagens obtidas pelo modo-M, conforme Schiller e cols., (1979), com as seguintes medidas: espessura diastólica do septo-interventricular (SIVDIA), diâmetro do VE ao final da diástole (VEDIA) e ao final da sístole, espessura diastólica da parede posterior (PARDIA). A massa ventricular esquerda foi então, obtida a partir da fórmula: 1,047 $\mathrm{x}$ [(SIVDIA+VEDIA+PARDIA $)^{3}-$ VEDIA $\left.^{3}\right] \times 0,8+0,6$ onde: 1,047 representa a densidade do miocárdio, validada em ratos (Fard e cols., 2000) e os índices 0,8 e 0,6 , fatores de correção (Watson e cols., 2004). Após a obtenção destas medidas, obtivemos os valores corrigidos pelo peso corporal (valor absoluto/peso corporal do animal).

Outro importante índice de morfometria avaliado, fornecido pelo ecocardiograma, para caracterização da hipertrofia cardíaca 
(excêntrica/concêntrica) foi a espessura relativa da parede (ERP), que leva em conta as medidas diastólicas da parede do ventrículo esquerdo e da cavidade do ventrículo esquerdo, cuja fórmula é: 2 X PARDIA / VEDIA (PARDIA: parede posterior do VE em diástole ; VEDIA : cavidade diastólica do VE). Qu e cols., em 2000 demonstraram ser este índice mais sensível em relatar alterações do VE na hipertensão do que outros, incluindo a massa ventricular esquerda. Tais medidas morfométricas, foram fornecidas pelo Modo-M, sempre guiado pelo modo bidimensional, conforme nos mostra a figura 8. 


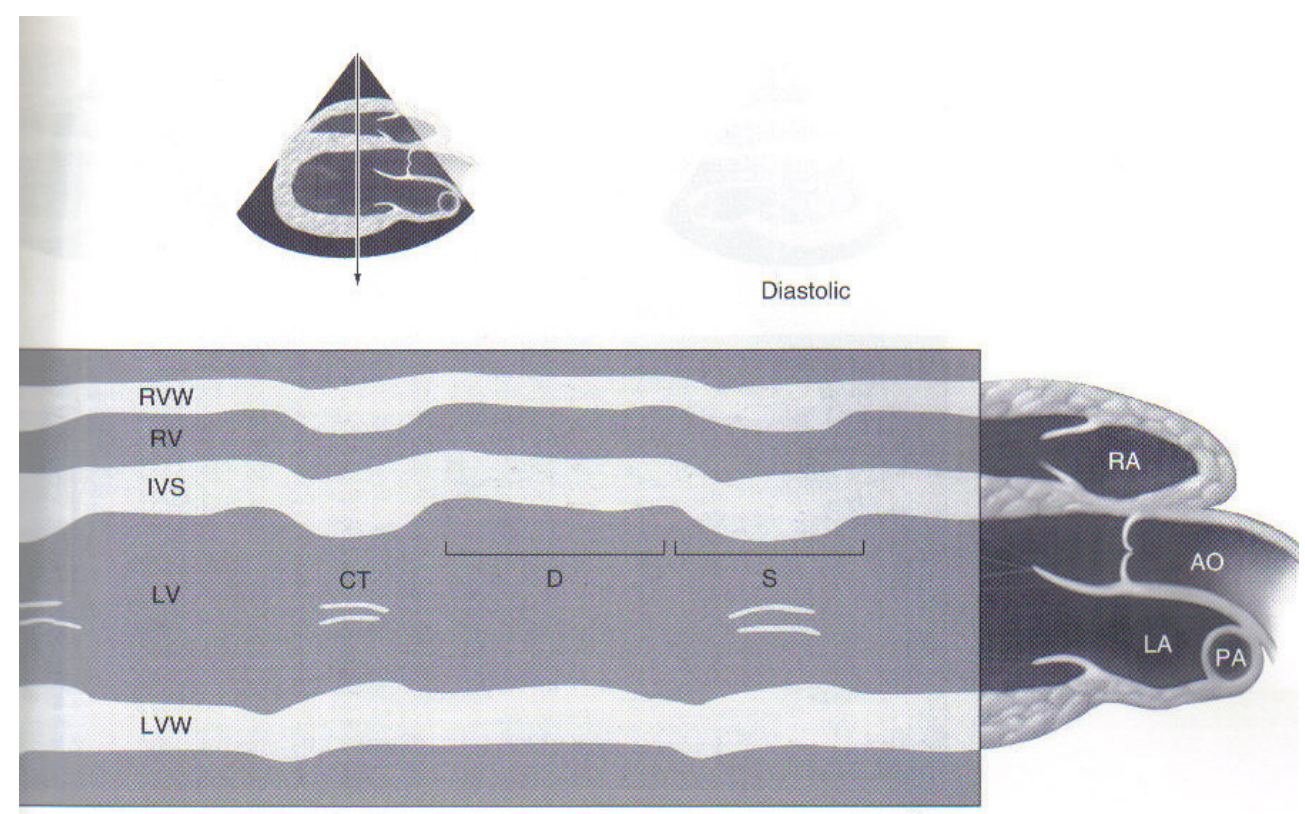

Figura 8 - Modo-M do VE, guiado pelo modo bidimensional, com o cursor posicionado entre a valva mitral e o músculo papilar, mostrando espessuras diastólica e sistólica do septo-interventricular (IVS), cavidade do ventrículo esquerdo na diástole e na sístole (LV) e espessuras diastólica e sistólica da parede posterior do ventrículo esquerdo (LVW). 
A função sistólica foi avaliada pelas frações de ejeção (FE\%), e de encurtamento $(\Delta \mathrm{D} \%)$ e velocidade de encurtamento circunferencial (VECcirc/seg), cujas fórmulas estão a seguir:

$\mathrm{FE}=(\mathrm{VDF})-(\mathrm{VSF}) /(\mathrm{VDF}) \times 100 \%$, onde: $\mathrm{VDF}=$ Volume Diastólico Final; VSF= Volume Sistólico Final, sendo que o volume foi obtido a partir da seguinte fórmula: $V=[7 /(2.4+D)] \times D^{3}$ (TEICHHOLZ e cols., 1974)

$$
\begin{aligned}
& \Delta \mathrm{D} \%=(\text { VEDIA-VESIS } / \text { VEDIA }) \times 100 \% \\
& \text { VEC }=(\text { VEDIA-VESIS }) /(\text { VEDIA } \times \text { TE }), \text { onde TE = tempo de ejeção }
\end{aligned}
$$

A função diastólica foi analisada utilizando-se os índices derivados da curva de velocidade de fluxo diastólico mitral e do fluxo sistólico da via de saída do ventrículo esquerdo obtidos pela técnica de Doppler pulsátil. A curva de velocidade do fluxo diastólico foi obtida a partir da imagem apical quatro câmaras, posicionando-se o volume-amostra próximo à face ventricular da valva mitral (Figura 9). 


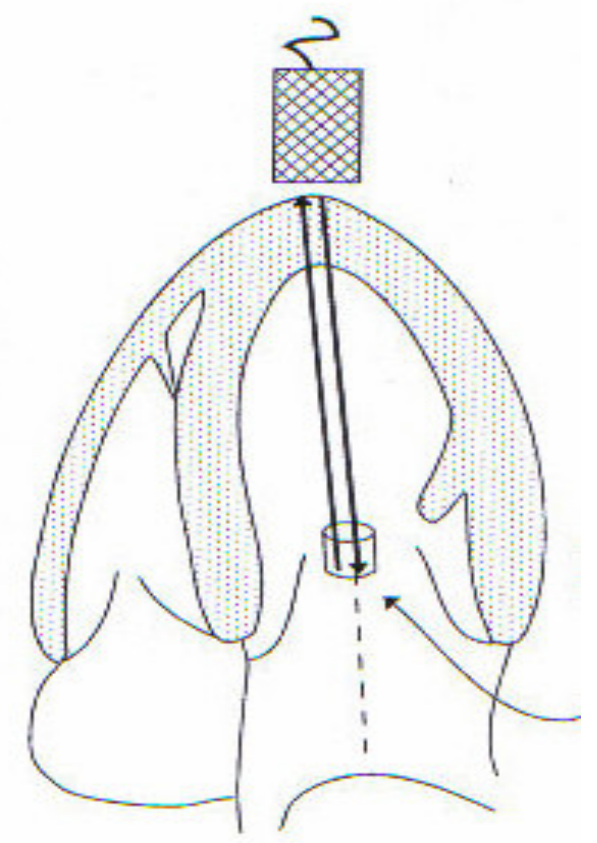

Figura 9 - Corte apical 4 câmaras mostrando o posicionamento do volume amostra (seta), próximo à face ventricular da valva mitral para avaliação do fluxo transmitral no estudo do Doppler pulsátil.

Foram determinadas: a) onda $E$ - maior valor da velocidade de fluxo inicial do enchimento ventricular (enchimento rápido do ventrículo); b) onda A - maior valor da velocidade de fluxo telediastólico mitral (correspondente à contração atrial); c) relação $E / A$ - razão entre a velocidade máxima da onda $E$ e a velocidade máxima da onda $A$; d) tempo de desaceleração da onda $E$ (TDE) tempo, em milissegundos (ms) entre o pico da onda $E$ e o ponto em que a 
rampa de desaceleração intercepta a linha de base da curva de velocidade do fluxo diastólico mitral. A curva de velocidade dos fluxos para análise do tempo de relaxamento isovolumétrico (TRIV) foi obtida posicionando-se o volumeamostra numa posição intermediária entra a valva mitral e a via de saída do ventrículo esquerdo. Foi determinado o TRIV em ms, entre o final do fluxo sistólico na via de saída do ventrículo esquerdo e o início do fluxo diastólico mitral. O TDE e o TRIV, posteriormente, foram corrigidos pela freqüência cardíaca (TDEcorr e TRIVcorr), dividindo-se seus valores pela raiz quadrada dos respectivos intervalos R-R. A avaliação do Doppler tecidual foi realizada com o posicionamento do volume-amostra no nível do anel mitral no corte apical quatro câmaras, para a obtenção dos picos de velocidade distólica máxima rápida ( $E$ ') e lenta ( $\left.A^{\prime}\right)$ das paredes septal e lateral do VE. Em seguida, obtivemos as razões dos picos E' e A', tanto para a parede septal ( $E^{\prime} / A^{\prime}$ s) quanto para a parede lateral do VE (E'/A'p).

Após a aquisição destas medidas, também obtivemos a razão do pico $E$ do fluxo transmitral pelo pico E's a partir do doppler tecidual no nível do anel mitral da parede septal do VE. Segundo Nagueh e cols. (1997), este índice guarda importante correlação com o nível da pressão capilar pulmonar em cunha (pressão de oclusão da artéria pumonar) em seres humanos. 
Entretanto, além das avaliações das funções sistólica e diastólica em separado, foi utilizado um outro método de avaliação funcional combinado, o índice de desempenho miocárdico (IDM), derivado de intervalos obtidos pelo Doppler pulsátil. Validado em camundongos por Broberg e cols.(2003), o IDM se correlaciona bem à máxima derivada da pressão do VE pelo tempo (dP/dt[Max]). Entre as vantagens do seu uso, está a de não depender da geometria ventricular, podendo portanto, ser bem utilizado em modelos que causem alterações na forma e função cardíacas, como nos estágios avançados de sobrecarga pressórica (Salemi e cols., 2004). Um estudo recente em cardiopatia congênita também demonstrou que o IDM é relativamente independente de mudanças na pré-carga e pós-carga, consideração importnte no cenário clínico (Mori e cols., 2001). Conceitualmente simples, é descrito como sendo mais preciso para análise da função cardíaca global do que os parâmetros de avaliação isolada (Tei, 1995; Tei e cols., 1997) e representa a razão do tempo total gasto na atividade isovolumétrica (contração isovolumétrica e relaxamento isovolumétrico) pelo tempo de ejeção. Para tanto, mede-se o tempo de fechamento da valva mitral (a), que corresponde à soma do tempo de contração isovolumétrica, tempo de ejeção e tempo de relaxamento isovolumétrico. O tempo de ejeção é obtido pela medida da 
duração do fluxo de via de saída do ventrículo esquerdo (b). Pela fórmula (a)(b)/b, podemos, então, obter o IDM.

Para a obtenção do débito cardíaco, foi utilizada a seguinte fórmula: $3.14 \mathrm{x}$ $(\mathrm{D} / 2)^{2} \times \mathrm{VTI} \times \mathrm{FC}$, onde $\mathrm{D}=$ diâmetro aórtico, obtido no modo bidimensional, VTI = integral da velocidade do fluxo aórtico, obtido no estudo Doppler pulsátil da via de saída do VE e FC = freqüência cardíaca, por intermédio dos intervalos RR. Slama e cols. (2003) demonstraram uma correlação positiva com $r=0,93$ entre esta metodologia e medidas invasivas de termodiluição para obtenção do débito cardíaco em ratos. Todas as medidas seguiram as recomendações da Sociedade Americana de Ecocardiografia (Sahn e cols., 1978)

\subsection{SACRIFÍCIO DOS ANIMAIS}

Após o registro das medidas hemodinâmicas, os animais foram sacrificados por decaptação. Em seguida, foram coletados os seguintes tecidos para pesagem em balança de alta precisão (METLER TOLEDO, modelo AB104 - Made in Switzerland):

- Ventrículo Esquerdo

- Ventrículo Direito

- Rim Direito 
- Rim Esquerdo

- Pulmões

Na seqüência, foi feita a correção dos pesos pelos respectivos pesos corporais dos animais.

Os ventrículos esquerdos foram armazenados em freezer a $-80^{\circ} \mathrm{C}$ para análise posterior da expressão das proteínas regulatórias do $\mathrm{Ca}^{2+}$ através da técnica Western blot.

\subsection{EXPRESSÃO DE PROTEÍNAS CARDÍACAS}

A expressão de proteínas envolvidas na recaptação de $\mathrm{Ca}^{2+}$ pelo retículo sarcoplasmático: $\mathrm{Ca}^{2+}$ ATPase do retículo sarcoplasmático (SERCA-2), fosfolambam (PLB), fosfolambam fosforilado na serina-16 (fosfo-Ser ${ }^{16}$-PLB), fosfolambam fosforilado na treonina-17 (fosfo-Tre ${ }^{17}$-PLB); na defosforilação de diferentes proteínas: o trocador $\mathrm{Na}^{+} / \mathrm{Ca}^{2+}(\mathrm{NCX}$, proteína responsável pela extrusão de $\mathrm{Ca}^{2+}$ da célula) foram analisadas nos homogeneizados de ventrículo esquerdo dos animais estudados por meio da técnica de eletroforese de proteínas (Western blot). 


\subsubsection{Preparação dos homogeneizados ventriculares}

Os ventrículos dos animais foram homogeneizados, utilizando-se um homogeneizador Polytron (PT-K Brinkman Instruments), em uma solução de tampão de lise hipotônico contendo tampão de fosfato de potássio $50 \mathrm{mM}(\mathrm{pH}$ 7,0), sacarose 0,3 M, DTT 0,5 mM, EDTA $1 \mathrm{mM}(\mathrm{pH} 8,0)$, PMSF 0,3 mM, NaF $10 \mathrm{mM}$ e coquetel de inibidor de fosfatase (1:100; Sigma-Aldrich-EUA). O processo de homogeneização foi realizado três vezes durante dez segundos com intervalos de vinte segundos entre as homogeneizações. Todo o processo foi realizado a $4^{\circ} \mathrm{C}$. Os homogeneizados foram centrifugados a $12.000 \mathrm{rpm}$ por vinte minutos a $4^{\circ} \mathrm{C}$. O sobrenadante foi então transferido para tubos de $1,5 \mathrm{~mL}$. A concentração de proteína das amostras foi analisada por meio do método de Bradford (Biorad-EUA). Alíquotas dos homogeneizados foram armazenadas em freezer $-80^{\circ} \mathrm{C}$ até serem utilizadas (Rolim e cols., 2007; Medeiros e cols., 2008). 


\subsubsection{Western blot}

Os homogeneizados ventriculares foram solubilizados a uma concentração final de $1 \%$ de SDS (sodium- dodecyl- sulfate) e em seguida as proteínas presentes nas amostras foram separadas eletroforeticamente em gel de SDS - poliacrilamida (6 e 10\%, dependendo do peso molecular da proteína a ser estudada). As proteínas foram transferidas para uma membrana de nitrocelulose em tampão de transferência contendo Tris (25 mM), glicina (192 $\mathrm{mM})$, metanol $(20 \%)$ e SDS $(0,1 \%)$. As membranas foram lavadas duas vezes com solução tampão (TBS: Tris 10mM, pH 7,6 e NaCl 150 mM). Em seguida, o bloqueio dos sítios antigênicos inespecíficos foi realizado por meio de uma mistura contendo TBS com o detergente Tween $20(0,1 \%)$ e leite desnatado (5\%) por 120 minutos em temperatura ambiente $\left(20-25^{\circ} \mathrm{C}\right)$ com agitação constante. A membrana, então, foi incubada com o anticorpo primário diluído na solução bloqueadora (TBS e albumina $3 \%$ ) a $4^{\circ} \mathrm{C}$ por 12 horas com agitação constante. Após a incubação com o anticorpo primário, a membrana foi lavada três vezes em solução de TBS-T. Em seguida, a membrana foi incubada com o anticorpo secundário em solução bloqueadora (TBS-T e leite desnatado 1\%) por uma hora e meia em temperatura ambiente com agitação constante. Após a incubação com o anticorpo secundário, a membrana foi lavada três vezes em 
solução de TBS-T para remover o excesso de anticorpo. Por fim, a imunodetecção foi realizada por meio do método de quimioluminescência de acordo com as instruções do fabricante (Enhancer Chemi-Luminescence, Amersham Biosciences, NJ-USA).

Como anticorpos primários foram utilizados:

- SERCA-2, camundongo IgG1 (Affinity BioReagents, CO-EUA): A titulação utilizada foi de 1:2500.

- Fosfolambam, camundongo IgG2a (Affinity BioReagents, CO-EUA): A titulação utilizada foi de 1:500.

- $\quad$ Fosfo-fosfolambam (serina-16), coelho IgG (RDI Incorporation, NJ-EUA): A titulação utilizada foi de 1:5000.

- Fosfo-fosfolambam (treonina-17), coelho lgG (Badrilla, Leeds-UK): A titulação utilizada foi de 1:5000.

- Trocador $\mathrm{Na}^{+} / \mathrm{Ca}^{2+}$, camundongo IgM (Affinity BioReagents, CO-EUA): A titulação utilizada foi de 1:2000.

Como anticorpos secundários foram utilizados anticorpos conjugados a peroxidase (IgG anti-camundongo ou anti-coelho, ECL, Amersham Biosciences, NJ-EUA) anti os anticorpos primários, utilizados na titulação de 1:10000. 


\section{9. ANÁLISE ESTATÍSTICA}

Os resultados são apresentados como média \pm erro padrão.

A análise de variância (ANOVA) de um fator foi realizada para comparação das médias dos grupos C, CLIPE-10 e CLIPE-30, na avaliação do efeito do tempo do clipe no desenvolvimento da hipertensão e hipertrofia cardíaca. $\mathrm{Na}$ comparação das médias dos grupos C, DSA, CLIPE-30 e ASSOCIAÇÃO para a análise do efeito da pressão arterial e da variabilidade da pressão arterial no desevenvolvimento da hipertrofia miocárdica foi utilizada a ANOVA de dois fatores. O teste complementar de Student Newmann Keuls foi utilizado sempre que necessário. Valores de $p<0,05$ foram considerados significativos. 
RESULTADOS 


\section{RESULTADOS}

\subsection{EFEITOS DO TEMPO DE CLIPE NA ARTÉRIA RENAL NO DESENVOLVIMENTO DA HIPERTENSÃo E HIPERTROFIA CARDÍACA}

\subsubsection{Avaliações Hemodinâmicas}

Os resultados hemodinâmicos do efeito do tempo de clipe na artéria renal mostraram aumento das pressões arteriais sistólica, diastólica e média no grupo clipe-30 com relação aos grupos controle e clipe-10. Já a variabilidade da pressão arterial média, o coeficiente da variabilidade da pressão arterial média e a freqüência cardíaca apresentaram-se semelhantes entre os 3 grupos. 0 intervalo de pulso também não mostrou diferença na comparação entre os grupos (Tabela 1, Figura 10). 
TABELA 1. Pressão arterial sistólica (PAS), pressão arterial diastólica (PAD), pressão arterial média (PAM), variabilidade da pressão arterial média (SD PAM), coeficiente da variabilidade da pressão arterial média (Cx SD), freqüência cardíaca (FC) e intervalo de pulso (IP) dos ratos controles (C), 10 dias de clipe (CLIPE-10) e 30 dias de clipe (CLIPE-30).

\begin{tabular}{l|ccc}
\hline & C & CLIPE-10 & CLIPE-30 \\
\hline PAS (mmHg) & $129 \pm 1$ & $132 \pm 6$ & $159 \pm 9 \dagger \ddagger$ \\
PAD (mmHg) & $91 \pm 1$ & $91 \pm 4$ & $111 \pm 7 \dagger \ddagger$ \\
PAM (mmHg) & $109 \pm 1$ & $109 \pm 5$ & $131 \pm 8 \dagger \ddagger$ \\
SD PAM (mmHg) & $4,82 \pm 0,49$ & $5,44 \pm 0,96$ & $6,23 \pm 0,50$ \\
Cx SD (\%) & $4,3 \pm 0,5$ & $4,8 \pm 0,6$ & $5,2 \pm 0,6$ \\
FC (bpm) & $342 \pm 12$ & $355 \pm 11$ & $349 \pm 12$ \\
IP (ms) & $177 \pm 6,3$ & $171 \pm 4,82$ & $175 \pm 5,90$ \\
\hline
\end{tabular}

Valores expressos como média \pm EPM. $\uparrow p<0,05$ vs. grupo controle; $\ddagger p<0,05$ vs. grupo clipe-10. 


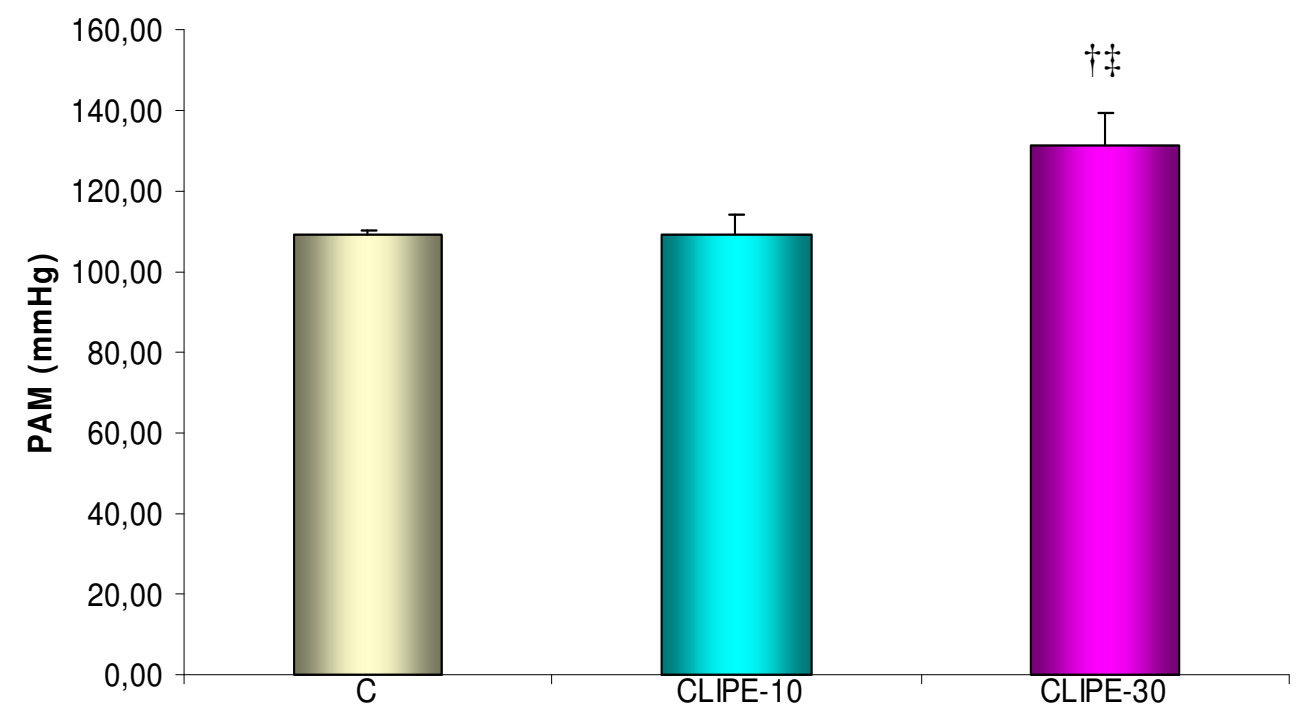

Figura 10- Pressão Arterial Média (PAM) nos grupos controle (C), 10 dias de clipe (CLIPE-10) e 30 dias de clipe (CLIPE-30). Observe-se o maior nível de pressão neste último grupo. $\nmid p<0,05$ vs. grupo controle; $\ddagger p<0,05$ vs. grupo clipe-10. 
O índice de bradicardia reflexa (IBR) foi menor nos grupos clipe-10 e clipe30 com relação ao grupo controle. O grupo clipe-30 também apresentou diminuição do índice de taquicardia reflexa com relação aos grupos clipe-10 e controle (Tabela 2).

TABELA 2. Índices de bradicardia reflexa (IBR) e taquicardia reflexa (ITR) dos ratos controles (C), 10 dias de clipe (CLIPE-10) e 30 dias de clipe (CLIPE-30).

\begin{tabular}{l|ccr}
\hline & C & CLIPE-10 & CLIPE-30 \\
\hline IBR $(\mathrm{bpm} / \mathrm{mmHg})$ & $2,19 \pm 0,13$ & $1,13 \pm 0,08 \dagger$ & $1,15 \pm 0,10 \dagger$ \\
ITR $(\mathrm{bpm} / \mathrm{mmHg})$ & $1,98 \pm 0,09$ & $1,99 \pm 0,13$ & $1,13 \pm 0,17 \dagger \ddagger$ \\
& & & \\
\multicolumn{1}{l}{ Valores expressos como média \pm EPM. $\uparrow p<0,05$ vs. grupo controle; $\neq \mathrm{p}<0,05$} \\
vs. grupo clipe-10.
\end{tabular}




\subsubsection{Variabilidade da freqüência cardíaca}

A variabilidade da FC avaliada pelo desvio do intervalo de pulso (SD IP) foi semelhante na comparação dos grupos. Entretanto, a análise da modulação autonômica cardíaca no domínio da freqüência mostrou que o componente de baixa freqüência (LF) normalizado e a razão entre os componentes de baixa e alta frequência (LF/HF) do intervalo de pulso foram maiores no grupo hipertenso (CLIPE-30) com relação aos outros dois grupos, enquanto o componente de alta freqüência (HF) normalizado do intervalo de pulso foi menor no grupo clipe 30 com relação aos outros dois (Tabela 3 ). 
TABELA 3. Desvio do intervalo de pulso (SD IP), banda de baixa freqüência (LF), banda de alta freqüência (HF) do intervalo de pulso e a relação entre baixa e alta freqüências (LF/HF) do tacograma dos ratos controles (C), 10 dias de clipe (CLIPE-10) e 30 dias de clipe (CLIPE-30).

\begin{tabular}{c|ccc}
\hline & C & CLIPE-10 & CLIPE-30 \\
\hline SD IP (ms) & $7,73 \pm 1,04$ & $8,73 \pm 1,38$ & $11,59 \pm 1,16$ \\
LF (\%) & $16,62 \pm 2,21$ & $19,02 \pm 1,97$ & $29,17 \pm 4,66 \dagger \ddagger$ \\
HF (\%) & $83,38 \pm 2,21$ & $80,98 \pm 1,97$ & $70,83 \pm 4,66 \dagger \ddagger$ \\
LF/HF & $0,20 \pm 0,03$ & $0,24 \pm 0,03$ & $0,44 \pm 0,10 \dagger \ddagger$ \\
\multicolumn{2}{l}{ Valores expressos como média \pm EPM. †p < 0,05 vs. grupo controle; $\ddagger p<0,05$} \\
\multicolumn{4}{l}{ vs. grupo clipe-10. }
\end{tabular}

\subsubsection{Variabilidade da pressão arterial sistólica}

A Tabela 4 mostra que a variância da PAS (VPAS) e o componente de baixa freqüência (LF) da PAS apresentaram comportamento semelhante entre os 3 grupos avaliados. 
TABELA 4. Variância da pressão arterial sistólica (VPAS) e componente de baixa freqüência (LF) do sistograma dos ratos controles (C), 10 dias de clipe (CLIPE-10) e 30 dias de clipe (CLIPE-30).

\begin{tabular}{c|ccc}
\hline & C & CLIPE-10 & CLIPE-30 \\
\hline VPAS $\left(\mathrm{mmHg}^{2}\right)$ & $30,4 \pm 5,6$ & $42,5 \pm 12,5$ & $45,7 \pm 7,8$ \\
LF $\left(\mathrm{mmHg}^{2}\right)$ & $3,43 \pm 0,60$ & $4,88 \pm 0,57$ & $6,47 \pm 1,32$ \\
\hline
\end{tabular}

Valores expressos como média \pm EPM.

\subsubsection{Avaliações morfométricas}

No dia da avaliação da estrutura cardíaca pelo ecocardiograma, o peso corporal médio dos animais do grupo controle foi de $339 \pm 32 \mathrm{~g}$, enquanto que 0 do grupo clipe-10 foi de $319 \pm 16 \mathrm{~g}$ e do grupo clipe-30, de $326 \pm 22 \mathrm{~g}$. Não houve diferença estatística na comparação de peso entre os três grupos.

A morfometria cardíaca foi avaliada através dos seguintes parâmetros: parede posterior do VE corrigida pelo peso do animal (PARcorr), dimensão diastólica da cavidade do VE corrigida pelo peso (VEDIAcorr), espessura relativa da parede (ERP) e massa ventricular esquerda corrigida pelo peso corpóreo (MVEcorr). 
Conforme se vê na Tabela 5, o grupo clipe-30 mostrou aumento da PARcorr e aumento da ERP com relação aos grupos controle e clipe-10 e aumento da MVEcorr com relação ao grupo controle, carcterizando uma hipertrofia ventricular esquerda do tipo concêntrica (Figura 11).

Já o grupo clipe-10 apresentou aumento da VEDIAcorr e diminuição da ERP quando comparadas aos grupos controle e clipe-30 e aumento da MVEcorr quando comparadas ao grupo controle, deixando evidente uma hipertrofia ventricular esquerda do tipo excêntrica (Tabela 5, Figuras 11 e 12).

Os valores de morfologia cardíaca do grupo controle foram semelhantes aos valores ecocardiográficos basais propostos por Watson e cols. (2004). 
TABELA 5. Parâmetros ecocardiográficos de morfometria cardíaca dos ratos controles (C), 10 dias de clipe (CLIPE-10) e 30 dias de clipe (CLIPE-30).

\begin{tabular}{l|ccc}
\hline & C & CLIPE-10 & CLIPE-30 \\
\hline PARcorr $(\mathrm{cm} / \mathrm{Kg})$ & $0,38 \pm 0,02$ & $0,39 \pm 0,007$ & $0,51 \pm 0,03 \dagger \ddagger$ \\
VEDIAcorr $(\mathrm{cm} / \mathrm{Kg})$ & $2,21 \pm 0,06$ & $2,59 \pm 0,06 \dagger \mathrm{a}$ & $2,201 \pm 0,09$ \\
ERP & $0,36 \pm 0,007$ & $0,30 \pm 0,005 \dagger$ & $0,46 \pm 0,03 \dagger \ddagger$ \\
MVEcorr $(\mathrm{g} / \mathrm{Kg})$ & $3,15 \pm 0,10$ & $3,52 \pm 0,07 \dagger$ & $3,68 \pm 0,11 \dagger$ \\
\multicolumn{4}{l}{ Valores expressos como média \pm EPM. $+\mathrm{p}<0,05$ vs. grupo controle; $\neq \mathrm{p}<0,05$}
\end{tabular}
vs. grupo clipe-10; a $p<0,05$ vs. grupo clipe-30 PARcorr: parede posterior do VE corrigida pelo peso corporal; VEDIAcorr: cavidade do VE na diástolo corrigida pelo peso corporal; ERP: espessura relativa da parede; MVEcorr: massa ventricular esquerda corrigida pelo peso corporal. 


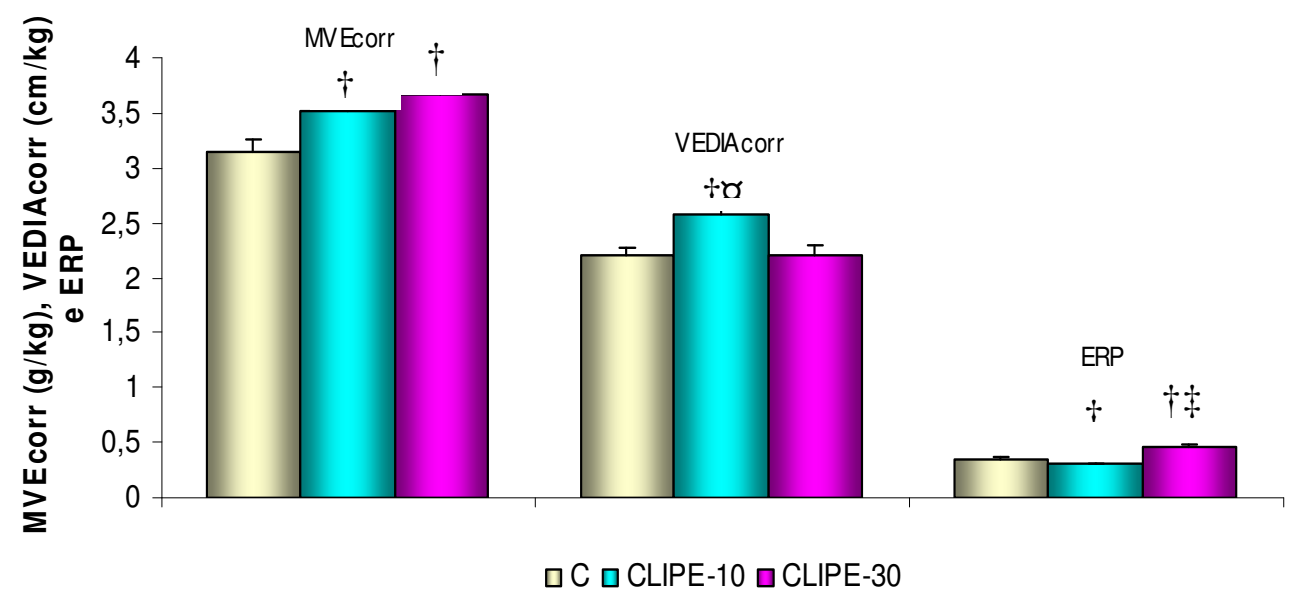

Figura 11 - Massa do ventrículo esquerdo obtida pelo ecocardiograma e corrigida pelo peso corporal (MVEcorr), dimensão diastólica do ventrículo esquerdo corrigida pelo peso corporal (VEDIAcorr) e espessura relativa da parede (ERP) nos grupos controle (C), 10 dias de clipe (CLIPE-10) e 30 dias de clipe (CLIPE-30). Note-se o aumento da MVEcorr dos grupos clipe-10 e clipe-30 com relação ao controle; aumento da VEDIAcorr do grupo clipe-10 com relação aos grupos controle e clipe-30 e diminuição da ERP do grupo clipe-10 com relação aos outros dois grupos e aumento da ERP do grupo clipe-30 com relação aos grupos controle e clipe-10. $\uparrow p<0,05$ vs. grupo $C ; \ddagger p<0,05$ vs. grupo CLIPE-10 e ap<0,05 vs. grupo CLIPE-30. 

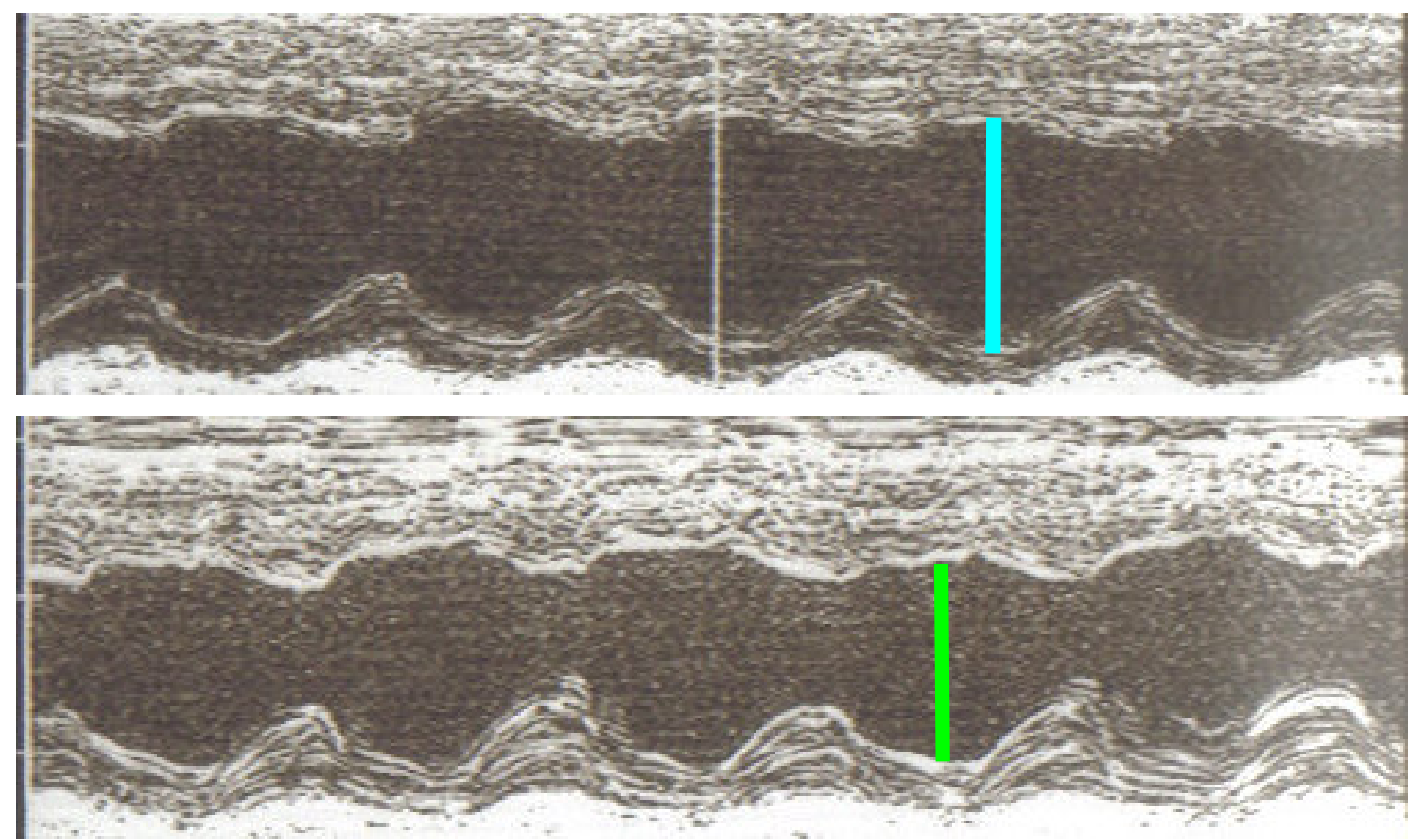

Figura 12 - Modo M do ventrículo esquerdo de um rato do grupo controle (acima) e de um rato do grupo clipe-10 (abaixo), demonstrando aumento da cavidade ventricular esquerda e diminuição da espessura das paredes no rato do grupo clipe-10.

\subsubsection{Avaliações da função sistólica}

A Tabela 6 mostra as avaliações da função sistólica do VE, obtidas pelos seguintes índices: fração de ejeção (FE), fração de encurtamento $(\Delta D \%)$ e velocidade de encurtamento circunferencial (VEC). Na mesma tabela, pode-se observar os valores do índice cardíaco, que se referem ao débito cardíaco 
corrigido pelo peso corpóreo do animal (IC) e o índice de desempenho miocárdico (IDM), que avalia a função global do VE.

O grupo clipe-30 apresentou aumento da FE, $\triangle \mathrm{D} \%$ e VEC quando comparado aos grupos controle e clipe-10. O índice de desempenho miocárdico também estava aumentado neste grupo, demonstrando um maior esforço cardíaco. Já o IC foi maior no grupo clipe-10 quando comparado ao grupo clipe30.

Os valores de função cardíaca do grupo controle foram semelhantes aos valores ecocardiográficos basais propostos por Watson e cols. (2004). 


\subsubsection{Avaliações da função diastólica}

A análise da função diastólica do VE, mostrou diminuição da relação $E / A$ nos animais com 30 dias de clipe com relação ao grupo controle. $O$ tempo de relaxamento isovolumétrico corrigido pela freqüência cardíaca (TRIVcorr) estava aumentado nestes animais, quando comparado aos outros dois grupos e a relação E'/A' tanto da parede septal (E'/A's) quanto da parede lateral do VE (E'A'p) estava diminuída, caracterizando uma disfunção diastólica no grupo clipe-30. O tempo de desaceleração do pico $E$ corrigido pela freqüência cardíaca (TDEcorr) não foi diferente entre os grupos, assim como a razão E/E's (Tabela 7, Figura 13).

Os valores de função cardíaca do grupo controle foram semelhantes aos valores ecocardiográficos basais propostos por Watson e cols. (2004). 
TABELA 7. Parâmetros ecocardiográficos da função diastólica dos ratos controles (C) , 10 dias de clipe (CLIPE-10) e 30 dias de clipe (CLIPE-30).

\begin{tabular}{|c|c|c|c|}
\hline & $C$ & CLIPE-10 & CLIPE-30 \\
\hline$E / A$ & $1,87 \pm 0,19$ & $1,63 \pm 0,19$ & $1,30 \pm 0,09 \dagger$ \\
\hline TRIVcorr (ms) & $1,50 \pm 0,06$ & $1,59 \pm 0,10$ & $1,97 \pm 0,10 \dagger \ddagger$ \\
\hline TDEcorr (ms) & $1,84 \pm 0,19$ & $1,65 \pm 0,12$ & $1,97 \pm 0,10$ \\
\hline$E^{\prime} / A^{\prime} s$ & $1,33 \pm 0,08$ & $1,51 \pm 0,14$ & $0,88 \pm 0,09 \dagger \ddagger$ \\
\hline$E^{\prime} / A^{\prime} p$ & $1,43 \pm 0,08$ & $1,41 \pm 0,13$ & $0,98 \pm 0,12 \dagger \ddagger$ \\
\hline E/E's & $12,37 \pm 0,89$ & $12,59 \pm 0,89$ & $12,75 \pm 0,70$ \\
\hline \multicolumn{4}{|c|}{$\begin{array}{l}\text { Valores expressos como média } \pm \text { EPM. } \uparrow p<0,05 \text { vs. grupo controle; } \ddagger p<0,05 \\
\text { vs. grupo clipe-10. E/A: relação dos picos E e A; TRIVcorr: tempo de } \\
\text { relaxamento isovolumétrico corrigido pela freqüência cardíaca; TDEcorr: tempo } \\
\text { de desaceleração do pico E corrigido pela freqüência cardíaca; E'/A's: relação } \\
\text { dos picos E' e A' da parede septal ; E'/A'p: relação dos picos E' e A' da parede } \\
\text { lateral do VE; E / E's: relação do pico E pelo pico E' da parede septal. }\end{array}$} \\
\hline
\end{tabular}




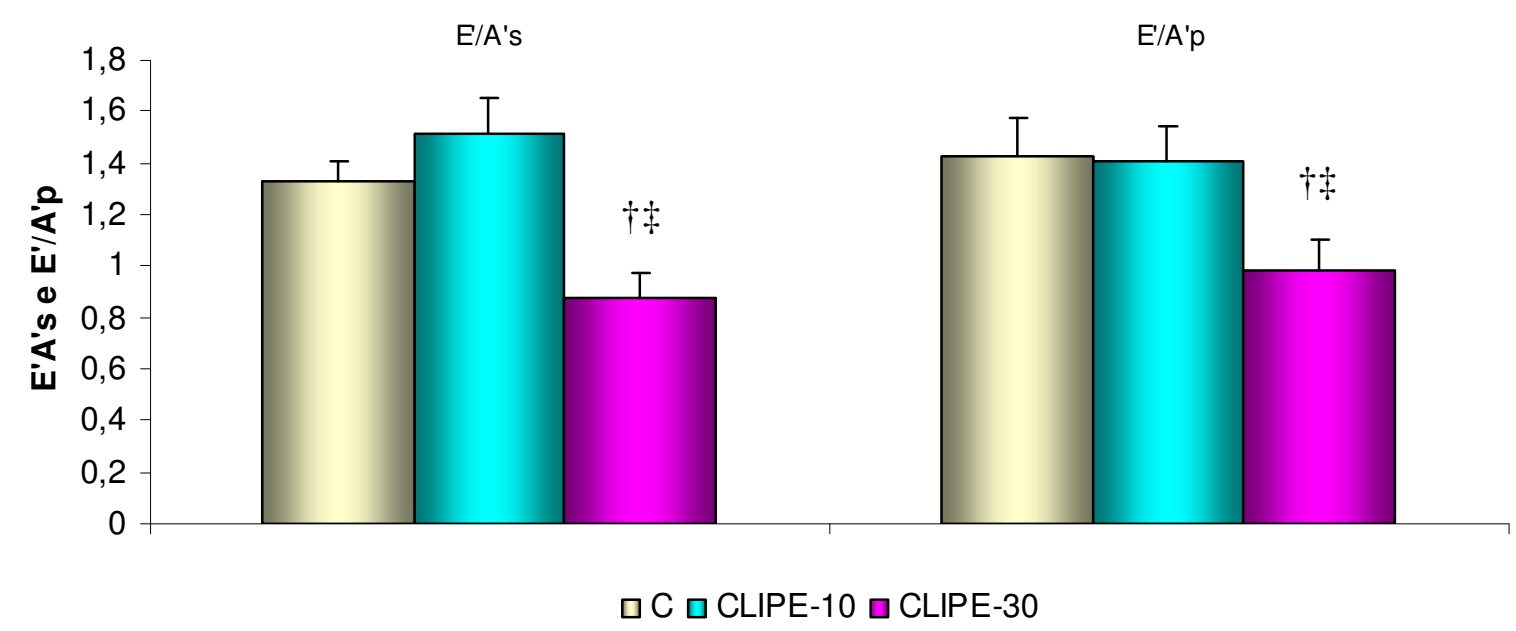

Figura 13 - Relação $E^{\prime} / A^{\prime}$ obtida ao nível do anel mitral da parede septal (E'/A's) e relação $E^{\prime} / A^{\prime}$ obtida ao nível da parede lateral do ventrículo esquerdo (E'/A'p) dos grupos controle (C), 10 dias de clipe (CLIPE-10) e 30 dias de clipe (CLIPE-30). O grupo CLIPE-30 mostrou redução dos dois índices com relação aos outros dois grupos de comparação. $\nmid p<0,05$ vs. grupo $C$ e $\neq p<0,05$ vs. grupo CLIPE-10.

\subsubsection{Avaliações post-mortem dos tecidos}

A análise post-mortem dos tecidos, mostrou que o peso do VE corrigido pelo peso corporal (VE/PESO) dos grupos clipe-10 e clipe-30 foi maior que o do grupo controle. Já o peso do VD corrigido pelo peso corporal (VD/PESO) e peso 
dos pulmões corrigido pelo peso corporal (PULMÕES/PESO) não mostraram diferença entre os grupos.

Nos grupos com clipe renal (clipe-10 e clipe-30), o rim direito não clipado corrigido pelo peso corporal (RIM D/PESO) mostrou valor maior com relação ao grupo controle.

Já o peso do rim esquerdo, cuja artéria foi parcialmente estenosada com o clipe de prata, corrigido pelo peso corporal (RIM E/PESO) não mostrou diferença entre os três grupos analisados (Tabela 8). 
TABELA 8. Peso dos tecidos corrigidos pelo peso corporal dos ratos controle (C), 10 dias de clipe (CLIPE-10) e 30 dias de clipe (CLIPE-30).

\begin{tabular}{c|ccc}
\hline & C & CLIPE-10 & CLIPE-30 \\
\hline VE/PESO $(\mathrm{g} / \mathrm{Kg})$ & $2,18 \pm 0,07$ & $2,61 \pm 0,10 \dagger$ & $2,97 \pm 0,26 \dagger$ \\
VD/PESO $(\mathrm{g} / \mathrm{Kg})$ & $0,79 \pm 0,02$ & $0,70 \pm 0,07$ & $0,74 \pm 0,04$ \\
PULMÕES/PESO $(\mathrm{g} / \mathrm{Kg})$ & $5,47 \pm 0,22$ & $6,22 \pm 0,37$ & $5,70 \pm 0,18$ \\
RIM D/PESO $(\mathrm{g} / \mathrm{Kg})$ & $3,42 \pm 0,07$ & $4,05 \pm 0,15 \dagger$ & $4,41 \pm 0,20 \dagger$ \\
RIM E/PESO $(\mathrm{g} / \mathrm{Kg})$ & $3,42 \pm 0,05$ & $3,43 \pm 0,18$ & $3,56 \pm 0,14$ \\
\hline \multicolumn{7}{l}{ Valores expressos como média \pm EPM. $\dagger \mathrm{p}<0,05$ vs. grupo controle. VE/PESO: }
\end{tabular}
peso do ventrículo esquerdo corrigido pelo peso corporal; VD/PESO: peso do ventrículo direito corrigido pelo peso corporal; PULMÕES/PESO: peso dos pulmões corrigido pelo peso corporal; RIM D/PESO: peso do rim direito corrigido pelo peso corporal; RIM E/PESO: peso do rim esquerdo corrigido pelo peso corporal. 


\subsubsection{Avaliações moleculares das proteínas da homeostase do $\mathrm{Ca}^{2+}$ intracelular}

A avaliação das proteínas da homeostase do cálcio intracelular incluiu as medidas de: SERCA-2, trocador sódio-cálcio (NCX), relação SERCA-2 pelo trocador sódio-cálcio (SERCA-2/NCX), fosfolambam (PLB), relação SERCA-2 pelo fosfolambam (SERCA-2/PLB), fosfolambam fosforilado no sítio da treonina 17 corrigido pelo fosfolambam total (PPLBthr17/PLB) e fosfolambam fosforilado no sítio da serina 16 corrigido pelo fosfolambam total (PPLBser16/PLB).

Nestas análises, não se observou alteração da SERCA-2 entre os grupos estudados, todavia observou-se redução do NCX nos grupos clipe-10 e clipe-30 com relação ao grupo controle. Esses achados induziram a um aumento da razão SERCA-2/NCX do grupo clipe-30 na comparação com o grupo controle, sugerindo um predomínio relativo da retirada de $\mathrm{Ca}^{2+}$ do citosol para dentro do retículo sarcoplasmático em comparação com o interstício.

Não foram observadas diferenças entre os grupos na expressão do PLB e na razão SERCA-2/PLB.

O grupo clipe-10 também mostrou as razões PPLBthr-17/PLB e a PPLBser16/PLB aumentadas com relação aos outros dois grupos de estudo, 
sugerindo um estágio compensatório da homeostase do cálcio intracelular à indução da hipertensão neste grupo (Tabela 9, Figura 14).

TABELA 9. Expressões da SERCA-2, trocador sódio-cálcio (NCX), relação serca-2 pelo trocador sódio-cálcio (SERCA-2/NCX), fosfolambam (PLB), relação serca-2 pelo fosfolambam (SERCA-2/PLB), fosfolambam fosforilado no sítio de fosforilação da treonina-17 corrigido pelo fosfolambam total (PPLBthr17/PLB) e fosfolambam fosforilado no sítio de fosforilação da serina-16 corrigido pelo fosfolambam total (PPLBser16/PLB) dos ratos controles (C), 10 dias de clipe (CLIPE-10) e 30 dias de clipe (CLIPE-30).

\begin{tabular}{|c|c|c|c|}
\hline & $\mathrm{C}$ & CLIPE-10 & CLIPE-30 \\
\hline SERCA - 2(\%) & $100 \pm 15,3$ & $65,8 \pm 20,1$ & $67,7 \pm 10,2$ \\
\hline $\operatorname{NCX}(\%)$ & $100 \pm 15,4$ & $44,9 \pm 13,3 \dagger$ & $28,5 \pm 6,8 \dagger$ \\
\hline SERCA-2/NCX & $1,04 \pm 0,14$ & $1,64 \pm 0,25$ & $3,54 \pm 0,86 \dagger$ \\
\hline PLB (\%) & $100 \pm 11,0$ & $75,2 \pm 14,6$ & $107,5 \pm 6,9$ \\
\hline SERCA-2/PLB & $1,05 \pm 0,14$ & $0,97 \pm 0,17$ & $0,72 \pm 0,08$ \\
\hline PPLBthr17/PLB(\%) & $100 \pm 17,2$ & $154 \pm 23,5 \dagger a$ & $86,9 \pm 8,9$ \\
\hline PPLBser16/PLB(\%) & $100 \pm 19,1$ & $200,6 \pm 51,2 \nmid a$ & $87,6 \pm 15,6$ \\
\hline Valor & média + F & 0,05 vs. gru & trole; $\neq \mathrm{p}<0$ \\
\hline
\end{tabular}




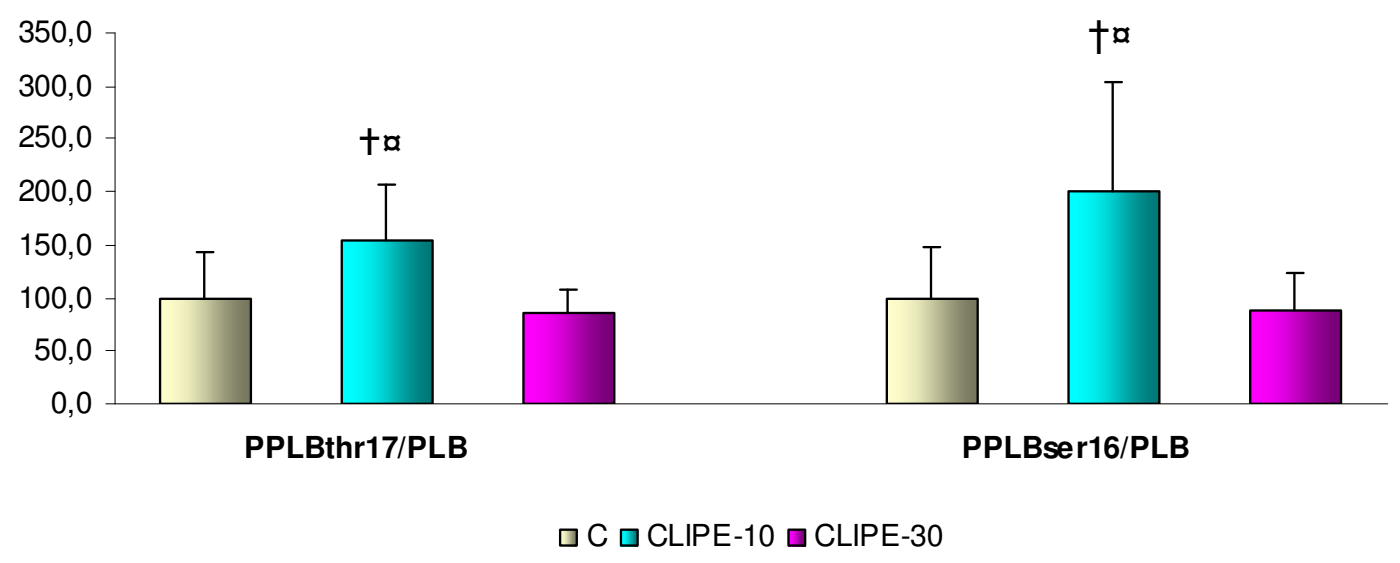

Figura 14 - Fosfolambam fosforilado no sítio de fosforilação da treonina-17 corrigido pelo fofolambam total (PPLBthr17/PLB) e fosfolambam fosforilado no sítio de fosforilação da serina-16 corrigido pelo fofolambam total (PPLBser16/PLB) dos grupos controle (C), clipe-10 e clipe-30. Note-se o aumento do PPLBthr17/PLB e PPLBser16/PLB do grupo clipe-10 com relação aos demais. $\uparrow p<0,05$ vs. grupo controle e ap $<0,05$ vs. grupo clipe-30. 


\subsection{EFEITOS DA PRESSÃO ARTERIAL E DA VARIABILIDADE DA PRESSÃO ARTERIAL NO DESENVOLVIMENTO DA HIPERTROFIA CARDÍACA}

\subsubsection{Avaliações Hemodinâmicas}

A avaliação hemodinâmica do estudo do efeito da PA e da variabilidade da PA no desenvolvimento da hipertrofia cardíaca mostrou que o grupo clipe-30 apresentou aumento da pressão arterial sistólica com relação aos grupos controle (C) e desnervado (DSA), enquanto que a pressão arterial diastólica estava maior apenas com relação ao grupo DSA. Já o grupo associação, no qual os pressorreceptores foram retirados e a artéria renal foi estenosada por apenas 10 dias, as pressões arteriais sistólica e diastólica se mostraram aumentadas com relação aos grupos controle $(C)$ e DSA.

A pressão arterial média (PAM) no grupo DSA foi semelhante ao grupo controle $(\mathrm{C})$. Já os grupos clipe-30 e associação apresentaram PAM parecidas e estatisticamente maiores que a dos grupos C e DSA. A variabilidade da PAM (SD PAM) e o coeficiente da variabilidade da pressão arterial média (Cx SD), apresentaram-se semelhantes nos grupos DSA e associação e maiores que nos grupos C e clipe-30 (Tabela 10, Figuras 15 e 16). 
A freqüência cardíaca não apresentou diferença estatística entre os quatro grupos comparados, assim como o intervalo de pulso (Tabela 10).

TABELA 10. Pressão arterial sistólica (PAS), pressão arterial diastólica (PAD), pressão arterial média (PAM), variabilidade da pressão arterial média (SD PAM), coeficiente da variabilidade da pressão arterial média ( $C x S D)$, freqüência cardíaca (FC) e intervalo de pulso (IP) dos ratos controles (C), desnervados (DSA), 30 dias de clipe (CLIPE-30) e desnervados com hipertensão (ASSOCIAÇÃO).

\begin{tabular}{|c|c|c|c|c|}
\hline & $\mathrm{C}$ & $\overline{D S A}$ & CLIPE-30 & ASSOCIAÇÃO \\
\hline PAS (mmHg) & $129 \pm 1$ & $122 \pm 4$ & $159 \pm 9+\S$ & $154 \pm 5 † \S$ \\
\hline PAD (mmHg) & $91 \pm 1$ & $87 \pm 4$ & $111 \pm 7 \S$ & $113 \pm 4 † \S$ \\
\hline PAM (mmHg) & $109 \pm 1$ & $103 \pm 4$ & $131 \pm 8+\S$ & $134 \pm 4 \dagger \S$ \\
\hline SDPAM $(\mathrm{mmHg})$ & $4,82 \pm 0,49$ & $12,5 \pm 1,73+£$ & $6,23 \pm 0,50$ & $11,4 \pm 0,96 \dagger £$ \\
\hline Cx SD (\%) & $4,3 \pm 0,5$ & $12,1 \pm 1,3+£$ & $5,2 \pm 0,6$ & $8,8 \pm 0,8 \dagger £$ \\
\hline FC (bpm) & $342 \pm 12$ & $379 \pm 14$ & $349 \pm 12$ & $374 \pm 7$ \\
\hline IP (ms) & $177 \pm 6,3$ & $158 \pm 6,12$ & $175 \pm 5,90$ & $160 \pm 5,13$ \\
\hline
\end{tabular}




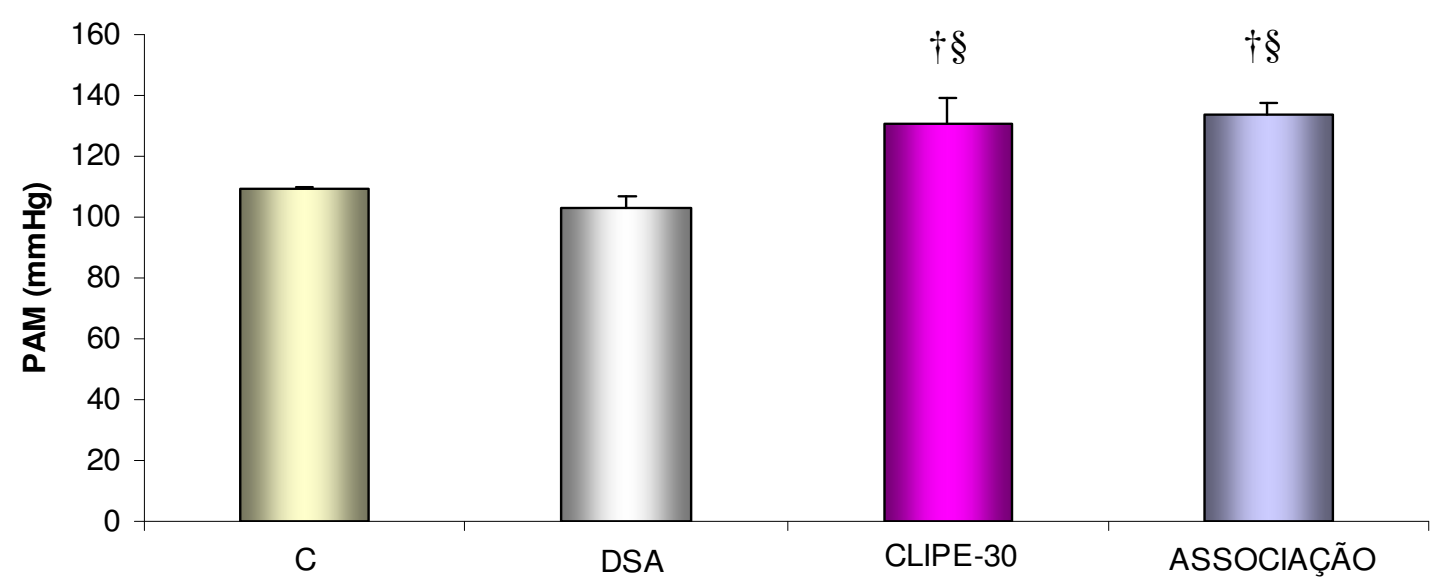

Figura 15 - Pressão Arterial Média (PAM) dos grupos controle (C), desnervados (DSA), 30 dias de clipe (CLIPE-30) e desnervados com hipertensão (ASSOCIAÇÃO). Note-se o maior nível de PAM dos grupos clipe-30 e associação com relação aos demais. $\uparrow p<0,05$ vs. grupo controle; $\$ p<0,05$ vs. grupo DSA. 


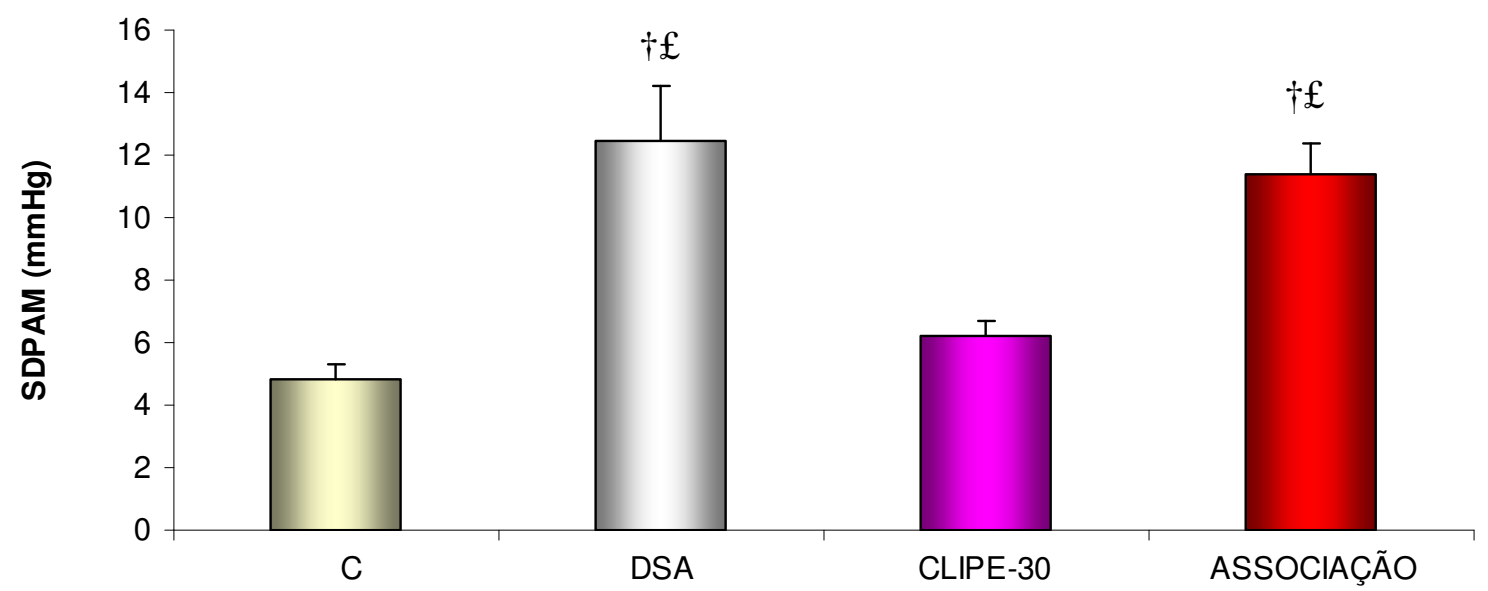

Figura 16 - Variabilidade da Pressão Arterial Média (SD PAM) dos grupos controle (C), desnervados (DSA), 30 dias de clipe (CLIPE-30) e desnervados com hipertensão (ASSOCIAÇÃO). Observe o SD PAM aumentado dos grupos DSA e associação. $\nmid p<0,05$ vs. grupo controle; $£ p<0,05$ vs. grupo CLIPE-30. 
Como se pode observar na Tabela 11, os grupos DSA e associação têm diminuição da sensibilidade do barorreflexo, representados pelos índice de bradicardia (IBR) e taquicardia (ITR) reflexas com relação aos grupos controle (C) e clipe-30.

O grupo clipe-30 apresentou diminuição do IBR e do ITR com relação ao grupo C.

TABELA 11. Índices de bradicardia reflexa (IBR) e taquicardia reflexa (ITR) dos ratos controles (C), desnervados (DSA), 30 dias de clipe (CLIPE-30) e desnervados com hipertensão (ASSOCIAÇÃO).

\begin{tabular}{c|cccc}
\hline & C & DSA & CLIPE-30 & ASSOCIAÇÃO \\
\hline IBR $(\mathrm{bpm} / \mathrm{mmHg})$ & $2,19 \pm 0,13$ & $0,46 \pm 0,06+£$ & $1,15 \pm 0,10 \dagger$ & $0,36 \pm 0,05 \dagger £$ \\
ITR $(\mathrm{bpm} / \mathrm{mmHg})$ & $1,98 \pm 0,09$ & $0,49 \pm 0,08 \dagger £$ & $1,13 \pm 0,17 \dagger$ & $0,47 \pm 0,06 \dagger £$ \\
\hline
\end{tabular}

Valores expressos como média \pm EPM. $\uparrow p<0,05$ vs. grupo controle; $£ p<0,05$ vs. grupo CLIPE-30. 


\subsubsection{Variabilidade do intervalo de pulso e variabilidade da freqüência cardíaca no domínio do tempo}

A variabilidade da freqüência cardíaca avaliada pelo desvio do intervalo de pulso (SD IP) foi semelhante entre os 4 grupos avaliados.

Entretanto, a análise da modulação autonômica cardíaca no domínio da freqüência mostrou aumento do componente de baixa freqüência (LF) normalizado do intervalo de pulso dos grupos hipertensos (CLIPE-30 e ASSOCIAÇÃO) com relação ao grupo controle. Redução do componente de alta freqüência (HF) normalizado do intervalo de pulso foi observado nos grupos hipertensos (CLIPE-30 e ASSOCIAÇÃO) com relação ao grupo controle. A relação LF/HF mostrou aumento apenas no grupo associação com relação ao grupo controle, evidenciando maior desbalanço autonômico destes animais (Tabela 12). 
TABELA 12. Desvio do intervalo de pulso (SD IP), banda e baixa freqüência (LF), banda alta freqüência (HF) e a relação LF/HF do intervalo de pulso dos ratos controles (C), desnervados (DSA), 30 dias de clipe (CLIPE-30) e desnervados com hipertensão (ASSOCIAÇÃO).

\begin{tabular}{c|cccc}
\hline & C & DSA & CLIPE-30 & ASSOCIAÇÃO \\
\hline SD IP (ms) & $7,73 \pm 1,04$ & $6,28 \pm 1,20$ & $11,59 \pm 1,16$ & $6,70 \pm 1,52$ \\
LF (\%) & $16,62 \pm 2,21$ & $20,96 \pm 3,93$ & $29,17 \pm 4,66 \dagger$ & $31,92 \pm 4,53 \dagger$ \\
HF (\%) & $83,38 \pm 2,21$ & $79,04 \pm 3,93$ & $70,83 \pm 4,66 \dagger$ & $68,08 \pm 4,53 \dagger$ \\
LF / HF & $0,20 \pm 0,03$ & $0,28 \pm 0,06$ & $0,44 \pm 0,10$ & $0,50 \pm 0,11 \dagger$ \\
\hline
\end{tabular}

Valores expressos como média \pm EPM. $\uparrow p<0,05$ vs. grupo controle.

\subsubsection{Variabilidade da pressão arterial sistólica e variabilidade da} pressão arterial no domínio da freqüência

A Tabela 13 mostra que a variância da PAS estava aumentada no grupo associação com relação aos grupos controle (C) e clipe-30. O componente de baixa freqüência (LF) da PAS do grupo associação também estava maior na 
comparação com os outros 3 grupos avaliados, mostrando aumento da modulação simpática vascular nestes animais.

TABELA 13. Variância pressão arterial sistólica (VPAS) e componente de baixa freqüência (LF) da pressão arterial sistólica dos ratos controles (C), desnervados (DSA), 30 dias de clipe (CLIPE-30) e desnervados com hipertensão (ASSOCIAÇÃO).

\begin{tabular}{c|cccc}
\hline & C & DSA & CLIPE-30 & ASSOCIACÃO \\
\hline VPAS & $30,4 \pm 5,9$ & $118,2 \pm 27,5$ & $45,7 \pm 7,8$ & $138,6 \pm 21,6 \dagger £$ \\
LF $\left(\mathrm{mmHg}^{2}\right)$ & $3,43 \pm 0,60$ & $3,58 \pm 0,59$ & $6,47 \pm 1,32$ & $13,16 \pm 3,81 \dagger \S £$ \\
\multicolumn{4}{l}{ Valores expressos como média \pm EPM. $+\mathrm{p}<0,05$ vs. grupo controle; $\$ p<0,05$} \\
vs. grupo DSA; $£ \mathrm{p}<0,05$ vs. grupo CLIPE-30.
\end{tabular}

\subsubsection{Avaliações morfométricas}

O peso corporal médio dos animais do grupo controle no dia da avaliação era de $339 \pm 32 \mathrm{~g}$, contra $352 \pm 21 \mathrm{~g}$ do grupo DSA, $326 \pm 22 \mathrm{~g}$ do grupo clipe-30 
e $331 \pm 36 \mathrm{~g}$ do grupo associação, sem diferença estatística significativa entre eles.

A Tabela 14 apresenta os parâmetros morfométricos do VE. A espessura da parede do VE na diástole corrigida pelo peso corporal (PARcorr) estava maior nos grupos clipe-30 e associação com relação aos grupos controle (C) e DSA, assim como a massa ventricular esquerda obtida pelo ecocardiograma corrigida pelo peso (MVEcorr).

A espessura relativa da parede (ERP) também se mostrou aumentada nos grupos clipe-30 e associação quando comparada aos grupos C e DSA. No entanto, o grupo associação também mostrou aumento da ERP com relação ao grupo clipe-30 e diminuição da cavidade do VE na diástole corrigida pelo peso corporal (VEDIAcorr) quando comparada aos grupos C e clipe-30, evidenciando uma hipertrofia concêntrica destes animais com relação aos outros grupos de comparação (Figuras 17 e 18).

Os valores de morfologia cardíaca do grupo controle foram semelhantes aos valores ecocardiográficos basais propostos por Watson e cols. (2004). 


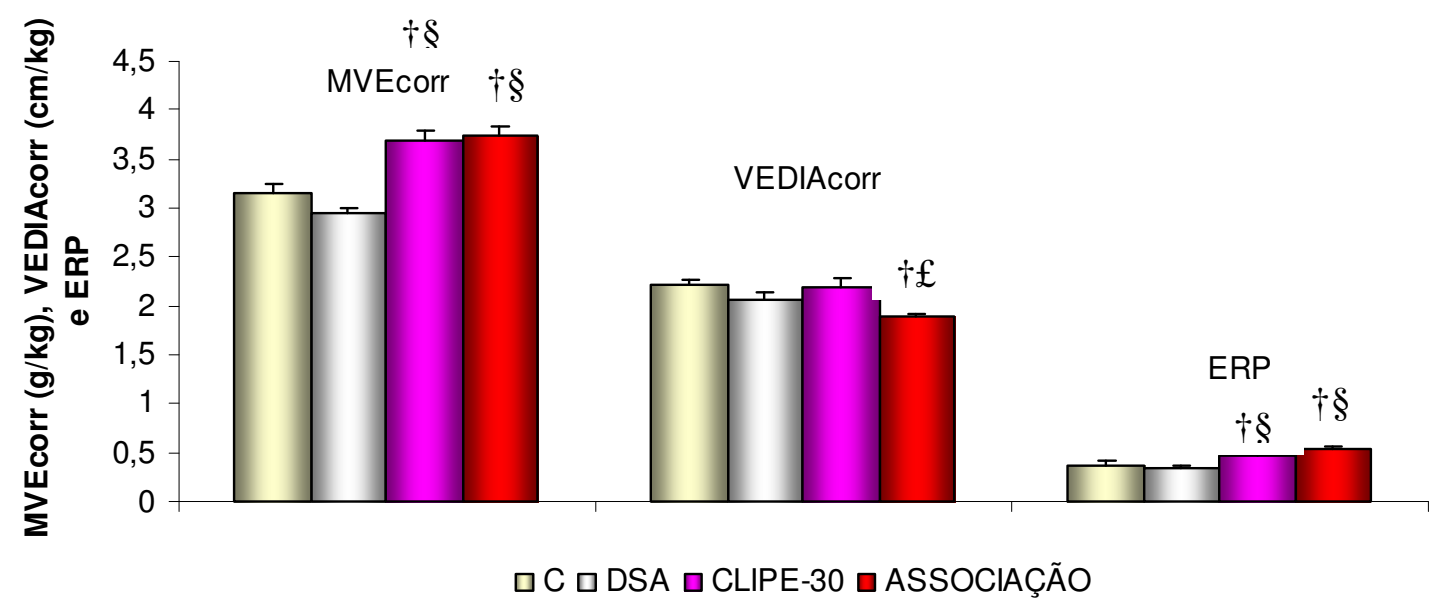

Figura 17 - Massa ventricular esquerda corrigida pelo peso corporal (MVEcorr), dimensão diastólica do VE corrigida pelo peso corporal (VEDIAcorr) e espessura relativa da parede (ERP) dos grupos controle (C), desnervados (DSA), 30 dias de clipe (CLIPE-30) e desnervados com hipertensão (ASSOCIAÇÃO). Note-se a MVEcorr aumentada dos grupos clipe-30 e associação, VEDIAcorr diminuída do grupo associação e ERP aumentada dos grupos clipe-30 e associação. $\uparrow \mathrm{p}<0,05$ vs. grupo controle; $\$ p<0,05$ vs. grupo DSA; $£ p<0,05$ vs. grupo CLIPE-30. 


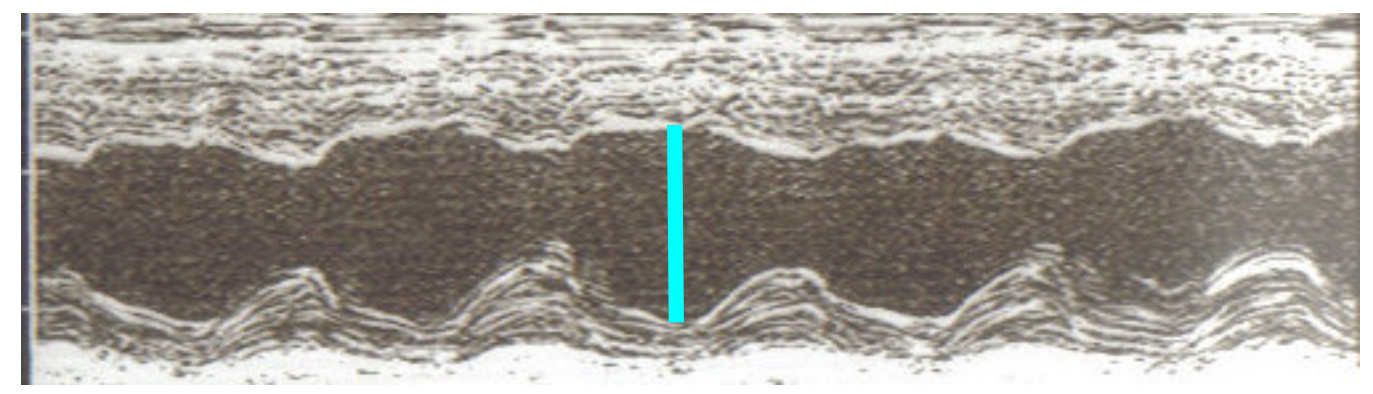

A.

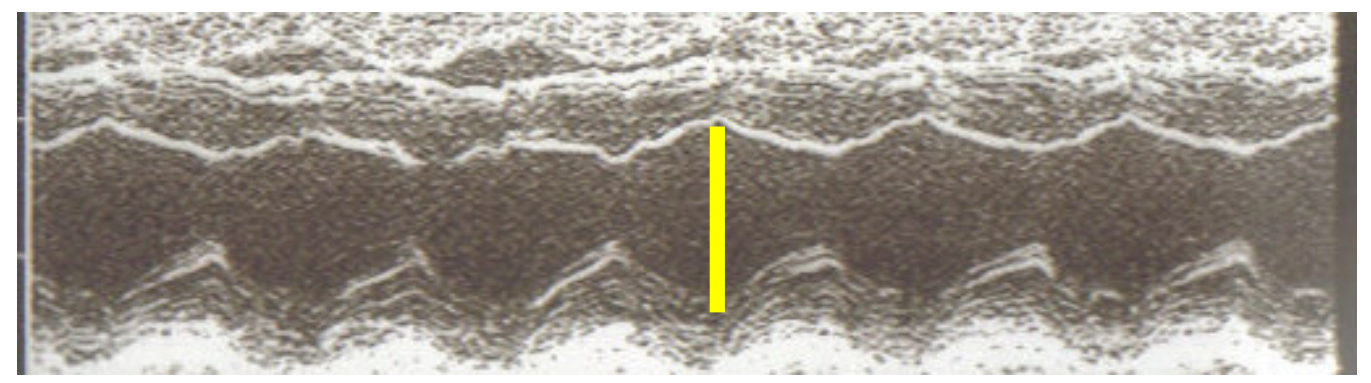

B.

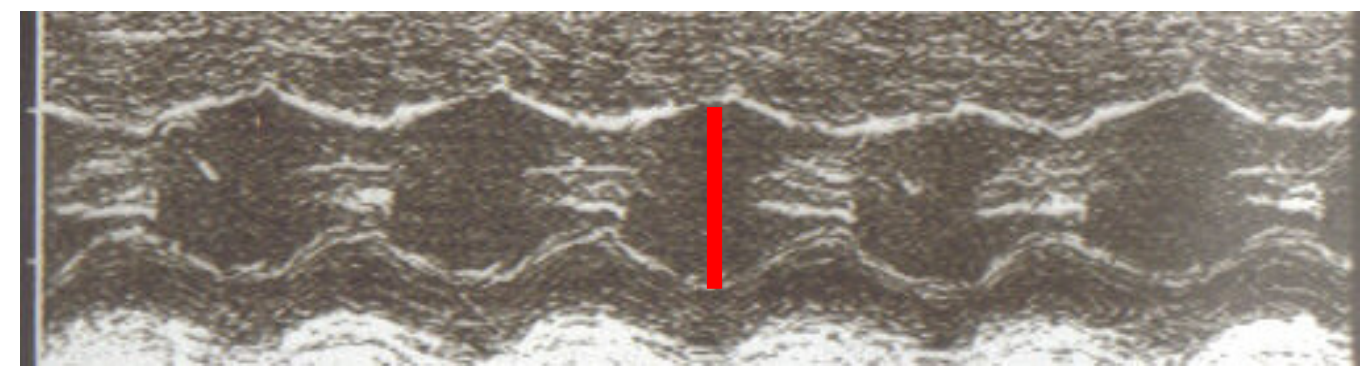

C.

Figura 18 - Modo $M$ do ventrículo esquerdo de um rato do grupo controle (A), de um rato do grupo clipe-30 (B) e de um rato do grupo associação (C). Observe a diminuição da cavidade ventricular esquerda e aumento da espessura das paredes no rato do grupo associação (C). 
Avaliando a importância da pressão arterial média (PAM em mmHg) no desenvolvimento da hipertrofia do VE, notamos uma correlação positiva entre essas variáveis. Para tanto, usamos a espessura relativa da parede (ERP) como índice de hipertrofia, por ser mais sensível quanto à classificação da hipertrofia (Qu e cols., 2000). Quanto maior o nível pressórico, maior a hipertrofia ventricular $(r=0,81, p<0,01)$ (Figura 19).

\section{C, CLIPE-30 e ASSOCIAÇÃO}

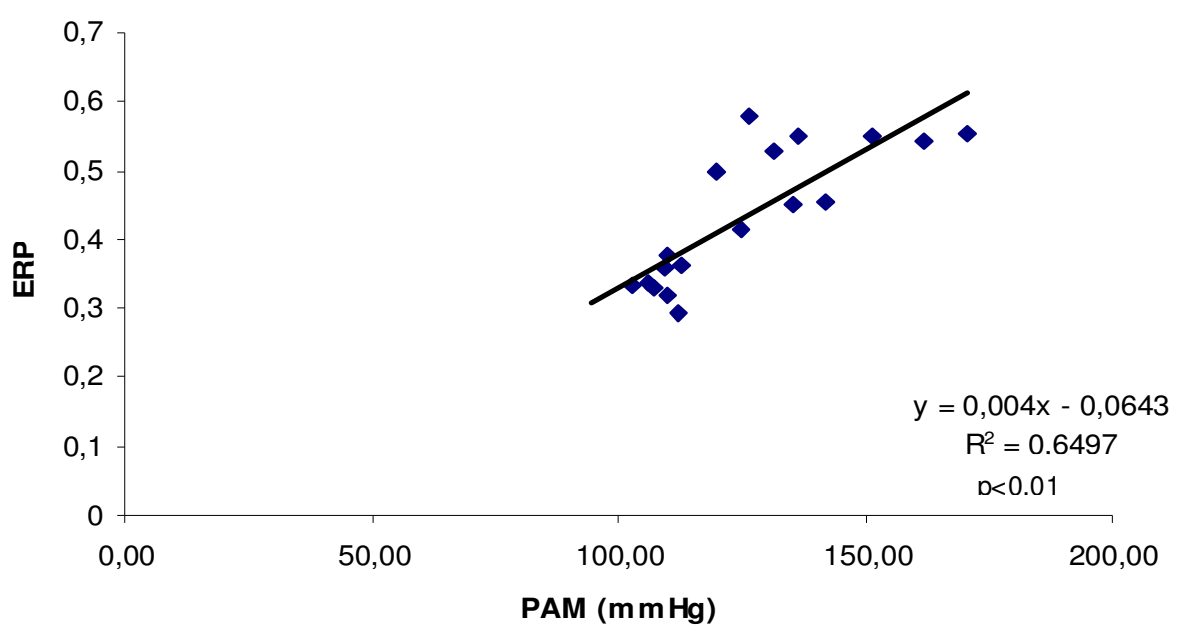

Figura 19 - Correlação entre o nível de pressão arterial média (PAM) e a espessura relativa da parede (ERP) entre os grupos controle (C), 30 dias de clipe (CLIPE-30) e desnervado com hipertensão (ASSOCIAÇÃO) ( $r=0,81$ e $p<0,01)$. 
Resultados semelhantes foram observados no estudo de correlação $(r=0,78$ e $p<0,01)$ com os mesmos grupos entre a sensibilidade do barorreflexo, representada pelo índice de taquicardia reflexa (ITR em bpm/mmHg) e a espessura relativa da parede (ERP). Observa-se uma associação negativa e significativa, sugerindo uma ligação entre essas variáveis. Os dados indicam que quanto maior a diminuição da sensibilidade do barorreflexo, ou seja, quanto menor a sensibilidade do ITR, maior o grau de hipertrofia cardíaca (Figura 20).

C, CLIPE-30 e ASSOCIAÇÃO

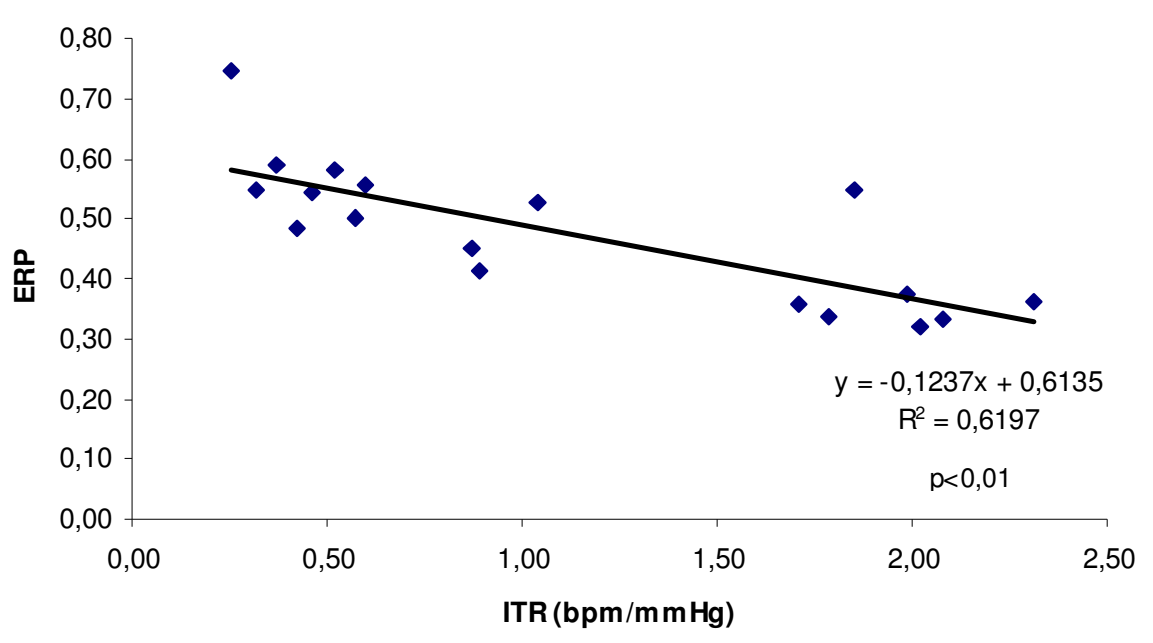

Figura 20 - Correlação entre o índice de taquicardia reflexa (ITR) e espessura relativa da parede (ERP) entre os grupos controle (C), 30 dias de clipe (CLIPE30) e desnervado com hipertensão (ASSOCIAÇÃO) ( $r=0,78$ e $p<0,01)$. 
Outra correlação interessante que observamos foi entre o coeficiente da pressão arterial média (Cx SD) e um índice de hipertrofia ventricular, a espessura relativa da parede (ERP) $(r=0,76$ e $p<0,01)$, entre os grupos controle (C), clipe-30 e associação. Esta correlação mostra que quanto maior o Cx SD, maior a hipertrofia desenvolvida pelo VE sob estímulo hipertensivo, sugerindo que não apenas o nível pressórico, mas principalmente o grau de variabilidade da pressão arterial, estimulam a hipertrofia (Figura 21).

C, CLIPE-30 e ASSOCIAÇÃO

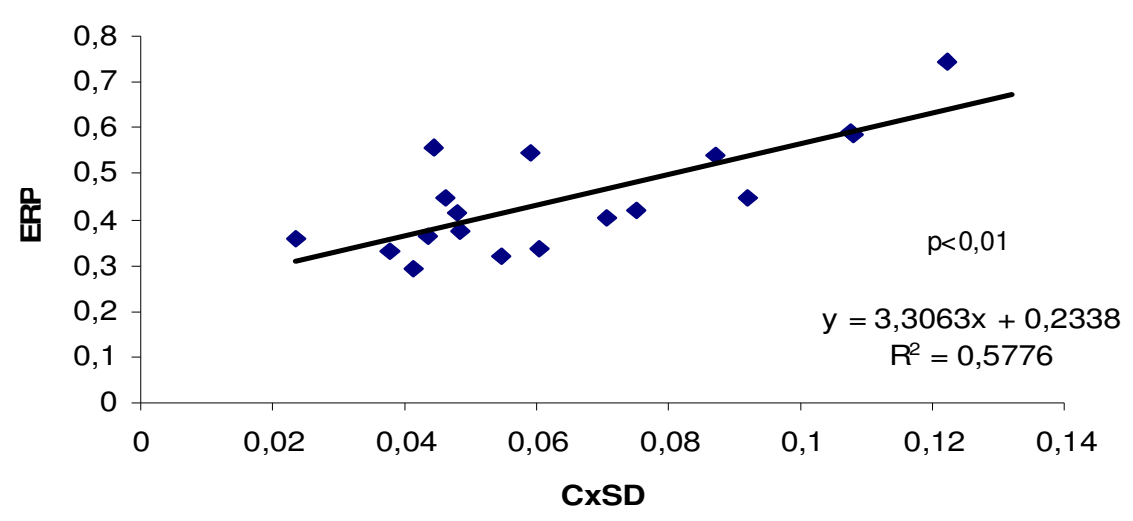

Figura 21 - Correlação entre o coeficiente da variabilidade da pressão arterial média (Cx SD) e a espessura relativa da parede (ERP) entre os grupos controle (C), 30 dias de clipe (CLIPE-30) e desnervado com hipertensão (ASSOCIAÇÃO) $(r=0,76$ e $p<0,01)$. 


\subsubsection{Avaliações da função sistólica}

A função sistólica, avaliada pelas frações de ejeção e encurtamento, além da velocidade de encurtamento circunferencial, não mostrou alteração entre os grupos comparados (Tabela 15, Figura 22).

O débito cardíaco corrigido pelo peso corporal do animal, representado pelo índice cardíaco (IC), também não mostrou diferença estatística entre os grupos (Tabela 15).

Já o índice de desempenho miocárdico, foi maior nos grupos clipe-30 e associação, quando comparado ao grupo controle, mostrando maior esforço cardíaco destes grupos com relação aos controles.

Os valores de função cardíaca do grupo controle foram semelhantes aos valores ecocardiográficos basais propostos por Watson e cols. (2004). 
TABELA 15. Parâmetros ecocardiográficos de função sistólica dos ratos controles (C), desnervados (DSA), 30 dias de clipe (CLIPE-30) e desnervados com hipertensão (ASSOCIAÇÃO).

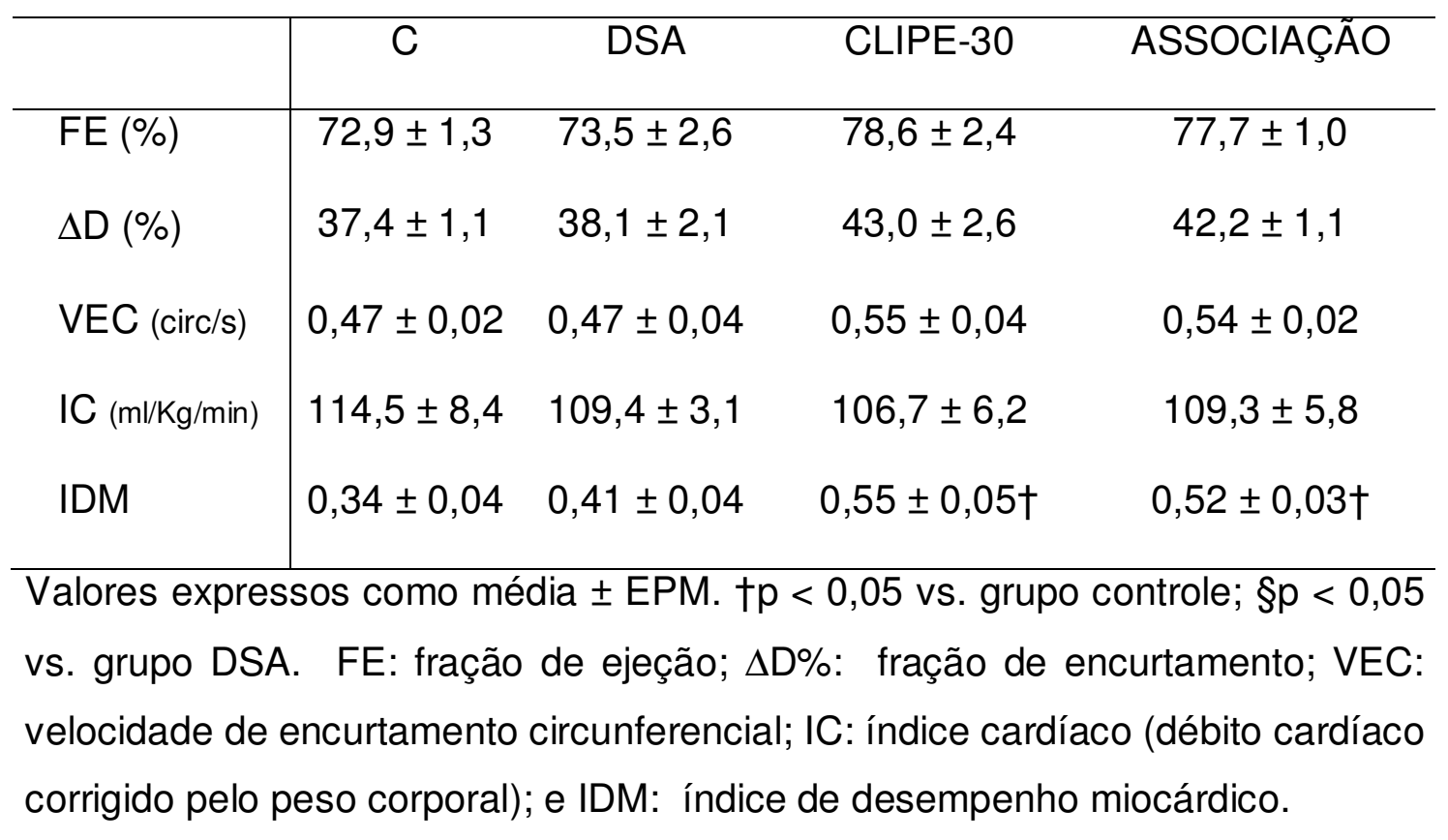




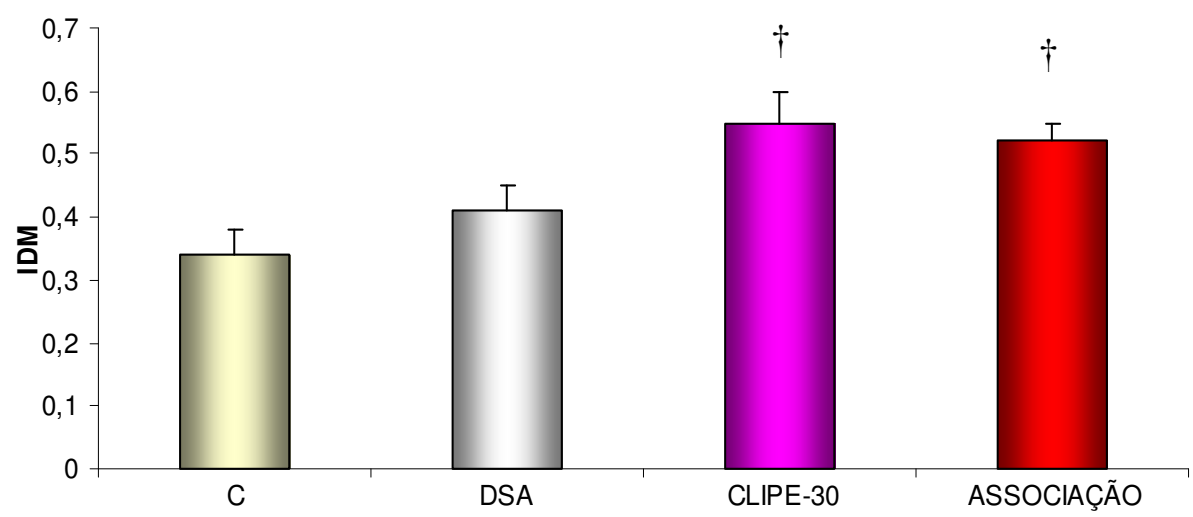

Figura 22 - Índice de desempenho miocárdico (IDM) dos grupos controle (C), desnervado (DSA), 30 dias de clipe (clipe-30) e desnervado com hipertensão (ASSOCIAÇÃO). Observe o aumento do IDM nos grupos clipe-30 e associação. $\mathrm{tp}<0,05$ vs. grupo controle. 
Levando-se em conta o índice de desempenho miocárdico (IDM) e a espessura relativa da parede dos animais com 10 dias de clipe na artéria renal, com os pressorreceptores preservados (clipe-10) e sem os pressorreceptores (ASSOCIAÇÃO), observamos uma correlação positiva, com $r=0,8$ e $p<0,01$ nestas duas variáveis, Quanto maior o IDM, maior o grau de hipertrofia ventricular esquerda (Figura 23).

\section{CLIPE-10 e ASSOCIAÇÃO}

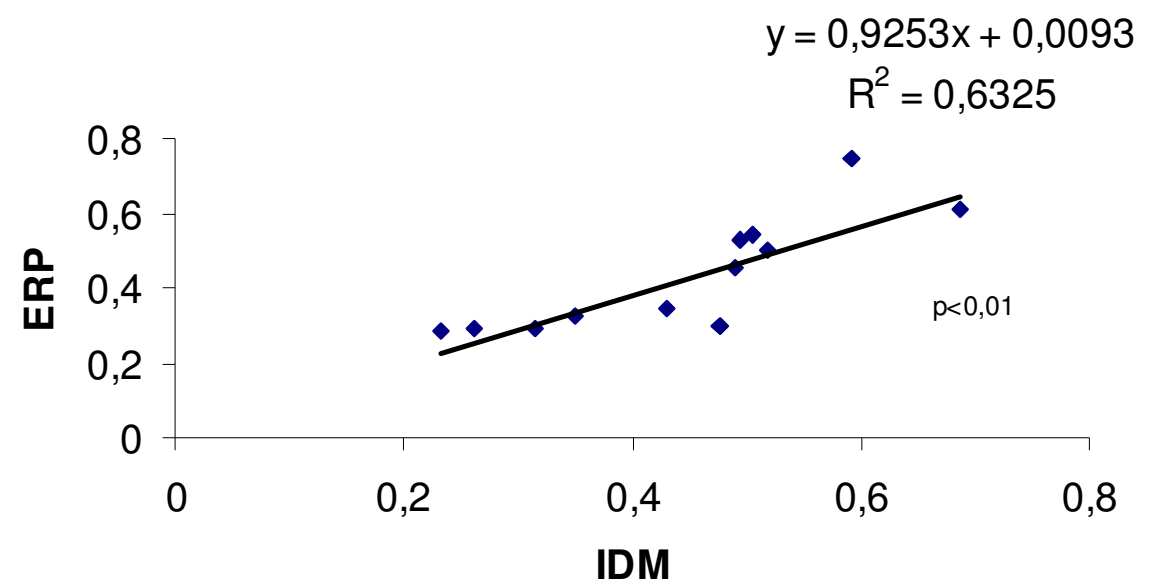

Figura 23 - Correlação entre o índice de desempenho miocárdico (IDM) e espessura relativa da parede (ERP) em ratos dos grupos clipe-10 e associação $(r=0,8$ e $p<0,01)$. 


\subsubsection{Avaliações da função diastólica}

Os grupos clipe-30 e associação mostraram déficit diastólico pela diminuição dos índices de relação $\mathrm{E} / \mathrm{A}$, tempo de relaxamento isovolumétrico corrigido pela freqüência cardíaca (TRIVcorr) e relação E'/A' da parede septal (E'/A's) e relação E'/A' da parede lateral do $V E$ (E'/A'p) com relação ao grupo controle. A relação E'/A'p no grupo ASSOCIAÇÃO também estava diminuída quando comparada ao grupo DSA (Tabela 16, Figuras 24, 25 e 26).

O tempo de desaceleração do pico $E$ corrigida pela freqüência cardíaca não mostrou diferença estatística entre os grupos, conforme se observa na Tabela 16.

$A$ razão E/E' do grupo associação foi maior do que nos outros 3 grupos estudados. 
TABELA 16. Parâmetros ecocardiográficos da função diastólica dos ratos controles (C), desnervados (DSA), 30 dias de clipe (CLIPE-30) e desnervados com hipertensão (ASSOCIAÇÃO).

\begin{tabular}{l|cccc}
\hline & C & DSA & CLIPE-30 & ASSOCIAÇÃO \\
\hline E/A & $1,87 \pm 0,19$ & $1,53 \pm 0,16$ & $1,30 \pm 0,09 \dagger$ & $1,15 \pm 0,06 \dagger$ \\
TRIV corr (ms) & $1,50 \pm 0,06$ & $1,86 \pm 0,12$ & $1,97 \pm 0,10 \dagger$ & $1,97 \pm 0,10 \dagger$ \\
TDEcorr (ms) & $1,84 \pm 0,19$ & $1,80 \pm 0,27$ & $1,97 \pm 0,10$ & $1,60 \pm 0,11$ \\
E'/A's & $1,33 \pm 0,08$ & $1,04 \pm 0,10$ & $0,88 \pm 0,09 \dagger$ & $0,82 \pm 0,07 \dagger$ \\
E'/A'p & $1,43 \pm 0,08$ & $1,34 \pm 0,13$ & $0,98 \pm 0,12 \dagger$ & $0,95 \pm 0,07 \dagger \S$ \\
E / E's & $12,37 \pm 0,89$ & $12,82 \pm, 08$ & $12,75 \pm 0,70$ & $17,76 \pm 1,90 \dagger \S £$ \\
\hline
\end{tabular}

Valores expressos como média \pm EPM. $\uparrow p<0,05$ vs. grupo controle; $\$ p<0,05$ vs. grupo DSA; $£ p<0,05$ vs. grupo CLIPE-30. E/A: relação dos picos E e A; TRIVcorr: tempo de relaxamento isovolumétrico corrigido pela freqüência cardíaca; TDEcorr: tempo de desaceleração do pico $E$ corrigido pela freqüência cardíaca; E'/A's: relação dos picos E' e A' da parede septal; E'/A'p: relação dos picos E' e A' da parede lateral do VE; E / E's: relação do pico E pelo pico E' da parede septal. 


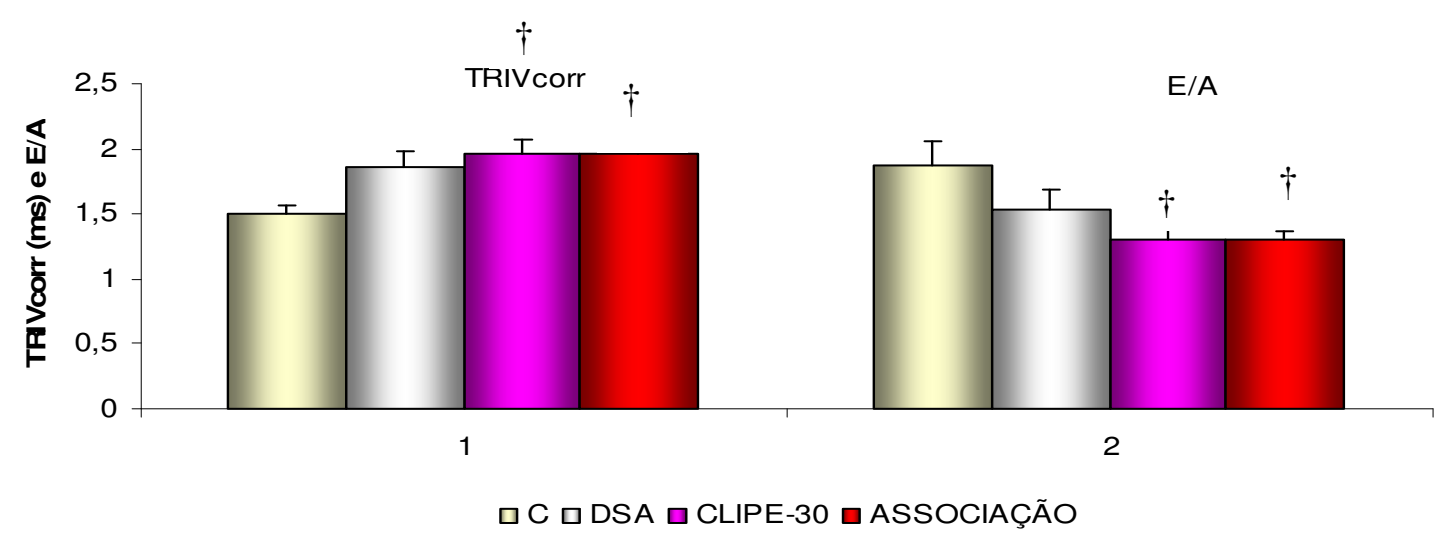

Figura 24 - Tempo de relaxamento isovolumétrico corrigido pela FC (TRIVcorr) e relação E/A no estudo Doppler dos grupos controle (C), desnervado (DSA), 30 dias de clipe (CLIPE-30) e desnervado com hipertensão (ASSOCIAÇÃO). Notese o TRIVcorr aumentado e E/A diminuída dos grupos clipe-30 e associação com relação ao grupo controle. $\uparrow p<0,05$ vs. grupo controle. 


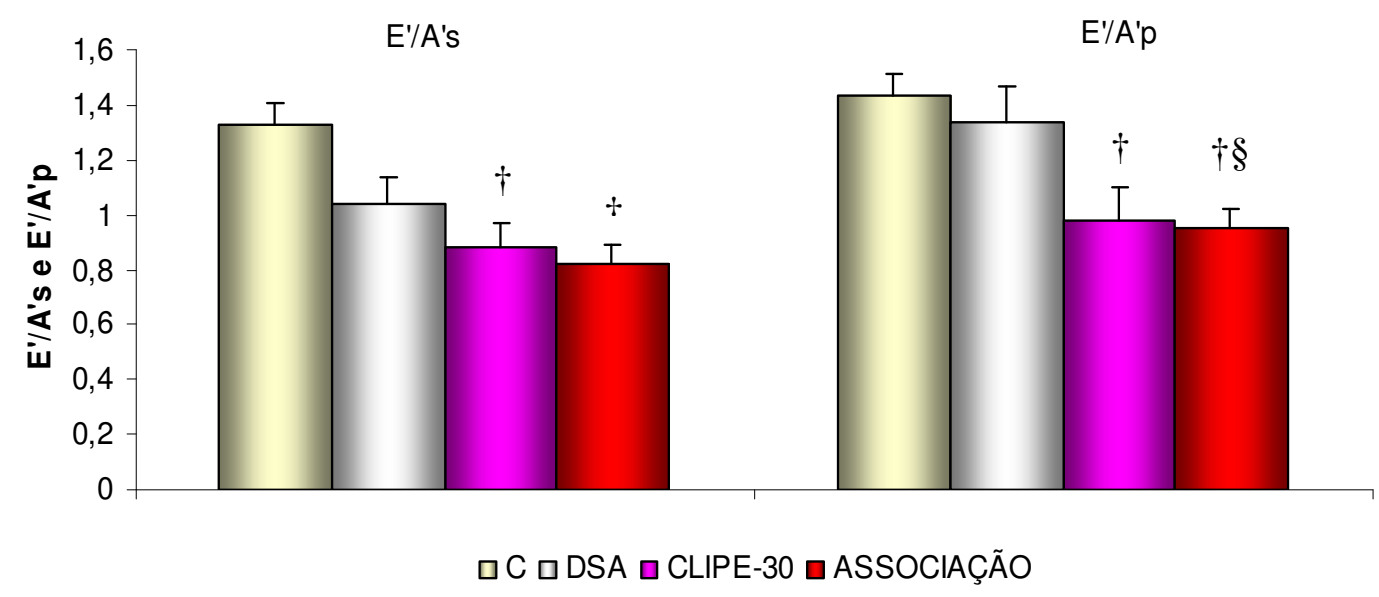

Figura 25 - Relações E'/A' do estudo Doppler tecidual obtidos nas paredes septal (E'/A's) e lateral (E'/A'p) do VE dos grupos controle (C), desnervado (DSA), 30 dias de clipe (CLIPE-30) e desnervado com hipertensão (ASSOCIAÇÃO). Observe a diminuição destes dois índices dos grupos clipe-30 e associação. $\uparrow p<0,05$ vs. grupo controle; $\$ p<0,05$ vs. grupo DSA. 


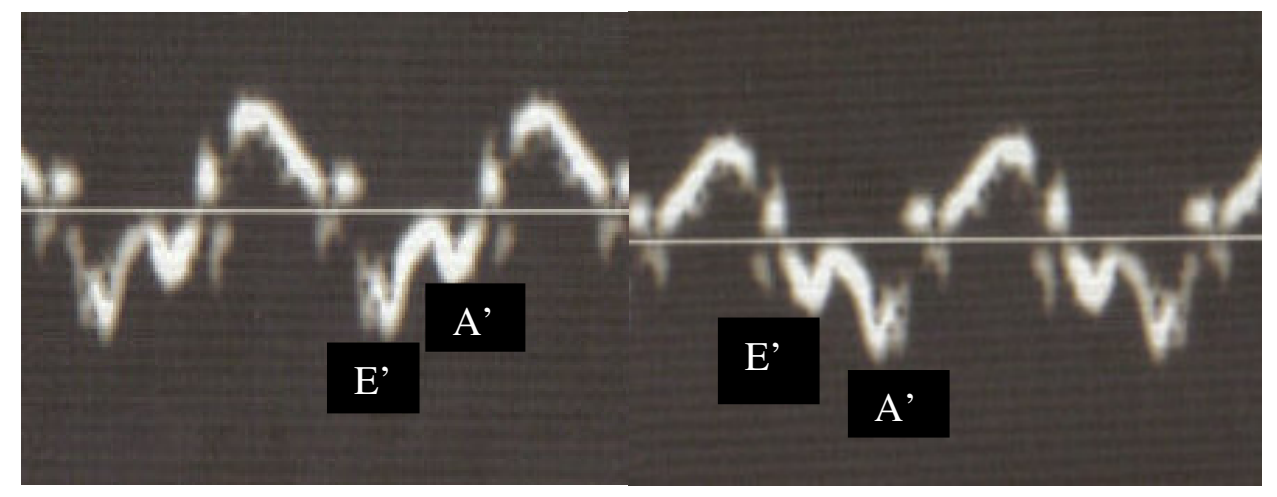

\section{Controle}

Associação

Figura 26. Relação E’/A' obtida pelo Doppler tecidual no nível da valva mitral na parede lateral do VE do grupo controle (à esquerda) e do grupo associação (à direita). Note-se a inversão desta relação no grupo associação $\left(E^{\prime}<A^{\prime}\right)$.

\subsubsection{Avaliações post-mortem dos tecidos}

A Tabela 17 apresenta a análise de peso post-mortem do coração, pulmões e rins. O peso do VE corrigido pelo peso corporal (VE/PESO) mostrou um aumento significativo nos grupos hipertensos (clipe-30 e associação) com relação aos grupos normotensos (controle e DSA). Já o peso do ventrículo direito corrigido pelo peso corporal (VD/PESO), se mostrou aumentado nos grupos desnervados (DSA e associação) quando comparado ao grupo clipe-30. 
O peso dos pulmões corrigido pelo peso corporal (PULMÕES/PESO) do grupo associação foi maior que nos grupos controle e DSA.

Já o peso do rim direito, não clipado, corrigido pelo peso corporal (RIM D/PESO) dos grupos clipe-30 e associacão apresentou-se maior que nos grupos controle e DSA. O rim esquerdo corrigido pelo peso corporal (RIM E/PESO) foi semelhante entre os 4 grupos estudados. 
TABELA 17. Peso dos tecidos corrigidos pelo peso corporal dos ratos controles (C), desnervados (DSA), 30 dias de clipe (CLIPE-30) e desnervados com hipertensão (ASSOCIAÇÃO).

\begin{tabular}{l|cccc}
\hline & C & DSA & CLIPE-30 & ASSOCIAÇÃO \\
\hline VE/PESO $(\mathrm{g} / \mathrm{Kg})$ & $2,18 \pm 0,07$ & $2,23 \pm 0,04$ & $2,97 \pm, 26+\S$ & $2,70 \pm 0,04 \dagger \S$ \\
VD/PESO $(\mathrm{g} / \mathrm{Kg})$ & $0,79 \pm 0,02$ & $0,93 \pm 0,05$ & $0,74 \pm 0,04$ & $1,01 \pm 0,08 £$ \\
PULMÕES/PESO $(\mathrm{g} / \mathrm{Kg})$ & $5,47 \pm 0,22$ & $5,48 \pm 0,20$ & $5,70 \pm 0,18$ & $6,43 \pm 0,27 \dagger \S$ \\
RIM D/PESO (g/Kg) & $3,42 \pm 0,07$ & $3,42 \pm 0,09$ & $4,41 \pm, 20 \dagger \S$ & $4,51 \pm 0,18 \dagger \S$ \\
RIM E/PESO (g/Kg) & $3,42 \pm 0,05$ & $3,28 \pm 0,09$ & $3,56 \pm 0,14$ & $3,07 \pm 0,26$ \\
Valores expressos como média \pm EPM. $\dagger p<0,05$ vs. grupo controle; $\S p<0,05$ \\
vs. grupo DSA; £p < 0,05 vs. grupo CLIPE-30. VE/PESO: peso do ventrículo \\
esquerdo corrigido pelo peso corporal; VD/PESO: peso do ventrículo direito \\
corrigido pelo peso corporal; PULMÕES/PESO: peso dos pulmões corrigido \\
pelo peso corporal; RIM D/PESO: peso do rim direito corrigido pelo peso \\
corporal; RIM E/PESO: peso do rim esquerdo corrigido pelo peso corporal.
\end{tabular}


Os resultados que obtivemos da massa do ventrículo esquerdo pelo ecocardiograma e do peso do VE (ambos corrigidos pelo peso corporal), mostraram uma correlação significativa $(r=0,85$ e $p<0,0001)$, indicando que há uma associação entre as medidas diretas e indiretas desta avaliação morfométrica entre todos os grupos do protocolo experimental (Figura 27).

C, DSA, CLIPE-10, CLIPE-30 e ASSOCIAÇÃO

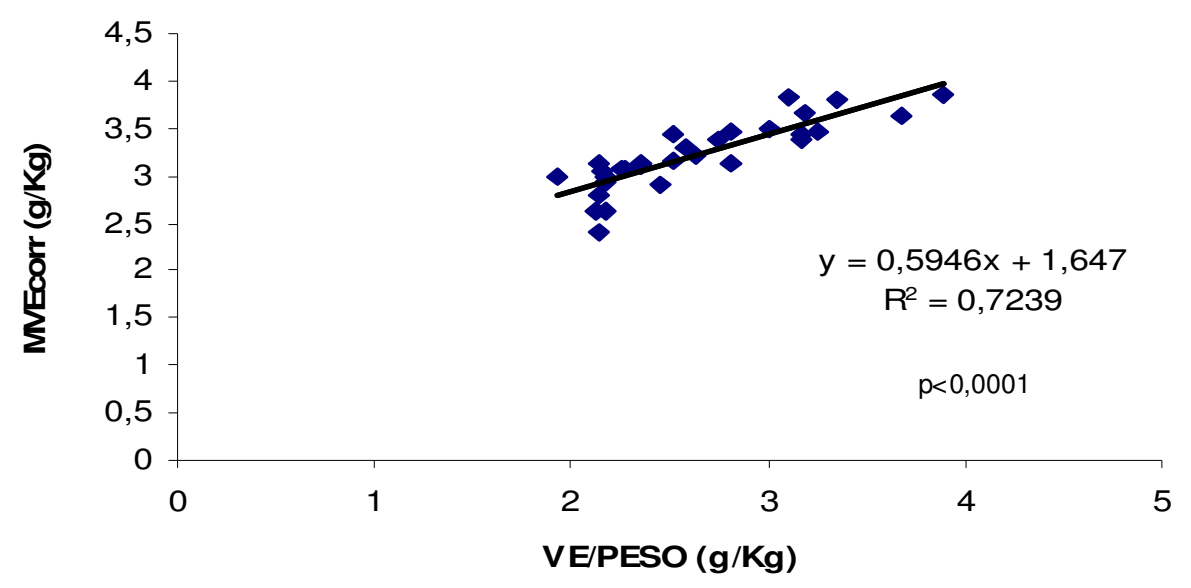

Figura 27 - Correlação entre o peso do VE corrigido pelo peso corporal (VE/PESO) e massa ventricular esquerda corrigida pelo peso corporal (MVEcorr) dos 5 grupos estudados: controle (C), desnervação sino-aórtica (DSA), 10 dias de clipe (CLIPE-10), 30 dias de clipe (CLIPE-30) e desnervado com hipertensão (ASSOCIAÇÃO) $(r=0,85, p<0,0001$ ). 
Avaliando as diferenças dos pesos entre o rim direito (intacto) corrigido pelo peso corporal e o rim esquerdo (cuja artéria renal foi clipada) também corrigido pelo peso corporal, pudemos observar uma correlação positiva ( $r=0,74$ e $p<0,001)$ com o nível de pressão arterial média (PAM em mmHg). Assim, quanto maior esta diferença, maior o nível pressórico desenvolvido (Figura 28).

\section{C, CLIPE-10, CLIPE-30 e ASSOCIAÇÃO}

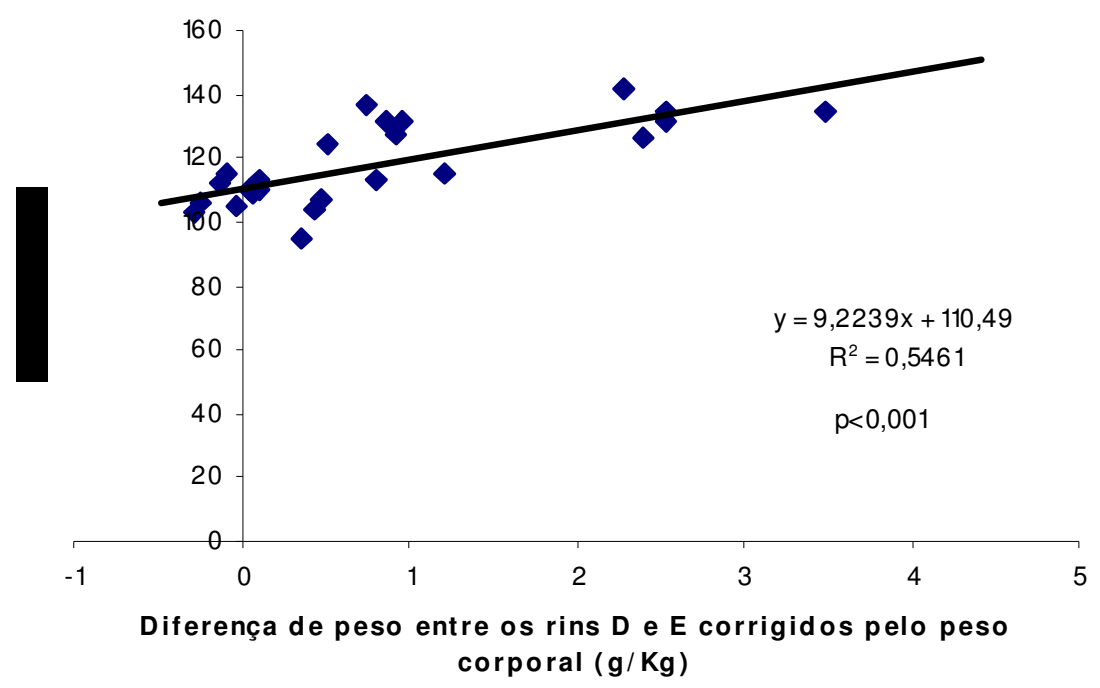

Figura 28. Correlação entre pressão arterial média (PAM) e diferença de peso entre o rim direito corrigido pelo peso corporal e rim esquerdo corrigido pelo peso corporal $(\mathrm{g} / \mathrm{Kg})$ entre os animas do grupo controle, clipe-10, clipe-30 e associação ( $r=0,74$ e $p<0,001)$. 


\subsubsection{Avaliações moleculares das proteínas da homeostase do $\mathrm{Ca}^{2+}$ intracelular}

As avaliações da expressão das proteínas da homeostase do cálcio intracelular no estudo do efeito da pressão arterial e da variabilidade da pressão arterial nas respostas cardiovasculares, evidenciaram diminuição da SERCA-2 no grupo associação com relação ao grupo controle (C).

O trocador sódio-cálcio (NCX) estava reduzido no grupo DSA com relação aos grupos controle (C) e associação. Além disto, observou-se redução do NCX nos grupos clipe-30 e associação com relação ao C. A relação SERCA-2/NCX, no entanto, se mostrou aumentada nos grupos DSA e clipe-30 quando comparada ao C e ao grupo associação (Figura 29). Note-se que a DSA e 30 dias de clipe isoladamente aumentaram a relação SERCA-2/NCX, enquanto a associação dos dois modelos, causou a redução da mesma. O fosfolambam total (PLB) e o fosfolambam fosforilado no sítio de fosforilação da serina-16 corrigido pelo fosfolambam total (PPLBser-16/PLB) foram semelhantes entre os 4 grupos estudados.

O grupo associação também mostrou redução da relação SERCA-2/PLB e do fosfolambam fosforilado no sítio de fosforilação da treonina-17 corrigido pelo fosfolambam total (PPLBthr17/PLB) com relação ao grupo controle (Tabela 18). 
TABELA 18. Expressões da SERCA-2, trocador sódio-cálcio (NCX), relação SERCA-2 pelo trocador sódio-cálcio (SERCA-2/NCX), fosfolambam (PLB), relação SERCA-2 pelo fosfolambam (SERCA-2/PLB), fosfolambam fosforilado no sítio de fosforilação da treonina-17 corrigido pelo fosfolambam total (PPLBthr17/PLB) e fosfolambam fosforilado no sítio de fosforilação da serina-16 corrigido pelo fosfolambam total (PPLBser16/PLB) dos ratos controles (C), desnervados (DSA), 30 dias de clipe (CLIPE-30) e desnervados com hipertensão (ASSOCIAÇÃO).

\begin{tabular}{c|cccc}
\hline & C & DSA & CLIPE-30 & ASSOCIAÇÃO \\
\hline SERCA-2 (\%) & $100 \pm 15,3$ & $66,7 \pm 13,9$ & $67,7 \pm 10,2$ & $47,9 \pm 5,9 \dagger$ \\
NCX (\%) & $100 \pm 15,4$ & $18,5 \pm 5,9 \dagger$ & $28,5 \pm 6,8 \dagger$ & $61,4 \pm 9,5 \dagger \S$ \\
SERCA-2/NCX & $1,04 \pm 0,14$ & $4,23 \pm 0,87 \dagger$ & $3,54 \pm 0,86 \dagger$ & $0,77 \pm 0,1 \S £$ \\
PLB (\%) & $100 \pm 11,0$ & $82,1 \pm 4,7$ & $107,5 \pm 6,9$ & $83,7 \pm 11,9$ \\
SERCA-2/PLB & $1,05 \pm 0,14$ & $0,93 \pm 0,14$ & $0,72 \pm 0,08$ & $0,54 \pm 0,05 \dagger$ \\
PPLBthr17/PLB(\%) & $100 \pm 17,2$ & $71,0 \pm 10,0$ & $86,9 \pm 8,9$ & $49,9 \pm 4,9 \dagger$ \\
PPLBser16/PLB(\%) & $100 \pm 19,1$ & $113,5 \pm 28,1$ & $87,6 \pm 15,6$ & $50,9 \pm 16,3$ \\
\hline
\end{tabular}




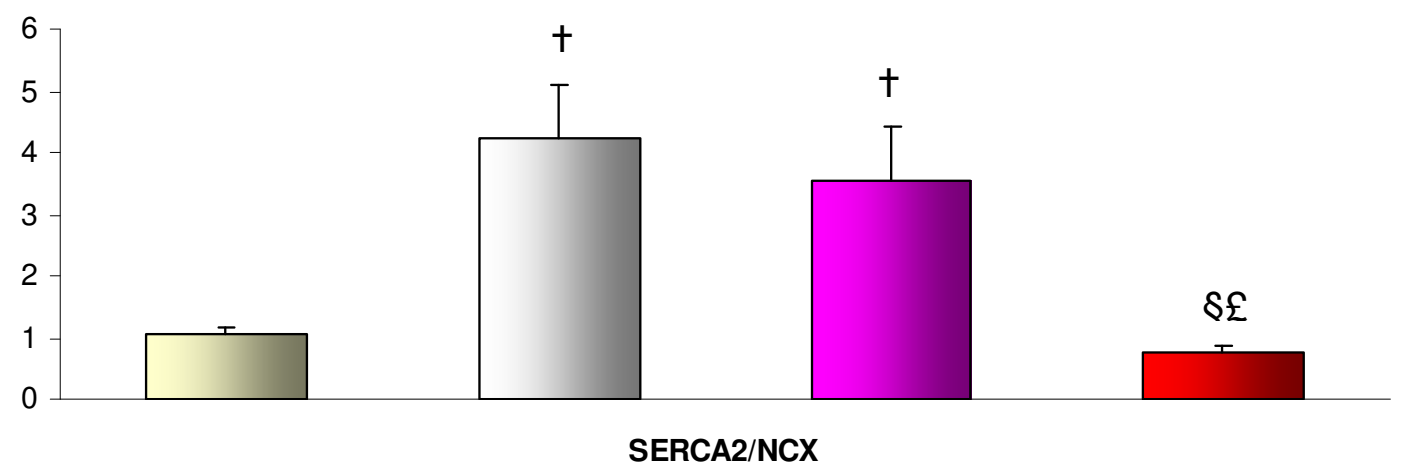

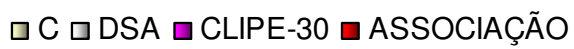

Figura 29. Relação SERCA-2/trocador $\mathrm{Na}^{+} / \mathrm{Ca}^{2+}$ (SERCA-2/NCX) nos grupos controle (C), desnervado (DSA), 30 dias de clipe (clipe-30) e associação. Notese o aumento desta proteína nos grupos DSA e clipe-30 com relação ao controle e diminuição da mesma no grupo associação com relação ao DSA e clipe-30. $\uparrow p<0,05$ vs. grupo controle; $\S p<0,05$ vs. grupo DSA; $£ p<0,05$ vs. grupo CLIPE-30. 
O trocador $\mathrm{Na}^{+} / \mathrm{Ca}^{2+}\left(\mathrm{NCX}\right.$ em \%), a principal proteína de extrusão do $\mathrm{Ca}^{2+}$ do citosol para o líquido extra-celular, apresentou correlação negativa $(r=0,78$ e $p<0,001$ ), incluindo-se todos os grupos deste estudo nesta análise, com um índice de função diastólica do VE, o tempo de relaxamento isovolumétrico corrigido pela freqüência cardíaca (TRIVcorr). Quanto menor a expressão no NCX, maior o TRIVcorr (em ms), evidenciando o efeito deletério do cálcio no citoplasma durante a diástole (Figura 30).

\section{C, DSA, CLIPE-10, CLIPE-30 e ASSOCIAÇÃO}

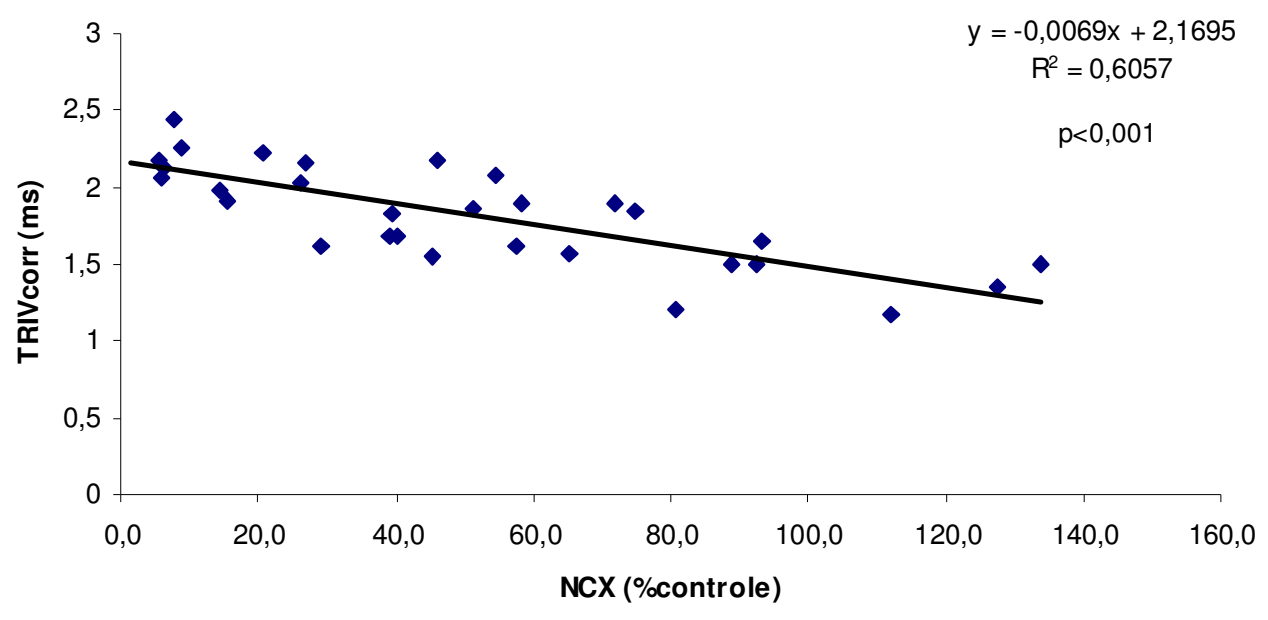

Figura 30 - Correlação entre a expressão do trocador sódio/cálcio (NCX) e tempo de relaxamento isovolumétrico corrigido pela freqüência cardíaca dos grupos controle (C), desnervado (DSA), clipe-10, clipe-30 e associação. ( $r=0,78$ e $p<0,001)$. 
O índice de bradicardia reflexa, que é um índice de sensibilidade do barorreflexo apresentou uma correlação positiva com a SERCA-2, principal proteína que recapta $\circ \mathrm{Ca}^{2+}$ para o retículo sarcoplasmático, com $r=0,73 \mathrm{e}$ $p<0,001$. Nesta correlação, quanto menor o IBR, menor a expressão da SERCA-2, mostrando que quanto maior a diminuição da sensibilidade do barorreflexo, pior a homeostasia do $\mathrm{Ca}^{2+}$ no cardiomiócito (Figura 31).

\section{C, DSA, CLIPE-10, CLIPE-30 e ASSOCIAÇÃO}

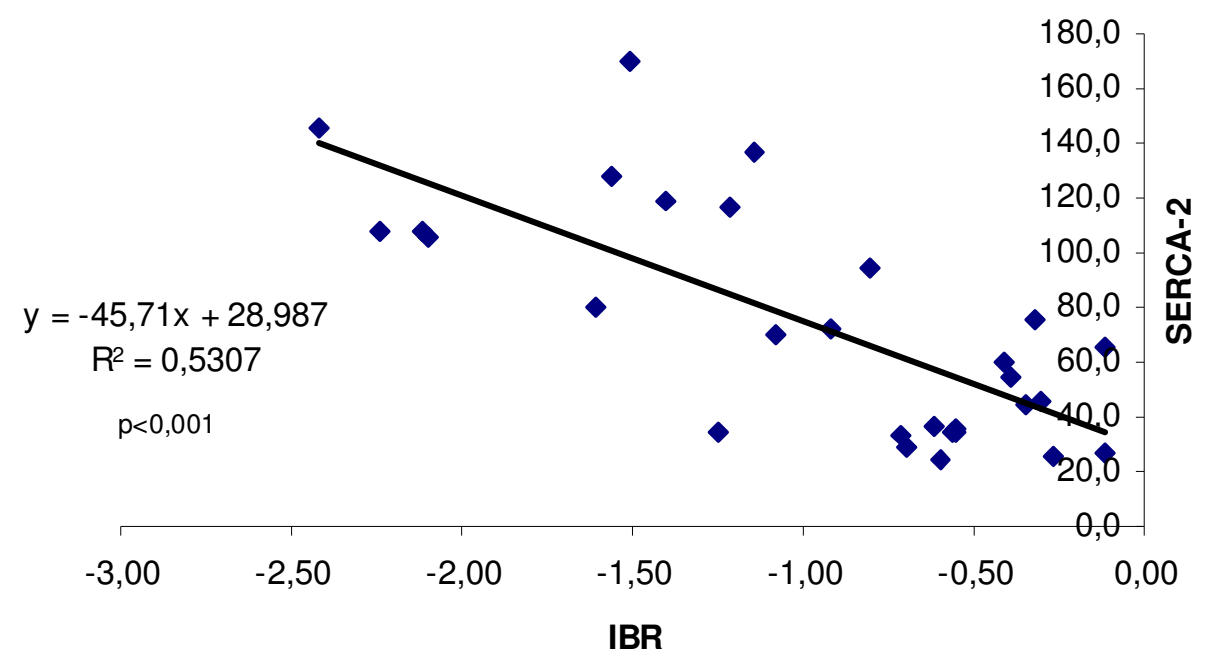

Figura 31 - Correlação entre índice de bradicardia reflexa (IBR em bpm/mmHg) e SERCA-2 (em \% do controle) dos grupos controle (C), clipe-10, clipe-30 e desnervado com hipertensão (ASSOCIAÇÃO) $(r=0,73$ e $p<0,001)$. 
Avaliando o coeficiente de variabilidade da pressão arterial média (CxSD) e a expressão da SERCA-2, encontramos uma correlação negativa, com $r=0,75$ e $p<0,001$ entre essas duas variáveis. Quanto maior o CxSD, menor a expressão da SERCA-2, evidenciando o prejuízo estabelecido pelo aumento da variabilidade da pressão na homeostasia do $\mathrm{Ca}^{2+}$ (Figura 32).

\section{C, DSA, CLIPE-10, CLIPE-30 e ASSOCIACÃO}

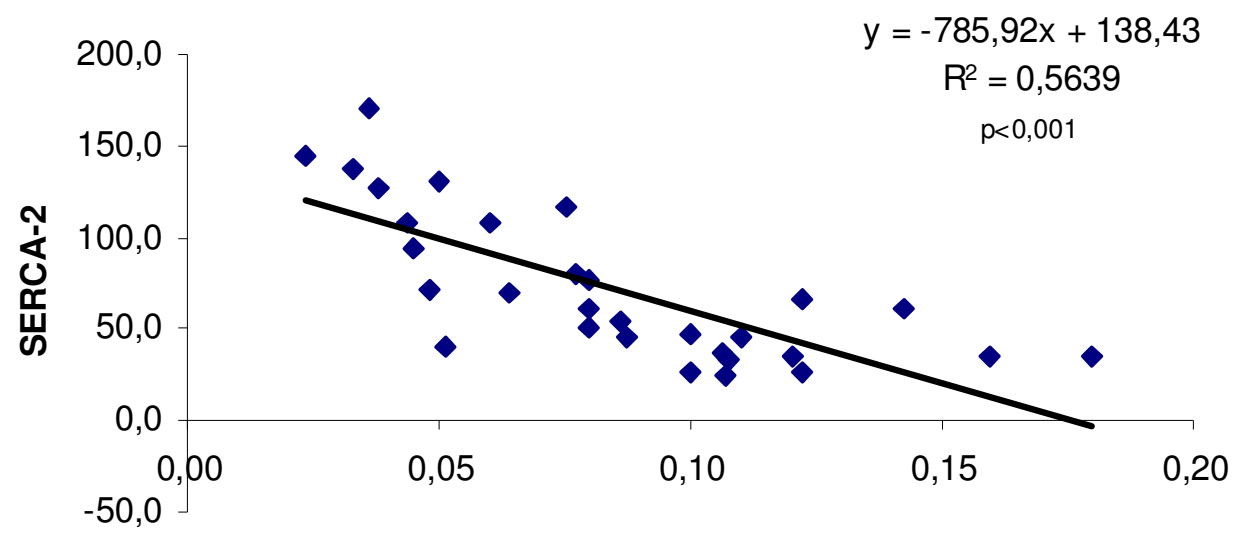

CxSD

Figura 32 - Correlação entre o coeficiente da variabilidade da pressão arterial média (CxSD) e a expressão da SERCA-2 nos grupos controle (C), desnervado (DSA), clipe-10, clipe-30 e associação ( $r=0,75$ e $p<0,001)$. 
DISCUSSÃO 


\section{DISCUSSÃO}

Neste trabalho, avaliando os dados hemodinâmicos e morfo-funcionais cardíacos, encontramos os seguintes resultados mais importantes:

1) A DSA crônica (30 dias), não modifica a PA nem a FC; reduz a sensibilidade do barorreflexo e não altera a morfologia cardíaca; tampouco modifica as funções sistólica e diastólica. No entanto, há redução na expressão do trocador sódio-cálcio, com evidente aumento na razão SERCA-2/NCX. Também não há evidências de alteração na modulação simpato-vagal.

2) Quanto à estenose parcial da artéria renal, 10 dias não são suficientes para o desenvolvimento da hipertensão arterial, mas neste período os mecanismos compensatórios já são ativados, como o aumento na fosforilação do fosfolambam nos sítios da serina-16 e da treonina-17. Há modificação na morfologia cardíaca e na sensibilidade do barorreflexo. Também se evidencia um aumento no peso do rim direito, como ajuste compensatório da estenose da artéria renal contralateral. Em 30 dias, porém, com a instalação da hipertensão, houve mudança do tipo de hipertrofia ventricular e diminuição da sensibilidade 
dos pressorreceptores. Neste período também foi notado um aumento da modulação simpática para o coração, e um evidente déficit diastólico.

3) A associação da DSA (30dias) e da hipertensão (10 dias) provoca aumento da PA sem modificação da FC, com redução da sensibilidade do barorreflexo e aumento da variabilidade da PA. Essas alterações foram acompanhadas de aumento da espessura do septo e da parede posterior do ventrículo na diástole e da espessura relativa da parede, redução do diâmetro da cavidade (VEDIA) e aumento da massa do VE. O desbalanço autonômico é notório, com predomínio da modulação simpática sobre a parassimpática, tanto no coração, como nos vasos. Há diminuição na expressão das proteínas regulatórias do cálcio e um comprometimento da função diastólica.

\subsection{A DESNERVAÇÃO SINO-AÓRTICA (DSA)}

Como já bem estudado por nosso grupo e outros pesquisadores, a DSA no rato tem sido utilizada desde sua descrição (Krieger, 1964) como um modelo biológico para avaliar o papel do barorreflexo em diferentes situações fisiológicas e patológicas (Osborn e England, 1990; Alexander e cols., 1990; Shade e cols., 1990) 
Descrita originalmente como um modelo de hipertensão neurogênica (Krieger, 1964), é atualmente utilizada como um modelo de variabilidade da PA. Isto se deu graças ao aperfeiçoamento tecnológico dos sistemas de registro, sendo possível após longos períodos de observação, detectar que a hipertensão observada agudamente (24h) retorna a níveis de normalidade na fase crônica (Norman e cols., 1980; Norman e cols., 1981; Franchini e Krieger, 1992; Irigoyen, 1995), mas acompanhada de aumento da variabilidade da PA, que se mantém (Irigoyen, 1995). A hipertensão é seguida de taquicardia (Vasquez e Krieger, 1982) e aumento da atividade simpática, que retornam a valores observados em animais intactos, na fase crônica da DSA.

Acompanhando este aumento da PA na fase aguda, foi descrita uma redução do débito cardíaco (Krieger, 1967) que também retorna ao normal depois de alguns dias. De fato, os valores do débito cardíaco corrigidos pelo peso corporal do animal, descritos como índice cardíaco, apresentaram-se semelhantes aos do grupo controle, confirmando a observação anteriormente citada. No presente trabalho, aos 30 dias de DSA, os animais não mostraram alteração nas funções sistólica e diastólica do VE, quando comparados aos animais controle. Estas medidas, inclusive (do grupo C), encontram-se semelhantes às medidas descritas por Watson e cols. (2004), num estudo onde são propostos valores ecocardiográficos basais para ratos. Entretanto, embora 
a avaliação funcional cardíaca tenha se mostrado normal, pudemos observar alteração na expressão das proteínas regulatórias do $\mathrm{Ca}^{2+}$, como a redução do trocador $\mathrm{Na}^{+} / \mathrm{Ca}^{2+}$ (NCX).

Como se sabe, o $\mathrm{Ca}^{2+}$ é o principal íon envolvido no processo da contração celular e várias proteínas estão relacionadas neste fenômeno. Após a despolarização da membrana celular, há abertura dos canais de $\mathrm{Ca}^{2+}$ dihidropiridina, com conseqüente entrada do íon para a célula, que dispara o gatilho para liberação de $\mathrm{Ca}^{2+}$ do retículo sarcoplasmático (RS) pela sensibilização dos receptores rianodina, presentes na membrana do RS. Desta feita, o $\mathrm{Ca}^{2+}$ se liga `a troponina $\mathrm{C}$ nos filamentos de actina, promovendo $\mathrm{o}$ deslizamento dos mesmos sobre os filamentos de miosina, provocando a contração propriamente dita. Em seguida, o $\mathrm{Ca}^{2+}$ se desliga da troponina e deve ser retirado rapidamente do citosol para que ocorra o relaxamento. Este processo é mediado pela proteina $\mathrm{Ca}^{2+}$ ATPase localizada na membrana do RS, a SERCA-2, que recapta $0 \mathrm{Ca}^{2+}$ para o $\mathrm{RS}$ e pelo $\mathrm{NCX}$, responsável pela extrusão do íon para o líquido extracelular (Mattiazzi e cols., 2005).

Sendo o NCX um componente importante da extrusão do $\mathrm{Ca}^{2+}$ citosólico após a sístole para o líquido extra-celular, poderíamos esperar neste grupo um déficit na função diastólica, fato que não ocorreu. Isto pode ser explicada pelo aumento relativo da SERCA-2, quando avaliamos a relação SERCA-2/NCX 
$(4,23 \pm 0,87$ no grupo DSA x 1,04 $\pm 0,14$ no grupo C). O aumento desta relação pode significar um mecanismo de proteção celular, através da maior recaptação do $\mathrm{Ca}^{2+}$ para o RS, na tentativa da preservação deste íon para o próximo batimento cardíaco, ao invés da sua extrusão para o líquido extra-celular.

Ademais, outras proteínas estão envolvidas no processo da recaptação do $\mathrm{Ca}^{2+}$, como o fosfolambam (PLB). Esta proteína coexiste na membrana do RS com a SERCA-2 e, em seu estado defosforilado, atua inibindo a ação da SERCA-2. No entanto, o PLB pode ser fosforilado em dois sítios: na serina-16 pela proteína quinase dependente do AMPc (PKA) e na treonina-17 pela proteína quinase dependente de cálcio-calmodulina (CAMKII). Quando fosforilado, ele aumenta a atividade de recaptação do $\mathrm{Ca}^{2+}$ para o RS pela SERCA-2. Uma vez recaptado para o $\mathrm{RS}$, o $\mathrm{Ca}^{2+}$, acontece o processo de relaxamento cardíaco, e o íon é armazenado para a próxima contração. Embora não tenhamos observado diferença estatística, o PLB fosforilado pela serina-16 apresentou valores absolutos maiores no grupo DSA, mesmo com relação ao controle. De fato, a função sistólica dos ratos DSA se mostrou semelhante à do grupo C. Considerando a presença destas alterações iniciais, acreditamos que numa análise posterior, com um tempo maior de desnervação, estes animais devam apresentar diminuição da função cardíaca. 
Mesmo não observando alterações significativas aos 30 dias de DSA, o aumento agudo da PA pela interrupção das aferências carotídeas e aórticas, liberando o simpático de sua inibição tônica, poderia levar a alterações de estrutura cardíaca. Embora pudéssemos esperar este tipo de alterações, mesmo que transitórias (acompanhando o aumento da PA, por exemplo) pelo ecocardiograma não observamos alterações significativas do diâmetro de cavidade, da espessura do septo ou da parede posterior do VE, avaliados durante a diástole. Os pesos do VE corrigidos pelo peso corpóreo, coerentemente às observações ecocardiográficas, confirmaram a ausência de hipertrofia ventricular esquerda nestes animais. De fato, na DSA crônica, a medida direta da atividade simpática renal não mostrou mais diferenças quando comparada a atividade de animais intactos, embora não se conheça a variação dessa atividade em outros territórios (Irigoyen e cols., 1995). Vale lembrar que, embora a modulação simpática nestes animas, avaliada pelo componente LF do tacograma tenha apresentado uma tendência ao aumento, os valores não foram estatisticamente diferente dos animais controle.

Considerando ainda a variabilidade da PA, alta na DSA, sabe-se que está ligada a lesões de diferentes órgãos quando presente na hipertensão e à predição de mortalidade após evento cardiovascular (La Rovere, 1998). Mesmo assim, não se observa in vivo, aos 30 dias de DSA alterações significativas das 
câmaras cardíacas. Esses resultados diferem dos obtidos por Miao e cols. (2003) que demonstraram hipertrofia moderada de VE e hipertrofia aórtica em ratos com DSA em tempos mais longos de observação. Nesse sentido, avaliações ainda não publicadas de nosso laboratório mostraram que ao se preservar a aferência simpática no procedimento da DSA, encontra-se hipertrofia de VE (apud). Esta informação talvez possa ajudar a explicar a controvérsia da literatura sobre alterações cardíacas pós desnervação sinoaórtica.

A hipertrofia de VD também tem sido relatada (Van Vliet, 1999) embora nem sempre encontrada (Miao e cols., 2003). Esses autores inclusive relatam que o aumento do VD encontrado por Van Vliet pode ser devido ao tipo de medida, pois o aumento do peso do VD está correlacionado à redução do peso corporal. Miao e cols., em 2003 fazem referência a dados não publicados de seu laboratório no qual encontraram aumento de $22 \%$ no VD e redução de $6 \%$ no peso corporal dos ratos WKY após a DSA. Leve-se em conta, entretanto, que foi descrita hipertrofia cardíaca em ratos WKY normotensos (Aiello e cols., 2003) o quê realmente dificulta a conclusão. Dessa forma, a hipertrofia de VD permanece por ser melhor estudada na DSA, inclusive porque há indicações de que dependa mais da desnervação dos quimiorreceptores com repercussões sobre a circulação pulmonar (Van Vliet, 1999). 
É possível que não tenha havido alterações estruturais na DSA em função do tempo de avaliação deste estudo. Miao e cols. (2003), avaliando o papel da angiotensina II e do receptor AT1 nas hipertrofias cardíaca e aórtica pós - DSA, observaram aumento do peso do coração com relação ao peso corpóreo, apenas a partir da 10 a semana, enquanto Van Vliet, em 1996, observou hipertrofia de VE após a 6ª semana. Nossas observações, no entanto, foram realizadas 30 dias após a desaferentação.

\subsection{A HIPERTENSÃO RENOVASCULAR - Efeito do tempo do clipe no desenvolvimento da hipertensão e hipertrofia cardíaca}

Após a constatação de que a implantação de um clipe de prata numa das artérias renais levava ao aumento da pressão arterial, com conseqüente hipertrofia ventricular esquerda por Goldblatt em 1934, estes modelos vêm sendo amplamente utilizados para o estudo da gênese da hipertensão e suas conseqüências. Diferentes estudos têm relatado que entre 6 e 8 semanas após a indução de hipertensão $2 \mathrm{~K} 1 \mathrm{C}$, ocorre aumento do volume dos cardiomiócitos, de fibrose intersticial e do espessamento da parede dos vasos miocárdicos (Hocher e cols., 1999; Smith e cols., 1988; Mall e cols., 1989; Fischer e cols., 
1992), condizente com um remodelamento cardíaco progressivo. A clipagem da artéria renal como modelo de hipertensão tem sido usada com a mutenção (2K1C) ou não (1K1C) do rim contralateral. Entretanto, como citado anteriormente, os dois modelos diferem quanto aos mecanismos fisiopatológicos envolvidos no processo de hipertensão. No modelo 1rim-1clipe, a ausência do rim contralateral à implantação do clipe, impede o aumento da diurese para contrabalançar o aumento da volemia ocasionado pela ativação do sistema renina-angiotensina-aldosterona (SRAA). Neste modelo, portanto, o desenvolvimento da hipertensão está associado ao aumento do volume plasmático. Holman e Page, em 1938, mostraram que neste modelo, 4 a 15 dias após a cirurgia, não havia aumento do débio cardíaco em cães, no início da instalação da hipertensão. Vários estudos posteriores, no entanto, detectaram que o débito cardíaco estava, sim, aumentado nos estágios iniciais do processo hipertensivo (Ledingham e Cohen, 1963; Bianchi e cols., 1970; Ferrario, 1974; Coleman e Guyton, 1969). Estas observações levaram a acreditar que os mecanismos de auto-regulação pudessem contribuir para o aumento da resitência periférica (Ferrario, 1974; Coleman e Guyton, 1969; Guyton e cols., 1974).

No modelo 2rins-1clipe, parece haver uma concordância entre os estudos de que a hipertensão é mantida pelo aumento da resistência vascular periférica 
(Bianchi e cols., 1972; Averill e cols., 1976; Hallback-Nordlander, 1979; Russel e cols., 1983). Dentre estes estudos, o de Bianchi e cols. em 1972, mostrou um pequeno aumento no débito cardíaco nas primeiras 24 horas após a implantação do clipe, que retornou ao normal pouco depois de uma semana. A pressão arterial e a resistência vascular periférica, entretanto, mantiveram-se aumentadas.

No presente trabalho, observamos que a pressão arterial (sistólica, diastólica e média) aumentou apenas no grupo com 30 dias de clipe, mostrando que o tempo de clipe é fundamental no desenvolvimento da hipertensão, especialmente em seus estágios iniciais. No entanto, apesar do grupo clipe-10 não ter apresentado aumento de pressão, algumas observações indicam um processo hipertensivo inicial, como a diminuição da sensibilidade do barorreflexo mostrado pela diminuição do índice de bradicardia reflexa. De fato, alterações de sensibilidade do barorreflexo têm sido descritas após isquemia renal induzida por clipe e, portanto, ligadas à ativação do sistema reninaangiotensina (Ribeiro e cols., 2005; Ylitalo e cols., 2000). Irigoyen e Krieger, em 1998 demonstraram que a hipertensão per se, está consistentemente associada à diminuição da sensibilidade do barorreflexo.

Por outro lado, a redução da sensibilidade do barorreflexo está correlacionada à redução de variabilidade da FC e conseqüentemente à lesão 
de órgãos-alvo tanto na hipertensão (Grassi, 2002) como após evento isquêmico (La Rovere, 1998). No presente estudo, observamos queda da sensibilidade do barorreflexo nos animais clipe-30. Entretanto, diferentemente do observado em animais desnervados, o aumento de variabilidade não necessariamente se correlaciona de forma direta com a diminuição da sensibilidade do barorreflexo, ou depende do grau de comprometimento da sensibilidade do barorreflexo.

As alterações na morfologia cardíaca que observamos com 10 dias de clipe demonstram a ativação de processos adaptativos, antes mesmo do aumento dos níveis pressóricos.

É o quê ocorre também, quando analisamos a diferença de peso dos rins direito e esquerdo corrigidos pelo peso corporal, encontrando valores aumentados nos grupos clipe-10 e clipe-30 com relação ao controle, comprovando a ativação de mecanismos adaptativos nos animais que tiveram a artéria renal clipada, mesmo antes que a hipertensão se desenvolvesse. Corroborando esta informação, um estudo recente in vivo de Stormark e cols. (2007), utilizando o método de ultra-sonografia tridimensional para comparar a modulação do volume renal ao longo do tempo em animais 2rins-1clipe, mostrou que, com 2 semanas, o volume do rim não clipado se mostrou maior do 
que o volume do rim clipado, embora a hipertensão só tenha se estabelecido a partir da quarta semana.

Sobre isso, vale enfatizar que encontramos uma correlação positiva significativa entre a diferença de peso dos rins direito e esquerdo corrigida pelo peso corporal e pressão arterial média, mostrando que quanto maior a diferença de peso entre o rim clipado e o não clipado, maior o nível de pressão arterial (dados obtidos dos grupos controle, clipe-10, clipe-30 e ASSOCIAÇÃO) com r= 0,74 e $p<0,001$ (Figura 28).

Os dados obtidos pela técnica de Western blot para a quantificação das proteínas da regulação do $\mathrm{Ca}^{2+}$ no grupo clipe-10 também ajudam a evidenciar os mecanismos compensatórios já ativados nestes animais. Como citado anteriormente, o NCX responde por aproximadamente $8 \%$ da retirada do $\mathrm{Ca}^{2+}$ do citosol em ratos, enquanto que a SERCA-2 é responsável por 92\% (Bers, 2002).

Deste modo, a SERCA-2 está envolvida não apenas no processo do relaxamento cardíaco mas também da contração, uma vez que o aumento na recaptação do $\mathrm{Ca}^{2+}$ para o $\mathrm{RS}$, além de facilitar a diástole, também disponibiliza maiores concentrações do íon para o próximo ciclo.

Outra proteína envolvida na homeostase do $\mathrm{Ca}^{2+}$ é o fosfolambam (PLB), que fica localizado bem próximo à SERCA-2 na membrana do RS e sua função 
é a de inibir a afinidade desta ao $\mathrm{Ca}^{2+}$. Uma vez inibida, esta proteína diminui a recaptação do $\mathrm{Ca}^{2+}$ para o RS, o quê altera tanto a diástole quanto a sístole cardíacas. De fato, estudos mostram que a redução dos níveis do PLB está associada a um aumento linear na afinidade SERCA-2/Ca ${ }^{2+}$ e, conseqüentemente a um aumento na contratilidade miocárdica (MacLennan e Kranias, 2003).

Embora sem diferença estatística, observamos uma tendência à diminuição na expressão da SERCA-2 no grupo clipe-10 e uma redução efetiva do NCX. Somadas, estas diminuições poderiam levar a um acúmulo de $\mathrm{Ca}^{2+}$ citosólico que induziria a uma disfunção cardíaca. No entanto, observamos neste grupo, um aumento da fosforilação do PLB, tanto no sítio da serina-16 quanto no da treonina-17, mostrando um processo compensatório para a manutenção da função cardíaca. Convém lembrar que a fosforilação do PLB em qualquer um dos dois sítios, ativa a ação da SERCA-2, aumentando portanto, a recaptação do $\mathrm{Ca}^{2+}$ para o $\mathrm{RS}$ e, ao mesmo tempo, mantendo-o em estoques adequados para a próxima sístole. De fato, ao ecocardiograma, tanto a função sistólica quanto a distólica nestes animais, se mostraram preservadas quando comparadas aos animais controle. 
Apesar de outros trabalhos mostrarem que 10 dias de clipe numa das artérias renais já sejam suficientes para provocar aumentos pressóricos, sabemos que vários fatores interferem neste processo. Nesse sentido, há que se ressaltar o calibre da artéria renal, a abertura do clipe a ser instalado e também a flexibilidade da prata. Materiais mais ou menos flexíveis podem promover maior ou menor estenose da artéria renal com alterações proporcionais na liberação das substâncias vasoativas. Estudos não publicados de nosso laboratório mostram, inclusive, que os resultados da cirurgia deste modelo feita em ratos pareados pelo peso e com o mesmo material para a confecção do clipe, apresentam grandes variações inter-observadores. Corroborando essas observações, está o fato de que, com 30 dias de clipe, o nível pressórico que encontramos, foi diferente do que outros autores já publicaram. Zanchi e cols. em 1997, encontraram valores de pressão arterial média de $143 \mathrm{mmHg}$ em ratos 2rins-1clipe (5 semanas de clipe), enquanto Kost e cols. (1994) observaram valores médios de $122 \mathrm{mmHg}$ com 4 semanas e meia, demonstrando a variabilidade inerente ao próprio modelo experimental. Entretanto, embora sendo um modelo predisposto a este tipo de variabilidade, vários autores descrevem uma razão do peso do rim esquerdo (cuja artéria renal foi clipada) pelo peso do rim direito (artéria renal sem clipe), na qual a hipertensão se estabelece (Smith e Bishop, 1986; Tsung-Ming e cols., 2006; 
Junhong e cols., 2008). Estes trabalhos demonstram que os valores entre $0,4 \mathrm{a}$ 0,9 desta relação ( $\operatorname{Rim} E$ / Rim D), permite estabelecer um nível de corte para os animais predispostos à instalação da hipertensão pela clipagem da artéria renal esquerda. Valores entre 0,0 a 0,3 indicam atrofia do rim esquerdo por estenose arterial muito grande e valores entre 0,9 a 1,0 indicam que a constrição arterial não foi suficiente para estabelecer a ativação do SRA. Vale aqui ressaltar que, no presente trabalho, os três grupos que tiveram a artéria renal esquerda estenosada pelo clipe de prata, obtiveram valores dentro da faixa na qual há ativação do SRA sem provocar atrofia completa do rim esquerdo, o quê levaria a ajustes compensatórios pelo rim contralateral (CLIPE10:0,81; CLIPE-30:0,75 e ASSOCIAÇÃO: 0,77. $p=0,81$ ).

Quanto às lesões de órgão-alvo, certamente que a variabilidade do modelo influencia os diferentes resultados morfológicos descritos na literatura. Enquanto alguns autores descrevem um remodelamento cardíaco lento e progressivo induzido pela hipertensão 2K1C (Hocher e cols., 1999; Smith e cols., 1988; Mall e cols., 1989; Fischer e cols., 1992), outros percebem evidências de que uma ou duas semanas de clipagem já é um tempo suficiente para aumentos importantes do VE (Ehmke e cols., 1999).

Este estudo mostrou aumento da massa ventricular esquerda nos animais com 10 e 30 dias de implantação de clipe, evidenciado tanto pelo 
ecocardiograma, quanto pela pesagem do VE. Neste sentido, é importante ressaltar que o estudo de correlação entre a massa ventricular medida pelo ecocardiograma e pela pesagem do VE mostrou um $r=0,85(p<0,0001)$. Outros índices de hipertrofia cardíaca analisados em conjunto, podem, no entanto, auxiliar na compreensão de massas ventriculares semelhantes em animais com e sem hipertensão. O aumento da cavidade do VE corrigida pelo peso no grupo clipe-10 e a diminuição da espessura relativa da parede nos permite dizer que o grupo sem hipertensão (clipe-10), apresentou hipertrofia do tipo excêntrica. Já o grupo clipe-30, que mostrou aumento da PA, apresentou uma hipertrofia de VE do tipo concêntrica (aumento da massa do VE com aumento da ERP). Este dado corrobora a afirmação de Qu e cols. que demonstraram em 2000, que a espessura relativa da parede é um índice mais sensível para se classificar as adaptações cardíacas à hipertensão arterial.

Como Bianchi e cols. em 1972, também pudemos observar um pequeno aumento do índice cardíaco no grupo clipe-10, embora os valores tenham apresentado diferença estatística apenas com relação ao grupo clipe-30. Com a função sistólica preservada, acreditamos que o fator causal deste aumento, tenha sido a retenção de volume ativada pelo SRAA. Neste caso, embora os sistemas controladores da PA a longo prazo estejam operantes, haja vista a normotensão observada nestes animais, acredita-se que a homeostase de 
volume possa estar alterada. O aumento da volemia, como se sabe, induz a um aumento do retorno venoso que, sendo o controlador primário do débito cardíaco, (Guyton, 1981) induz ao aumento do índice cardíaco, pela ativação do mecanismo de Frank-Starling, desde que haja a preservação da contratilidade.

Embora não tenhamos quantificado a expressão da ECA tecidual cardíaca nestes animais, tampouco da angiotensina II no miocárdico, acreditamos ser a ativação precoce do sistema renina-angiotensina a responsável por estas observações, baseado em evidências anteriores (Kost e cols., 1994). Como se sabe, a ativação deste sistema, converge para a retenção de volume em função do aumento da reabsorção de $\mathrm{Na}^{+}$e água pelos túbulos renais. Estando a contratilidade miocárdica inalterada, fato que pudemos constatar ao exame ecocardiográfico, o aumento de volume elevaria a pressão média de enchimento circulatório e, em conseqüência, o retorno venoso, culminando no aumento do débito cardíaco.

Sobre isso, vale ressaltar que já está bem estabelecido que a atividade da renina e a secreção da aldosterona estão aumentadas no modelo 2rins-1clipe (Koletsky e cols., 1967; Mikshe e cols., 1970) e que a saralasina, um antagonista da angiotensina II diminui a pressão arterial nestes animais (Pals e cols., 1971). Kost e cols., em 1994 demonstraram que o SRAA está ativado 
mesmo precocemente neste modelo, com menos de 4 semanas da implantação do clipe.

Embora ocorra uma ativação do SRAA nos 2 tempos de clipe, o aumento da modulação simpática para o coração foi observado apenas com 30 dias. É possível que isso tenha contribuído para as diferentes alterações morfométricas cardíacas encontradas em cada grupo. Além disso, embora sem diferença estatística, o componente de baixa freqüência (LF) da variabilidade da pressão arterial sistólica (VPAS), representativo da modulação simpática sobre os vasos, apresentou-se maior no animais com 30 dias de clipe. De fato, a hipertensão só foi detectada após 30 dias de estenose da artéria renal.

No grupo com 30 dias de clipe observamos uma hipertrofia do tipo concêntrica, com aumento da espessura diastólica da parede do VE sem alteração das dimensões diastólicas da cavidade. O aumento pressórico, como se sabe, leva a um aumento da tensão sistólica da parede ventricular esquerda, o quê induz a adição de sarcômeros em paralelo. Pela expressão da lei de La Place, a tensão na parede é diretamente proporcional ao raio da cavidade e inversamente proporcional à espessura da parede, de modo tal, que o aumento desta, leva à diminuição daquela (Mill e Vassallo, 2001).

Com o aumento da pressão arterial neste grupo, também observamos uma diminuição significativa da sensibilidade do barorreflexo, demonstrado pela 
diminuição dos índices de bradicardia e taquicardia reflexas. Este grupo demonstrou também que, apesar de ter sua função sistólica preservada, já apresenta algum grau de disfunção diastólica, consideração importante na instalação da insuficiência cardíaca causada pela hipertensão arterial (Signolet e cols., 2007, Wright e cols., 2007; Rossi e cols., 2006; Desay 2007). Esta disfunção foi observada pela consistência dos dados analisados: diminuição do picos $E$ e $A$ no estudo do fluxo sangüíneo na via de entrada do VE, aumento do tempo de relaxamento isovolumétrico corrigido pela freqüência cardíaca e diminuição dos índices de velocidade diastólica máxima (E’/A') avaliadas no nível do anel mitral das parede septal e lateral do VE no estudo Dopller tecidual.

A avaliação global do VE através do índice de desempenho miocárdico, que analisa períodos sistólico e diastólico no estudo Doppler, também mostrou elevação deste índice no grupo com 30 dias de clipe, concordando com achados de Salemi e cols. que, em 2004 demonstraram aumento progressivo do IDM no curso temporal da hipertrofia cardíaca em ratos submetidos à cirurgia de coarctação da aorta ascendente. Além disso, este índice tem boa correlação com medidas invasivas das funções sistólica e diastólica em humanos (Tei e cols., 1997) e animais (Broberg e cols., 2003). Em conjunto, estes dados nos mostram que, com 30 dias de clipe na artéria renal, os animais 
desenvolveram um nível de hipertensão moderada, mas suficiente para induzir alterações na morfologia e função cardíacas.

Corroborando os achados de função no grupo clipe-30, foi observada uma diminuição na expressão do NCX, que certamente manteve a concentração de $\mathrm{Ca}^{2+}$ citosólica elevada, justificando o prejuízo diastólico encontrado nestes animais. No entanto, a relação SERCA-2/NCX se mostrou elevada o suficiente para manter a contratilidade dentro de parâmetros normais. Ou seja, apesar da dificuldade do $\mathrm{Ca}^{2+}$ ser retirado do citosol pela diminuição do NCX, houve um aumento relativo da SERCA-2, na tentativa de recaptar o $\mathrm{Ca}^{2+}$ para o RS e mantê-lo num nível adequado para o próximo batimento.

Some-se a isso, o fato de termos encontrado uma importante correlação negativa entre a expressão do NCX com o tempo de relaxamento isovolumétrico corrigido pela freqüência cardíaca $(r=0,78$ e $p<0,001)$. Sendo o NCX um dos importantes mecanismos para a extrusão do $\mathrm{Ca}^{2+}$ citosólico e, portanto como afirmado anteriormente, uma proteína fundamental para o relaxamento do cardiomiócito, e o TRIVcorr um dos índices de função diastólica, observamos que quanto menor a expressão do NCX, maior o tempo de relaxamento isovolumétrico. Em outras palavras, quanto menos o $\mathrm{Ca}^{2+}$ é retirado da célula cardíaca após a contração, maior o tempo necessário para o 
relaxamento adequado do miócito, o quê, clinicamente conhecemos por disfunção diastólica.

Sumarizando a importância do tempo de clipe na artéria renal para o desenvolvimento da hipertensão e hipertrofia cardíaca, este estudo mostrou que, embora 10 dias não tenha sido um tempo suficiente para aumentar a PA, já o foi para diminuir a sensibilidade do barorreflexo e para alterar a morfologia cardíaca e expressão das proteinas de $\mathrm{Ca}^{2+}$. Com 30 dias de clipe, no entanto, já houve instalação da hipertensão, diminuição na sensibilidade do barorreflexo e alterações na função cardíaca.

\subsection{ASSOCIAÇÃO ENTRE DSA+2K1C}

A associação entre a DSA (30 dias) e clipe (10dias) modificou significativamente a pressão arterial (sistólica, diastólica e média) quando comparada aos animais com mesmo tempo de clipe, mas com os barorreceptores preservados (clipe-10). Da mesma forma, a diminuição da sensibilidade do barorreflexo nesse grupo foi semelhante ao observado nos animais DSA. Quanto à variabilidade da PA, ela foi semelhante na associação dos dois modelos quando comparada aos animais DSA, tanto em seu índice absoluto, quanto na expressão de seu coeficiente. Como se sabe, este 
coeficiente normaliza o desvio padrão pela PAM em cada indivíduo para depois se obter a média do grupo. Dessa forma poderíamos entender que um desvio maior sobre uma pressão maior poderia não ser diferente de um desvio menor sobre uma PA menor. Aceitando que a diminuição da sensibilidade do barorreflexo pudesse estar diretamente associada à labilidade da PA, de fato poderíamos entender que uma diminuição semelhante do reflexo comandado pelos barorreceptores pudesse levar a uma variabilidade semelhante da PAM como observado nos grupos DSA e associação.

Talvez a maior diferença entre esses grupos (DSA e associação) seja o aumento súbito da pressão sofrido pelo segundo, em razão da ausência do efeito homeostático do barorreflexo. Em 10 dias, os animais do grupo associação tiveram sua PAM elevada para mais de $130 \mathrm{mmHg}$, caracterizando uma potencialização da resposta hipertensora induzida pelo clipe, uma vez que unicamente o clipe, conforme observado no grupo clipe-10, não produziu resposta hipertensiva, provavelmente pela ativação de mecanismos compensatórios. De fato, se lembrarmos o grupo clipe-30, veremos uma PAM também aumentada (semelhantemente ao grupo associação), mas sabemos que este processo de instalação da hipertensão foi lento. Isto provavelmente permitiu que outros mecanismos de ajuste tivessem tido tempo de ser recrutados, fato que não ocorreu no grupo associação. 
A avaliação da análise espectral nos mostrou que no grupo associação, cuja artéria renal esquerda foi estenosada no vigésimo dia após a desnervação sino-aórtica, o componente LF, que mostra a modulação da atividade simpática na freqüência cardíaca, estava tão aumentado quanto no grupo clipe-30. Embora a redução do componente $\mathrm{HF}$, que informa sobre a modulação vagal, também tenha sido semelhante nos dois grupos, a relação LF/HF mostrou aumento maior no grupo associação, evidenciando um desbalanço autonômico mais consistente neste grupo. Vale ressaltar novamente, que este grupo recebeu estímulo hipertensivo por um terço do tempo do grupo clipe-30, comprovando os efeitos homeostáticos do barorreflexo, ainda que eles estejam atenuados.

Ao lembrarmos da análise do sistograma, estas informações se tornam mais evidentes, uma vez que o aumento da modulação simpática sobre os vasos se mostrou aumentada de modo impressionante apenas no grupo associação. A diminuição da perfusão renal, como ocorre na estenose da artéria renal, além de levar à ativação do SRAA, também é um estímulo para a hiperatividade simpática. Conforme observado por Reams e Bauer em 1987, a angiotensina II potencializa os efeitos vasoconstritores da norepinefrina em indivíduos hipertensos. Deste modo, como era de se esperar, os grupos que tiveram a artéria renal clipada, apresentariam uma maior atividade simpática. 
Com a retirada dos pressorreceptores, sabidamente moduladores do sistema nervoso simpático, a modulação dessa atividade se mostrou intensa no grupo associação. Estas observações vão ao encontro daquelas relatadas por Greenwood e cols. que, em 2001, associaram maior hipertrofia ventricular esquerda à maior descarga simpática em seres humanos com níveis semelhantes de hipertensão moderada à severa.

Além disso, o grupo associação apresentou aumento da variabilidade da pressão arterial que, somado ao aumento da modulação simpática foi determinante nas respostas cardíacas mais drásticas neste grupo. Sobre isso, vale salientar a correlação negativa e significativa que encontramos entre o coeficiente da variabilidade da pressão arterial média (CxSD) e a expressão da proteína SERCA-2 entre os 5 grupos do presente estudo $(r=0,75$ e $p<0,001)$ (Figura 32) . Esta correlação mostra que, quanto maior a variabilidade da pressão arterial, sabidamente um preditor de lesão de órgão-alvo, menor a expressão da SERCA-2 no miócito cardíaco. Levando-se em conta a fundamental importância desta proteína tanto para a sístole quanto para a diástole, acreditamos que este mecanismo possa contribuir para explicar a predição de eventos cardiovasculares decorrentes do aumento da variabilidade da PA (La Rovere, 1998). 
A diferença na instalação da hipertensão, dependente exclusivamente da ausência do barorreflexo é, talvez, o mecanismo mais importante para a indução das alterações morfométricas e funcionais observadas no grupo associação. Considere-se ainda que no grupo clipe-10, a diminuição da sensibilidade do controle reflexo da circulação momento a momento se mostrou presente apenas no índice de bradicardia reflexa e que no grupo clipe-30, o prejuízo encontrado, ainda não privou completamente esses animais da ação tamponadora do reflexo. Nesse sentido, a adaptação dos pressorreceptores que vai ocorrendo enquanto a hipertensão se instala, é provavelmente o mecanismo que permite o ajuste aos novos níveis pressóricos, mesmo que a sensibilidade esteja reduzida. De fato, Cowley e Guyton (1975), demonstraram efeito semelhante na imediata resposta hipotensora após a retirada de sobrecarga de sal em cães com desnervação sino-aórtica. Dessa forma, ajustes fisiológicos adequados a estímulos hiper ou hipotensores, dependem da ação dos barorreceptores através de seu processo de adaptação. (Krieger e cols., 1982). De fato, a diminuição da sensibilidade do barorreflexo avaliada pelo índice de bardicardia reflexa mostrou uma correlação positiva e significativa com a expressão da SERCA-2 no cardiomiócito ( $r=0,73$ e $p<0,001)$ (Figura 31). Nesta avaliação, a diminuição da sensibilidade barorreflexa (diminuição do IBR) parece estar associada à menor expressão desta proteína que é a maior 
responsável pela recaptação do $\mathrm{Ca}^{2+}$ do citosol após a sístole para o retículo sarcoplasmático. Este mecanismo pode ajudar a esclarecer os ajustes homeostáticos moleculares dos pressorreceptores na manutenção da pressão arterial e, conseqüentemente às lesões de órgãos-alvo que ocorrem em função da perda de sensibilidade por eles sofridas na hipertensão.

Além disto, no grupo associação, onde as fibras aferentes carotídeas e aórticas foram seccionadas, foram constatadas, ao ecocardiograma, alterações morfométricas consistentes reveladas tanto nas medidas absolutas (não mostradas), como nas corrigidas pelo peso corporal. Observou-se aumento significativo da espessura do septo interventricular, da parede posterior do VE e da massa do ventrículo avaliadas na diástole. Outro índice importante, a ERP foi maior no grupo associação do que, inclusive no grupo que teve o estímulo hipertensivo por 30 dias (clipe-30), indicando que a resposta de remodelamento da geometria ventricular neste grupo sofreu alterações mais drásticas, uma vez que há redução evidente da cavidade do VE.

Os dois grupos nos quais houve a instalação da hipertensão, apresentaram comprometimento diastólico, observado pela redução na razão dos picos $\mathrm{E}$ e $\mathrm{A}$ do fluxo transmitral e aumento do tempo de relaxamento isovolumétrico corrigido pela freqüência cardíaca $O$ pico $E$ do estudo do fluxo em via de entrada do VE, representa o enchimento ventricular rápido, enquanto 
o pico A, o enchimento lento fornecido pela contração atrial. A razão destes dois picos informa quanto aos diferentes tipos de disfunção diastólica. Diversos padrões de anormalidades diastólicas podem ser observadas pelo estudo do fluxo transmitral. A diminuição do enchimento rápido (pico E) com o aumento da velocidade do fluxo obtido pela contração atrial (pico A), são comumente atribuídos a uma deficiência de relaxamento ventricular. Neste cenário clínico, também é comum se observar um aumento do tempo de relaxamento isovolumétrico, com prolongamento do tempo de desaceleração do pico $\mathrm{E}$. Deficiência de complacência ventricular, como ocorre na cardiomiopatia restritiva, leva a um aumento significativo da relação $E / A$, que passa a ser maior que 2 (Signolet e cols., 2007), acompanhado por diminuição do tempo de relaxamento isovolumétrico e diminuição do tempo de desaceleração do pico E.

No entanto, estas avaliações, podem depender da pré-carga imposta ao coração, assim como da influência da freqüência cardíaca (Slama e cols., 2003). Outros fatores como a complacência atrial, patologias valvares e pressão atrial também podem ser determinantes do fluxo Doppler transmitral (Choong e cols., 1988). Em razão disto e pelo fato de um relaxamento ventricular anormal poder coexistir a um aumento de pressão de enchimento, os padrões avaliados pelo estudo Doppler podem evoluir para um padrão conhecido por "pseudonormalização", no qual as variáveis ficam parecidas com aquelas 
encontradas em indivíduos normais (Garcia e cols., 1998). Embora a avaliação do fluxo da veia pulmonar seja efetivo na diferenciação entre os padrões "pseudonormal" (onde há déficit diastólico) e "normal", (Masuyama e cols.,1992), a aquisição destes parâmetros em ratos ainda é desafiadora.

Deste modo, utilizamos o Doppler tecidual, que mostra as velocidades sistólica e diastólica no próprio miocárdio. Assim como no estudo do fluxo através da valva mitral, no Doppler tecidual avaliamos a presença dos picos: E', que à semelhança do pico $\mathrm{E}$ do fluxo sangüíneo, está relacionado à primeira fase da diástole; e o pico A', relacionado ao período final da diástole. A razão dos dois mostra alterações semelhantes ao estudo do fluxo sangüíneo, sem sofrer alteração em função do volume, entretanto (Nagueh e cols., 1997; Slama e cols., 2004). Nos 2 grupos hipertensos, encontramos redução da relação E'/A' do Doppler tecidual obtido no nível do anel mitral da parede septal do VE. No entanto, na comparação desta relação obtida na parede lateral do VE, o grupo associação apresentou uma redução mais signiticativa, mostrando um comprometimento diastólico maior.

Nagueh e cols., em 1997 sugeriram que a velocidade do pico E' pudesse ser um índice de relaxamento ventricular não influenciado pela pressão atrial esquerda. Ainda segundo estes autores, a correção do pico E pelo pico E' (razão E/E'), é uma forma acurada de se avaliar a pressão de enchimento 
ventricular, e apresenta uma boa correlação com medidas invasivas da pressão capilar pulmonar média em cunha (pressão de oclusão da artéria pulmonar).

Esta medida no grupo associação se mostrou significativamente aumentada com relação aos demais, incluindo o outro grupo hipertenso (clipe30). Segundo Garcia e cols., 1998, E/E' maior do que 10, indica pd2 elevada $\left(E / E^{\prime}>15=p d 2>15 \mathrm{mmHg}\right)$. Nagueh e cols., em 1997, descreveram que E/E' maior que 17, conforme encontramos nos animais associação, revela aumento da pressão capilar pulmonar média em cunha. Corroborando este achado, o peso dos pulmões corrigido pelo peso corporal dos ratos do modelo associação, se mostrou significativamente maior que o dos grupos controle e desnervado, o quê pode sugerir uma retenção hídrica em razão do aumento da pressão capilar hidrostática. Ademais, encontramos nestes animais, um aumento de peso do VD corrigido pelo peso corpóreo, muito provavelmente responsivo ao aumento da pressão capilar pulmonar. De fato, conforme descrição anterior, animais desnervados podem apresentar hipercapnia pela secção desproposital dos quimiorreceptores, uma vez que a localização anatômica destes é extremamente próxima a dos pressorreceptores (Van Vliet, 1999), fato que repercute na circulação pulmonar. Entretanto, no outro grupo no qual foram seccionados os pressorreceptores (DSA), não houve aumento do peso dos pulmões, tampouco do peso ventricular direito, indicando mais uma vez que a 
associação dos dois modelos (DSA + clipe) induz a alterações hemodinâmicas mais severas e agudas (10 dias), contra as alterações cronicamente induzidas na presença do barorreflexo (30 dias).

Estes animais também apresentaram aumento do índice de desempenho miocárdico, já indicando uma maior carga de trabalho nesse coração, como acontece na avaliação ecocardiográfica de corações infartados (Morgan e cols., 2004). Salemi e cols. (2004), também demonstraram aumento progressivo do IDM no curso temporal da hipertrofia cardíaca em ratos submetidos à cirurgia de coarctação da aorta ascendente. Nesse sentido, chamamos atenção para a correlação positiva que encontramos entre a espessura relativa da parede e o índice de desempenho miocárdico quando analisamos os dois grupos que tiveram a artéria renal esquerda clipada, associado ou não com a DSA ( $r=0,80$, $p<0,01)$. Nessa correlação, quanto maior a ERP, maior o IDM, indicando maior esforço do coração. Como no gráfico, o grupo clipe-10 está à esquerda e abaixo, e o grupo associação à direita e acima, estas alterações podem ter dependido da instalação da hipertensão, pois os níveis pressóricos atingidos foram diferentes e menores no grupo clipe-10 (Figura 23).

Analisando os dados das proteínas homeostáticas do $\mathrm{Ca}^{2+}$, percebe-se claramente uma disfunção cardíaca no grupo associação mais evidente do que no grupo clipe-30. Há uma diminuição da SERCA-2, responsável pela retirada 
do $\mathrm{Ca}^{2+}$ do citosol em 92\% (Bers, 2002), com aumento relativo do NCX quando comparado aos outros grupos, provavelmente na tentativa de aumentar a extrusão do $\mathrm{Ca}^{2+}$ citosólico. No entanto, o $\mathrm{NCX}$ extrui o $\mathrm{Ca}^{2+}$ para o líquido extra-celular, enquanto a SERCA-2 recapta o mesmo para o interior do RS. Baartscheer e cols. (2008) observaram que inibindo o trocador $\mathrm{Na}^{+} / \mathrm{Ca}^{2+} 1$ mês após a indução de hipertrofia cardíaca por sobrecarga de pressão/volume em coelhos, e mantendo essa inibição por cerca de 2 meses, há regressão da hipertrofia e redução dos sinais de insuficiência cardíaca.

Parece haver um consenso na literatura a respeito do aumento do NCX nos estágios avançados da insuficiência cardíaca, tanto na experimentação animal, (Hatem e cols., 1994; Lu e cols., 2002; Medeiros e cols., 2008; Ross e cols., 2007), quanto em seres humanos (Studer e cols., 1994). Embora os 30 dias de DSA interpostos a 10 dias de clipe não tenham sido suficientes para causar uma disfunção sistólica nestes animais, o déficit diastólico foi evidente, levando inclusive ao aumento de peso dos pulmões corrigido pelo peso corporal com relação aos outros grupos, provavelmente pela retenção hídrica em função do aumento da pressão capilar média em cunha, evidenciado pelo aumento do índice E/E'.

Além disso, a análise da razão SERCA-2/PLB no grupo associação também se mostrou reduzida, com aumento relativo do PLB defosforilado com 
relação à SERCA-2. Esses dados, somados ainda à diminuição do PLB fosforilado no sítio da treonina-17 corrigido pelo PLB total, explicam o maior prejuízo diastólico encontrado no grupo associação. Uma diminuição da recaptação de $\mathrm{Ca}^{2+}$ com a redução do PLB fosforilado (que aumentaria a atividade da SERCA-2), converge num aumento de $\mathrm{Ca}^{2+}$ citosólico durante a diástole, dificultando sobremaneira o relaxamento dos cardiomiócitos. Corroborando estas informações, encontramos uma correlaçào positiva entre a relaçào SERCA-2/PLB e o TRIVcorr $(r=0,76, p<0,01)$. Quanto maior o aumento relativo da SERCA-2 sobre o PLB, menos inibida estará a SERCA-2, o quê aumenta a recaptação de $\mathrm{Ca}^{2+}$ para o RS, facilitando a diástole. Convém aqui, nova referência às alterações encontradas nos índices de função diastólica no modelo associação pelo exame ecocardiográfico.

\subsection{CONSIDERAÇÕES FINAIS}

O presente estudo demonstra pela primeira vez, que a colocação do clipe na artéria renal em animais previamente desnervados (DSA 20 dias) provoca, em 10 dias, as mesmas respostas de hipertrofia com repercussão na função cardíaca que os animais com a preservação do barorreflexo têm, num tempo 
três vezes maior. O mesmo tempo de clipe (10 dias) em animais com a presença da proteção barorreflexa não induz a essas alterações, assim como na desnervação sino-aórtica isolada.

Quando associada à DSA, a colocação do clipe na artéria renal elevou a PA a níveis semelhantes aos observados na hipertensão renovascular 2K1C (30 dias), fato observado por nós, no presente estudo, e por outros pesquisadores (Goldblatt e cols., 1934; Pickering e cols., 1938; Buzello e cols., 2003). Masson e colaboradores haviam demonstrado na década de 60 que a DSA em ratos potencializava a hipertensão observada no modelo $1 \mathrm{~K} 1 \mathrm{C}$. Entretanto, o presente estudo demonstra que 10 dias após o clipe em animais intactos, não se verifica hipertensão. Entretanto a associação com a DSA além de promover a elevação da PA, também induziu um aumento na velocidade com que essa PA subiu quando comparada com a DSA ou com a colocação do clipe na artéria renal, isoladamente.

A que poderiam ser devidas estas respostas funcional e estrutural do coração frente à associação de DSA com 2K1C (10 dias)? Embora saibamos que o aumento da PA pode ser um dos mecanismos desencadeadores da resposta hipertrófica do coração, deve ficar claro que hipertensão semelhante observada no grupo clipe-30 produziu as mesmas alterações em tempo muito maior: 30 dias após a clipagem. Portanto, não só os níveis pressóricos 
atingidos, mas provavelmente a velocidade com que estes níveis são atingidos, deve ter sido decisivo para a resposta observada. Nem a diminuição da sensibilidade do barorreflexo nem a hipertensão isoladamente, produziram tal resposta, caracterizando a necessidade da associação desses dois elementos para a obtenção das respostas morfológica e funcional observadas.

Por outro lado, o aumento da labilidade isolado (12.5 \pm 1.73$)$ conforme observado na DSA, também não produziu esta resposta, levando-se em conta que a variabilidade da PA foi semelhante nesse grupo quando comparado ao grupo associação (11.4 \pm 0.96$)$, o mesmo tendo ocorrido com o coeficiente de variabilidade. De fato, embora a PA claramente tenha um papel na patogênese da hipertrofia cardíaca, também tem sido demonstrado que o aumento da massa cardíaca pode ser produzido na ausência de hipertensão, indicando que outros fatores além do estresse hemodinâmico podem também afetar a resposta hipertrófica do miocárdio (Cabral e cols., 1988 a e b; De Simone e cols., 2001; Schlaich e cols., 2003). Além disso, o aumento da variabilidade da pressão arterial tem sido associado com marcadores inflamatórios, principalmente a interleucina-6 e o fator de necrose tumoral, em pacientes hipertensos, sendo estes talvez, os mediadores da lesão de órgãos-alvo por ele causado (Kim e cols., 2008). Também tem sido proposto que o aumento da 
variabilidade da pressão arterial contribua significativamente para a progressão da aterosclerose (Eto e cols., 2003).

Resultados recentes mostraram que animais tratados com isoproterenol desenvolvem hipertrofia (Murad e Tucci, 2000) mediada pela estimulação dos receptores beta adrenérgicos (Gava e cols., 2004), sem hipertensão. De certa forma, também pudemos observar que não é só a elevação da PA o fator determinante da hipertrofia e das alterações funcionais aqui observadas. Foi necessária a retirada das aferências aórticas e carotídeas, de maneira a não contrabalançar homeostaticamente os efeitos produzidos pela clipagem da artéria renal, tanto hemodinâmicos como hormonais, que culminaram com as alterações morfo-funcionais cardíacas.

Está bem demonstrado na literatura que existe ativação do SRAA no modelo 2K1C no rato (Koletskys e cols., 1967) e que a resposta adaptativa do miocárdio depende da ativação da cascata desse sistema (Della-Bruna, 1995), do sistema nervoso simpático (Katholi e cols., 1983) e de outros (Ehmke e cols., 1999).

Embora o grupo associação tenha passado pela clipagem da artéria renal no vigésimo dia do protocolo experimental, enquanto o grupo clipe-30 o fez no início dos experimentos (portanto com pesos corporais e idades diferentes), acreditamos que este fator não tenha sido decisivo nas respostas 
cardiovasculares e hemodinâmicas sofridas pelo mesmo, uma vez que tomamos o cuidado de incluir o grupo clipe-10 no presente estudo. Este grupo, portanto, teve a artéria renal esquerda clipada com pesos corporais pareados com relação ao grupo associação e, tendo os pressorreceptores preservados, responderam de maneira muito diferente ao mesmo estímulo hipertensivo.

Dessa forma, pudemos confirmar a nossa hipótese de que a desnervação sino-aórtica muda os parâmetros morfo-funcionais induzidos pela hipertensão $2 \mathrm{~K} 1 \mathrm{C}$ e mais do que isso, de que o papel homeostáticos do barorreflexo é fundamental, não só para corrigir variações momento a momento da PA reduzindo ou, pelo menos, mantendo a variabilidade dentro de limites fisiológicos, mas também prevenindo a variação rápida, aguda e sustentada da PA, o quê certamente dificulta a resposta de ajuste à alterações patológicas.

A DSA, pela retirada das aferências aórticas e carotídeas, quando associada com a hipertensão renal do tipo $2 \mathrm{~K} 1 \mathrm{C}$ em ratos, potencializa a resposta hipertensora e a hipertrofia cardíaca, de maneira a induzir em curto espaço de tempo alterações da função sistólica e diastólica. 
TABELA 19 - Sumário dos efeitos do tempo de clipe na artéria renal

\begin{tabular}{|c|c|c|}
\hline & 10 dias de clipe & 30 dias de clipe \\
\hline PAM & $\Leftrightarrow$ & + \\
\hline VPAM & $\Leftrightarrow$ & $\Leftrightarrow$ \\
\hline BARORREFLEXO & - & -- \\
\hline BALANÇO AUTONÔMICO & $\Leftrightarrow$ & - \\
\hline MORFOLOGIA CARDÍACA & + & ++ \\
\hline FUNÇÃO SISTÓLICA & $\Leftrightarrow$ & + \\
\hline FUNÇÃO DIASTÓLICA & $\Leftrightarrow$ & - \\
\hline ALTERAÇÃO PROT. Ca ${ }^{2+}$ & + & ++ \\
\hline \multicolumn{3}{|c|}{$\begin{array}{l}\text { PAM: pressão arterial média; VPAM: variabilidade da pressão arterial média; } \\
\text { Prot. } \mathrm{Ca}^{2+} \text { : proteínas da homeostase do cálcio; } \Leftrightarrow \text { : sem alteração; +: alteração } \\
\text { discreta para valores mais altos; ++: alteração significativa para valores mais } \\
\text { altos; - : alteração discreta para valores mais baixos; - - : alteração significativa } \\
\text { para valores mais baixos. }\end{array}$} \\
\hline
\end{tabular}


TABELA 20 - Sumário dos efeitos da pressão arterial e da variabilidade da pressão arterial

\begin{tabular}{|c|c|c|}
\hline & 30 dias de clipe & ASSOCIAÇÃO \\
\hline PAM & + & + \\
\hline VPAM & $\Leftrightarrow$ & ++ \\
\hline BARORREFLEXO & - & -- \\
\hline BALANÇO AUTONÔMICO & - & - \\
\hline MORFOLOGIA CARDÍACA & + & ++ \\
\hline FUNÇÃO SISTÓLICA & $\Leftrightarrow$ & $\Leftrightarrow$ \\
\hline FUNÇÃO DIASTÓLICA & - & - \\
\hline ALTERAÇÃO PROT. $\mathrm{Ca}^{2+}$ & + & ++ \\
\hline
\end{tabular}

PAM: pressão arterial média; VPAM: variabilidade da pressão arterial média; Prot. $\quad \mathrm{Ca}^{2+}$ : proteínas da homeostase do cálcio; $\Leftrightarrow$ : sem alteração; +: alteração discreta para valores mais altos; ++: alteração significativa para valores mais altos; - : alteração discreta para valores mais baixos; - - :alteração significativa para valores mais baixos. 
CONCLUSÃO 


\section{CONCLUSÃO}

Concluímos, a partir desse estudo, que o papel homeostático do barorreflexo nas adaptações cardíacas e hemodinâmicas em resposta à hipertensão é essencial no curso dessas alterações, por sua ação não só no controle das variações momento a momento (labilidade) como também no seu papel tamponador em variações drásticas da PA, interferindo nas respostas hemodinâmicas, morfométricas e moleculares. Esses resultados dão suporte a estudos populacionais que associam a sensibilidade do barorreflexo com melhor prognóstico e sobrevida após evento cardiovascular. 
REFERÊNCIAS BIBLIOGRÁFICAS 


\section{REFERÊNCIAS BIBLIOGRÁFICAS}

Aiello EA, Villa-Abrille MC, Escudero EM, Portiansky EL, Perez NG, de Hurtado MC, Cingolani HE. Myocardial hypertrophy of normotensive Wistar-Kyoto rats. American Journal of Physiology. 2004, 286:H1229-235.

Alexander N, Kaneda N, Ishii A, Mogi M, Harada M, Nagatsu T. Right-left asymmetry of tyrosine hydroxylase in rat median eminance:influence of arterial baroreflex nerves. Brain Research. 1990; 253:195-198.

Averill DB, Ferrario CM, Tarazi RC, Sen S, Bajbus R. Cardiac performance in rats with renal hypertension. Circulation Research. 1976; 38:280-288.

Baartscheer A, Hardiyenka M, Schumacher CA, Belterman CNW, Borren MMGJV, VerkerkAO, Coronel R, Fiolet JWT. Chronic inhibition of the $\mathrm{Na}^{+} / \mathrm{H}^{+}$

- exchanger causes regression of hypertrophy, heart failure, and ionic and electrophysiological remodeling. British Journal of Pharmacology. 2008 [EPUB]. 
Balke CW, Shorofsky SR. Alterations in calcium handling in cardiac hypertrophy and heart failure. Cardiovascular Research. 1998; 37:290-299.

Barres C, Lewis SJ, Jacob HJ, Brody MJ. Arterial pressure lability and renal sympathetic nerve activity are dissociated in SAD rats. American Journal of Physiology. 1992; 263:R639-646.

Berridge MJ. Elementary and global aspects of calcium signalling. Journal of Physiology 1997; 499:291-306.

Bers DM. Cardiac excitation-contraction coupling. Nature. 2002; 415:198-205.

Bianchi GL, Tencani T, Lucca R. Effects in the conscious dog of constriction of the renal artery to a sole remaining kidney on haemodynamics, sodium balance, body fluid volume, plasma renin concentration and pressor responsiveness to angiotensin II. Clinical Science. 1970; 38:741-766. 
Bianchi G, Baldoni E, Lucca R, Barbin P. Pathogenisis of arterial hypertension after the constriction of the renal artery bearing the opposite kidney intactobath in the anesthetized and conscious dogs. Clinical Science. 1972; 42:651-667.

Braun-Menendez E, Fasciolo JC, Leloir LF, Munõz JM. The substance causing renal hypertesion. Journal of Physiology. 1940; 98:283-298.

Bright R. Tabular view of the morbid appearance in 100 cases, connected with albuminous urine with observations. Guys Hosp Rep 1836; 1:380-400.

Broberg CS, Pantely GA, Barber BJ, et al. Validation of the myocardial performance index by echocardiography in mice: a noninvasive measure of left ventricular function. Journal of the American Society of Echocardiography. 2003; 16:814-823.

Brunch, C; Schmermund, D.M.; Katz, M.; Bartel, T.; Schaar, J.; Erbel, R. Teiindex in patients with mild-to-moderate congestive heart failure. European Heart Journal. 2000; 21:1888-1895. 
Brunner HR, Kirshmann JD, Sealey JE, Laragh JH. Hypertension of renal origin: evidence for two different mechanisms. Science 1971; 174:1344-1346.

Buzello M, Boehm C, Orth S, Fischer B, Ehmke H, Ritz E, Mall G, Amann K. Myocyte loss in early left ventricular hypertrophy of experimental renovascular hypertension. Virchows Archieves.. 2003; 442:364-371.

Cabral AM, Antonio A, Moyses MR, Vasquez EC. Left ventricular hypertrophy differences between male and female renovascular hypertensive rats. Brazilian Journal of Medical and Biological Research. 1988; 21:633-635.

Cabral AM, Vasquez EC, Moyses MR, Antonio A. Sex hormone modulation of ventricular hypertrophy in sinoaortic denervated rats. Hypertension 1988; 11:193-197.

Carafoli E. Calcium signaling: a tale for all seasons. Proceedings of the National Academy of Science of the United States of America 2002; 99:1115-1122. 
Cash JR. A preliminary study of blood pressure following reduction of renal substance with a note on simultaneous changes in blood chemistry and blood volume. Bull Johns Hopkins Hosp Balt 1924; 35:168-180.

Cerqua S, Samaan A. Cure of experimental renal hypertension. Clinical Science. 1939; 40: 113-118.

Chautin A, Ferris EB. Experimental renal insufficiency produced by partial nephrectomy. Archieves of Internal Medicine. 1932; 49:767-787.

Choong CY, Abascal VM, Thomas JD, Guerrero JL, McGlew S, Weyman AE. Combined influence of ventricular loading and relaxation on the transmitral flow velocity profile in dogs measured by Doppler echocardiography. Circulation. 1988; 78:672-683.

Coleman TG, Guyton AC. Hypertension caused by salt loaded in the dog. Circulation Research. 1969; 25:136-160.

Colucci WS. Molecular and cellular mechanisms of myocardial failure. American Journal of Cardiology 1997; 80:15L-25L. 
Cowley AW, Jr, Guyton AC. Baroreceptor reflex effects on transient and steadystate hemodynamics of salt-loading hypertension in the dogs. Circulation Research. 1975, 36:536-546.

Dash R, Kadambi V, Schmidt AG, Tepe NM, Biniakiewicz D, Gerst MJ, Canning AM, Abraham WT, Hoit BD, Liggett SB, Lorenz JN, Dorin 2 ND GW, Kranias EG. Interactions between phospholamban and beta-adrenergic drive may lead to cardiomyophathy and early mortality. Circulation. 2001; 103:889-896.

De Simone G, Devereux RB, Camargo MJF, Volpe M, Wallerson DC, Atlas SA, Laragh $\mathrm{JH}$. In vivo left ventricular anatomy in rats with two-kidney, one clip and one-kidney, one clip renovascular hypertension. Journal of Hypertension. $1992 ; 10: 752-753$.

De Simone G, Devereux RB, Kimball TR, Roman MJ, Palmieri V, Celentano A, Daniels SR. Relation of heart rate to left ventricular dimensions in normotensive, normal-weight children, adolescents and adults. Italian Heart Journal. 2001; 2:599-604. 
Della-Bruna R, Bernhard I, Gess B, Schricker K, Kurtz A. Renin gene and angiotensin II $A T_{1}$ receptor gene expression in the kidneys of normal and of two-kidney/one clip rats. Pflugers Archieves. 1995; 430:265-272.

Desay A. Current understanding of heart failure with preserved ejection fraction. Current Opinion in Cardiology. 2007; 22(6):578-585.

DeQuattro V, Feng M. The sympathetic nervous system: the muse of primary hypertension. Journal of Human Hypertension. 2002; 16:s64-69.

Devereux, R.B. And N. Reichek. Echocardiographic determinations of left ventricular mass in man: anatomic validation of the method. Circulation. $1977 ; 55: 613-618$.

Devereux, R.B. Detection of left ventricular hypertrophy by M-mode echocardiography. Anatomic validation, standardization and comparison to other methods. Hypertension. 1987;9, Suppl.II:II-19-II-26. 
Devereux, R.B., D.R. Alonso, E.M. Lutas, G.J. Gottlieb, E. Campo, I. Sachs, And N. Reichek. Echocardiographic assessment of left ventricular hypertrophy: comparison to necropsy findings. American. Journal of. Cardiology. 1986; $57: 450-458$.

Dias D, Viana P, de M, Fazan R Jr, Ruscone TG, Porta A, Malliani A, Salgado HC, Montano NIntravenous amiodarone modifies autonomic balance and increases baroreflex sensitivity in conscious rats. Autonomic Neuroscience. 2002; 95:88-96.

Edmunds ME, Russell GI, Swales JD. Vascular capacitance and reversal of two kidney one clip hypertension in rats. American Journal of Phisioogy.l 1989; 256:H502-H507.

Ehmke H, Faulhaber J, Münter K, Kirchengast M, Wiesner RJ Chronic $E T_{A}$ receptor blockade attenuates cardiac hypertrophy independently of blood pressure effects in renovascular hypertensive rats. Hypertension. 1999; 33:954-960. 
Engelhardt S, Hein L, Wiesmann F, Lohse MJ. Progressive hypertrophy and heart failure in beta1-adrenergic receptor transgenic mice. Proceedings of the National Academy of Sciences of the United States of America. 1999; 96:7059-7064.

Eto M, Toba K, Akishita M, Kozaki K, Watanabe T, Kim S. Reduced endothelial vasomotor functional and enhanced neointimal formation after vascular injury in a rat model of blood pressure lability. Hypertension Research. 2003; 26:991-998.

Farah VM, Moreira ED, Irigoyen MC, Krieger EM. Baroreflex depression persists in the early phase after hypertension reversal. American Journal of Physiology. 2001; 280:R1620-1626.

Fard, A.; Wang, C.Y.; Takuma, S.; Skopicki, H.A.; Pinsky, D.J.; Di Tullio, M.R.; Homma, S. Noninvasive assessment and necropsy validation of changes in left ventricular mass in ascending aortic banded mice. Journal of the American Society of Echocardiography. 2000; 13:582-587. 
Ferrario CM. Contribution of cardiac output and peripheral resistance to experimental hypertension. American Journal of Physiology. 1974; 226:711-717.

Fischer M, Wiest G, Tekesin I, Amann K, Mann J, Hasslacher, Derks H, Mall G Effects of combined renovascular hypertension and diabetes mellitus on myocardial cells, non-vascular interstitium and capillaries: a stereological study on rat hearts. Virchows Archieves. 1992; 420:499-506.

Floras JS, Hassan MO, Jones JV, Osikowska BA, Sever PS, Sleight P. Consequences of impaired arterial baroreflexes in essential hypertension: effects on pressor responses, plasma noradrenaline and blood pressure variability. Journal of Hypertension. 1988; 6:525-535.

Folkow B, Hallback M, Lundgren $\mathrm{Y}$, Sivertsson R, Weiss L. Importance of adaptative changes in vascular desing for establishment of primary hypertension, studied in mass and in spontaneously hipertensive rats. Circulation Research. 1973; 32-33 (Suppl 1): 2-13. 
Fowler MR, Naz JR, Graham MD, Orchard CH, Harrison SM. Journal of Molecular and Cellular Cardiology. 2007; 42:582-589.

Franchini, KG and Krieger EM. Carotid chemoreceptor influence arterial pressure in intact and aortic-denervated rats. American Journal of Physiology. 1992; 262 R677-683.

Hallback-Nordlander M. Haemodynamic alterations after reversal of renal hypertension in rats. Clinical Science. 1979; 57:155-175.

Galinier M, Rouge P, Albenque JP, Assoun B, Massabuau P, Fauvel JM, Bounhore JP, Montastruc JL, Montastruc P. Absence of the effect of nitric oxide on pulmonary and systemic hypertendion induced by sino-aortic denervation. Archieves des Malaladies du Coeur et des Vaisseaux. 1995; 88:1209-1212.

Garcia MJ, Thomas JD, Klein AL. New Doppler echocardiographic applications for the study of diastolic function. Journal of the American College of Cardiology. 1998; 32:865-875. 
Gava AL, Peotta VA, Cabral AM, Meyrelles SS, Vasquez EC. Decreased baroreflex sensitivity in isoproterenol-treated mice with cardiac hypertrophy. Autonomic Neuroscience. 2004; 30;114:47-54.

Gavras H, Brunner HR, Thurston H, Laragh $\mathrm{JH}$. Reciprocation of tenin dependency with sodium volume deficiency in renal hypertension. Science. $1975 ; 188: 1316-1317$.

Goldblatt H, Lynch J, Hanzal RF, Summerville WW. Studies on experimental hypertension. 1: The production of persistent elevation of systolic blood pressure by means of renal ischaemia. Journal of Experimental Medical Sciences. 1934; 9:347-378.

Grassi, G. Sympathetic and baroreflex function in hypertension: implicantions for current and new drugs. Current Pharmaceutical Design. 2004; 10:35793589.

Greenwood JP, Scott EM, Stoker JB, Mary DASG. Hypertensive Left Ventricular Hypertrophy: Relation to Peripheral Sympathetic Drive. Journal of the American College of Cardiology. 2001; 38:1711-1717. 
Guyton AC. The regulation of cardiac output and arterial pressure control. Circulation. 198; 64(6):1079-1088.

Guyton AC, Coleman TG, Cowley AW Jr, Davis Manning R Jr, Norma RA Jr, Fergusson JS. A systems analyses approach to understanding long-range arterial blood pressure control and hypertension. Circulation Research. $1974 ; 55: 159-176$.

Hajjar RJ, Muller FU, Schmitz W, Schnabel P, Bohm M. Moleculas aspects of adrenergic signal transduction in cardiac failure. Journal of Molecular Medicine 1998; 76:747-755.

Hartman FW, Bollinger A, Douls HP. Experimental nephritis produced by radiation. American Journal of Medical Science. 1926; 172:478-500.

Hatem SN, Sham JS, Morad M. Enhanced $\mathrm{Na}(+)-\mathrm{Ca} 2+$ exchange activity in cardiomyopathic Syriam hamster. Circulation Research. 1994; 74:253-261. 
Hocher B, George I, Rebstock J, Bauch A, Schwarz A, Neumayer HH, Bauer C Endothelin system-dependent cardiac remodeling in renovascular hypertension. Hypertension. 1999; 33:816-822.

Holman DV, Page IH. The cardiac output in arterial hypertension II. A study of arterial hypertension produced by constricting the renal arteries in unanesthetized and anesthetized (pentobarbital) dogs. American Heart Journal. 1938; 16:321-328.

Irigoyen MC, Cestari IA, Moreira ED, Oshiro MS, Krieger EM. Measurements of renal sympathetic nerve activity in conscious sinoaortic denervated rats. Brazilian Journal of Medical and Biological Research. 1988; 21:869-872.

Irigoyen MC, Consolim-Colombo FM, Krieger EM. Controle cardiovascular: regulação reflexa e papel do sistema nervoso simpático. Revista Brasileria de Hipertensão 2001; 8:55-62.

Irigoyen MC, Krieger EM. Baroreflex control of sympathetic activity in experimental hypertension. Brazilian Journal of Medical and Biological Research. 1998; 31:1213-1220. 
Irigoyen MC, Moreira ED, Ida F, Pires M, Cestari IA, Krieger EM. Changes of renal sympathetic activity in acute and chronic conscious sinoaortic denervated rats. Hypertension. 1995; 26:1111-1116.

Ito $\mathrm{H}$, Hiroe $\mathrm{M}$, Hirata $\mathrm{Y}$, Fujisaki $\mathrm{H}$, Adachi $\mathrm{H}$, Akimoto $\mathrm{H}$, Ohta $\mathrm{Y}$, Marumo $\mathrm{F}$ Endothelin $\mathrm{ET}_{\mathrm{A}}$ receptor antagonist blocks cardiac hypertrophy provoked by hemodynamic overload. Circulation. 1994; 89:2198-2203.

Jones JV, Floras JS: Baroreflex sensitivity changes during the development of Goldblatt two-kidney one-clip hypertension in rats. Clinical Science. 1980; 59:347-353.

Junhong Wang, Jing Yang, Jizheng Ma, Shushu Zhu, Xiangjian Chen, Hengfang Wu, Di Yang, Jinan Zhang. Proteomic analysis of left ventricular diastolic dysfunction hearts in renovascular hypertensive rats. International Journal of Cardiology. 2008; 127:198-207. 
Kagaya Y, Hajjar RJ, Gwathmey JK, Barry WH, Lorell BH. Long-term angiotensin-converting enzyme inhibition with fosinopril improves depressed responsiveness to $\mathrm{Ca} 2+$ in myocytes from aortic-banded rats. Circulation. 1996; 94:2915-2922.

Kaplan NM. Primary Hypertension: Pathogenisis. In: Clinical Hypertension, Kaplan NM. Baltimore: Williams \& Wilkins, 1998; 41-99.

Katholi RE Renal nerves in the pathogenesis of hypertension in experimental animals and humans. American Journal of Physiology. 1983; 245:F1-F14.

Kim K, Lee JH, Chang HJ, Cho YS, Youn TJ, Chung WY, Chae IH, Choi DJ, Park $\mathrm{KU}, \mathrm{Kim} \mathrm{CH}$. Association Between Bood Pressure Variability and Inflammatory Marker in Hypertensive Patients. Circulation Journal. 2008; 72: 293-298. 
Kiss E, Ball NA, Kranias EG, Walsh RA. Differential changes in cardiac phospholamban and sarcoplasmatic reticular $\mathrm{Ca}(2+)$-ATPase protein levels. Effects on $\mathrm{Ca} 2+$ transport and mechanics in compensated pressure-overload hypertrophy and congestive heart failure. Circulation Research. 1995; 77:759764.

Koletskys, Rivera-Velez JM, Marsh DG, Pritchard WH. Relation of reninangiotensin system in renal hypertension. Proceedings of. Society for. Experimental. Biology and Medicine. 1967; 125:96-100.

Kost CK Jr, Li P, Pfeifer CA, Jackson EK. Telemetric blood pressure monitoring in benign 2-kidney, 1-clip renovascular hypertension: effect of chronic caffeine ingestion. Journal of Pharmacology and Experimental Therapeutics. 1994; 270:1063-1070.

Krieger EM, Irigoyen MC, Krieger JE. Fisiopatologia da hipertensão. Revista da Soiedade de Cardiologia do Estado de São Paulo. 1999; 9:1-7. 
Krieger EM, Marseillan RF. Aortic depressor fibers in the rat: an electrophysiological study. American Journal of Physiology. 1963; 205:771774.

Krieger EM, Salgado HC, Michelini LC. Resetting of the baroreceptors. Internal Rev Physiology. 1982; 26:119-146.

Krieger EM. Effect of sinoaortic denervation on cardiac output. American Journal of Physiology. 1967; 213:139-142.

Krieger EM. The acute phase of neurogenic hypertension in the rat. Experientia. 1970 15;26:628-629.

Krieger, EM. Neurogenic hypertension in the rat. Circulation Research. 1964; $\mathrm{XV}: 511-5217$.

Krishnan U. Diagnosis and management of primary pulmonary hypertension. Indian Journal of Pediatry. 2000; 67:523-527. 
La Rovere MT, Bigger JT Jr, Marcus FI, Mortara A, Schwartz PJ. Baroreflex sensitivity and heart-rate variability in prediction of total cardiac mortality after myocardial infarction. ATRAMI (Autonomic Tone and Reflexes After Myocardial Infarction) Investigators: Lancet. 1998; 351:478-84.

Ledingham JM, Cohen RD. The role of the heart in the pathogenesis of renal hypertension. Lancet 1963; ii: 979-981.

Lee Tsung-Ming, Lin Mei-Shun, Tsai Chang-Her, Chang Nen-Chung. Effect of pravastatin on left ventricular mass in the two-kidney, one-clip hypertensive rats. American Journal of Physiology. 2006; 291:H2705-H2713.

Liggett SB, Tepe NM, Lorenz JN, Canning AM, Jantz TD, Mitarai S, Yatani A, Dorn 2ND GW. Early and delayed consequences of beta(2)-adrenergic receptor overexpression in mouse hearts : critical role for expression level. Circulation. $2000 ; 101: 1707-1714$.

Lo M, Julien C, Michel JB, Vincent M, Cerutti C, Gomes-Sanchez CE, Sassard J. Antirenin immunization versus angiotensin converting enzyme inhibition in rats. Hypertension 1990; 16:80-88. 
Lu JY, Wu DM, Wu BW, Chai Wx, Kang Cs, Li TL. $\mathrm{Na}^{+} / \mathrm{Ca}^{2+}$ exchange current in myocytes isolated from rat hypertrophied heart. Sheng Li Xue Bao. 1999; 51:588-592.

Lu L, Mei DF, Gu AG, Wang S, Lentzner B, Gutstein DE, Zwas D, Homma S, Yi $\mathrm{GH}$, Wang J. Exercise training normalizer altered calcium proteins during development of heart failure. Journal of Applied Physiology. 2002; 92:15241530.

Lundin S, Friberg P, Hallback-Nordlander M. Left ventricular hypertrophy improves cardiac performances in spontaneously hypertensive rats. Acta Physiologica Scandinavica. 1982; 114:321-328.

Lopes HF, Silva HB, Soares JA, Filho B, Consolim-Colombo FM, Giorgi DM, Krieger EM. Lipid metabolism alterations in normotensive subjects with positive family history of hypertension. Hypertension. 1997; 30:629-631.

Lundgren Y, Weiss L. Cardiovascular desing after 'reversal' of long standing renal hypertension in rats. Clinical Science. 1979; 57 (Suppl 5):19-21. 
Mace LC, Palmer BM, Brown DA, Jew KN, Lynch JM, Glunt JM, Parsons TA, Cheung JY, Moore RL. Influence of age and run training on cardiac $\mathrm{Na}+\mathrm{Ca} 2+$ exchange. Journal of Applied Physiology. 2003; 95:1994-2003.

Mall G, Mattfeldt T, Rambausek M, Hasslacher C, Mann J, Ritz E. Reaction patterns of the myocardial interstitium in different models of cardiac hypertrophy-sterological investigations. Gegenbaurs Morphologisches Jahrbuch. 1989;135:151-158.

Mattiazzi A, Mundiña-Weilwnmann C, Guoxiang C, Vittone L, Kranias E. Role of phospholamban on $\mathrm{Thr}^{17}$ in cardiac physiological and pathological conditions. Cardiovascular Research. 2005; 68:366-375.

Mancia G, Ferrari A, Gregorini L, Parati G, Pomidossi G, Bertinieri G, Grassi G, di Rienzo M, Pedotti A, Zanchetti A. Blood pressure and heart variabilities in normotensive and hypertensive human beings. Circulation Research. 1983;53:96-104. 
Mancia G, grassi G, Ferrari AU. Reflex control of circulation in experimental and human hypertension. In: Zanchetti A, Mancia G. Handbook of hypertension, Pathophisiology of hypertension. Amsterdam: Elsevier Science Publishers BV. 1997. pp. 568-601.

Marks AR, Priori S, Memmi M, Kontula K, Laitinen PJ. Involvement of the cardiac ryanodine receptor/calcium release channel in catecholaminergic polymorphic ventricular tachycardia. Journal of Cellular Physiology. 2002; 190:1-6.

Massaki Z, Ferrario CM, Bumpus FM, Bravo EL, Khosla MC. The course of arterial pressure and effect of SAR-1 THR-8 angiotensin II in a new model of two kidney hypertension in conscious dogs. Clinical Science of $\mathrm{Mol}$ Medicine. 1977; 52:163-170.

Masson GMC, Aoki K, Page IH. Effects of sinoaortic denervation on renal and adrenal hypertension. American Journal of Physiology. 1966; 211:94-104. 
Masuyama T, Jung-Myung L, Yamamoto K, Tanouchi J, Hori M, Kamada T. Analysis of pulmonary venous flow velocity patterns in hypertensive heart: its complementary value in the interpretation of mitral flow velocities patterns. American Heart Hournal. 1992; 124:983-994.

McLennan DH, Kranias EG. Phospholamban: a crucial regulator of cardiac contractility. Nature. 2003; 4:566-577.

McDonald GJ, Boyd GW, Peart WS. Effect of angiotensin II blocker 1 Sar 8 Ala angiotensin II on renal artery clip hypertension in the rat. Circulation Research. 1975; 37: 640-646.

Medeiros A, Rolin NP, Oliveira RS, Rosa KT, Mattos KC, Casarini DE, Irigoyen MC, Krieger EM, Krieger JE, Negrao CE, Brum PC. Exercise Training Delays Cardiac Dysfunction and Prevents Calcium Handling Abnormalities in Sympathetic Hyperactivity-Induced Heart Failure Mice. Journal of Applied Physiology. 2008; 104:103-109. 
Meyer M, Schillinger W, Pieske B, Holubarsch C, Heilmann C, Posival H, Kuwajima G, Mikoshiba K, Just H, Hasenfuss G. Alterations of sarcoplasmatic reticulum proteins in failing human dilated cardiomyopathy. Circulation. 1995; 92:778-784.

Mikshe LW, Mikshe U, Gross F. Effect of sodium restriction on renal hypertension and rennin activity in the rat. Circulation Research. 1970; 27:973-984.

Miao CY, Su DF. The importance of blood pressure variability in rat aortic and left ventriculat hypertrophy produced by sinoaortic denervation Journal of Hypertension. 2002; 20:1865-1872.

Miao CY, Yuan WJ, Su DF. Comparative study of sinoaortic denervated rats and spontaneously hypertensive rats; Amercian Journal of Hypertension. 2003; 16:585-591.

Miao CY, Zhang LM, Yuan WJ, Su DF. Angiotensin II and AT1 receptor in hypertrophied ventricules and aortas of sinoaortic-denervated rats. Acta Pharmacologica Sinica. 2003; 24:812-818. 
Michelini L. Regulação neuro-humoral da pressão arterial. In: Fisiologia, Ayres MM, Rio de Janeiro: Guanabara Koogan, 1999. pp. 473-488.

Mill JG, Vassallo DV. Hipertrofia cardiaca. Revista Brasileira de Hipertensão. $2001 ; 8: 63-75$.

Morgan EE, Faulx MD, McElfresh TA, Kung TA, Zawaneh MS, Stanley WC, Chandler MP, Hoit BD. Validation of echocardiographic methods for assessing left ventricular dysfunction in rats with myocardial infarction. American Journal of Physiology. Heart and Circulatory Physiologyl. 2004; 287:H2049-2053.

Mori Y, Rice MJ, McDonald RW, Reller MD, Wanitkun S, Harada K, Sahn DJ. Evaluation of systolic and diastolic ventricular performance of the right ventricle in fetuses with ductal constriction using the Doppler Tei index. American Journal of Cardiology. 2001; 88:1173-1178.

Murad N, Tucci PJ. Isoproterenol-induced hypertrophy may result in distinct left ventricular changes. Clinical and Experimental Pharmacology and Physiology. . 2000; 27:352-357. 
Nagueh SF, Middleton KJ, Kopelen HA, Zoghbi WA, Quiñones MA. Doppler tissue imaging: a noninvasive technique for evaluation of left ventricular relaxation and estimation of filling pressures. Journal of the American College of Cardiology.. 1997; 30: 1527-1533.

Norman RA Jr, Coleman TG, Dent AC. Continuous monitoring of arterial pressure indicates sinoaortic denervated rats are not hypertensive. Hypertension. 1981; 3(1):119-125.

Norman RA Jr, Coleman TG, Dent AC. Pseudohypertension in sinoaorticdenervated rats. Clinical Science (Lond).1980 59 Suppl 6:303s-306s.

Norman RA Jr, Coleman TG, Dent AC: Continuous monitoring of arterial pressure indicates sinoaortic denervated rats are not hypertensive. Hypertension $1981 ; 3: 119-125$.

Osborn JW, England SK. Normalization of arterial pressure after barodenervation: role of pressure natriureses. American Journal of Physiology. 1990; 259:R1172-1180. 
Ou LC, Smith RP. Probable strain differences of rats in susceptibilities and cardiopulmonary responses to chronic hypoxia. Respiratory Physiology. 1983 Sep;53(3):367-377.

Page IH. Production of persistent arterial hypertension by cellophane perinephritis. JAMA The Journal of the American Medical Association. 1939; 113:2046-2048.

Pals DT, Masucci FD, Denning GS, Sipos F, Fessler DC. Role of pressor action of angiotensin II in experimental hypertension. Circulation Research. 1971; 29:673-681.

Pawlush DG, Moore RL,. Musch TI and Davidson WR Jr. Echocardiographic evaluation of size, function and mass of normal and hypertrophied rat ventricles Journal of Applied Physiology. 1993; 74(5):2589-2605. 
Pederson, AH. A method of producing experimental chronic hypertension in the rabitt. Archives of Pathology and Laboratory Medicine. 1927; 3:912.

Pickering GW, Prinzmetal M. Experimental hypertension of renal origin in rabbit. Clinical Science. 1938; 68:693-701.

Pickering GW, Prinzmetal M. Experimental hypertension of renal origin in the rabbit. Clinical Science. 1938; 3:357-368.

Qu P, Hamada M, Ikeda S, Hiasa G, Shigematsu Y, Hiwada K. Time-course changes in left ventricular geometry and function during the development of hypertension in Dahl salt-sensitive rats. Hypertension Research. 2000; 23:613-623.

Reams GP, Bauer JH. Angiotensin II potentiates the vasoconstrictive effect of norepinephrine in normotensive and hypertensive man. Journal of Clinical Hypertension. 1987; 3:610-616. 
Ribeiro JM, Santos RA, Pesquero JB, Bader M, Krieger EM. Autonomic control in rats with overactivity of tissue renin-angiotensin or kallikrein-kinin system. Regulatory Peptides. 2005; 129(1-3):155-159.

Rolin NP, Medeiros A, Rosa KT, Mattos KC, Irigoyen MC, Krieger EM, Krieger JE, Negrao CE, Brum PC. Exercise training improves the net balance of cardiac $\mathrm{Ca} 2+$ handling protein expression in heart failure. Physiological Genomics, 2007; 29: 246-252.

Ross KP, Jordan MC, Fishbein MC, Ritter MR, Friedlander M, Chang HC, Rahgozar P, Han T, Garcia AJ, MacLellan WR, Ross RS, Philipson KD. Hypertrophy and Heart Failure in Mice Overexpressing the Cardiac SodiumCalcium Exchanger. Journal of Cardiac Failure. 2007; 13(4):318-329.

Rossi A, Cicoira M, Florea VG, Golia G, Florea ND, Khan AA, Murray ST, Nquyen JT, O'Callaghan P, Anand IS, Coats A, Zardini P, Vassanelli C, Henein M. Chronic heart failure with preserved left ventricular ejection fraction: diagnost and prognostic of left atrial size. Internal Journal of Cardiology. 2006; 110(3):386-392. 
Russel GI, Bing RS, Swales JD, Thurton H. Hemodynamic changes induced by reversal of early and late renovascular hypertension. American Journal of Phisiology. 1983; 245: H734-H740.

Rytand DA. The renal factor in arterial hypertension with coarctation of the aorta. Journal of Clinical Investigation. 1938;17:391-399.

Salemi VMC, Pires MD, Cestari IN, Cestari IA, Picard MH, Leirner AA, Mady, C. Echocardiographic assessment of global ventricular function using the myocardial performance index in rats with hypertrophy. Artificial Organs. 2004; 28:332-337.

Sahn DJ, Demaria A, Kisslo J, Weyman A. Recommendations regarding quantitation in M-mode echocardiography: results of a survey of echocardiographics measurements. Circulation. 1978; 58:1072-1083.

Setoguchi Y, Fukuchi Y. Gene therapy for pulmonary hypertension. Nippon Rinsho. 2001; 59:1151-1158. 
Shade RE, Bishop VS, Haywood JR, Hamm CK. Cardiovascular and neuroendocrine responses to baroreceptor denervation in baboons. American Journal of Physiology. 1990; 258:R930-938.

Shan ZZ, Dai SM, Fang F, Su DF. Angiotensin II contents in plasma, and cardiac and renal tissues of sinoaortic denervated rats. Sheng Li Xue Bao. 2003; 25; $55: 75-87$

Schiller NB, Acquatella H, Ports TA, Drew D, Goerke J, Ringertz H, Silverman $\mathrm{NH}$, Brundage B, Botvinick EH, Boswell R, Carlsson E, Parmley WW. Left ventricular volume from paired biplane two-dimensional echocardiography. Circulation. 1979; 60:547-555.

Schlaich MP, Kaye DM, Lambert E, Sommerville M, Socratous F, Esler MD. Relation between cardiac sympathetic activity and hypertensive left ventricular hypertrophy. Circulation.2003; 108:560-565. 
Schwinger RH, Munch G, Bolck B, Karczewski P, Krause EG, Erdmann E. Reduced $\mathrm{Ca}^{2+}$ sensitivity of SERCA2a in failing human myocardium due to reduced serin-16 phospholamban phosphorilation. Journal of Molecular and Cellular Cardiology 1999; 31:479-91.

Signolet I, Gasser B, Bousquet P, Monassier L. Echocardiography in conscious $1 \mathrm{~K}, 1 \mathrm{C}$ Goldblatt rabbits reveals typical features of human hypertensive ventricular diastolic dysfunction. Internal Journal of Cardiology. 2007 [EPUB].

Skeggs LT, Marsh WH, Kahn JR, Shumway NP. The existence of two forms of hypertension. Journal of Experimental Medicine. 1954; 99:275-282.

Slama M, Ahn J, Peltier M, Maizel J, Chemla D, Varagic J, Susic D, Tribouilloy C, Frohlich ED. Validation of echocardiographic and Doppler indexes of left ventricular relaxation in adult hypertensive and normotensive rats. American Journal of Physiology. Heart and Circulatory Physiologyl. 2004; 289:11311136. 
Slama M, Ahn J, Varagic J, Susic D, Frohlich ED. Long-term left ventricular echocardiographic follow up of SHR and WKY rats: effects of hypertension and age. American Journal of Physiology. Heart and Circulatory Physiologyl. 2004; 286:181-185.

Slama M, Susic D, Varagic J, Ahn J, Frohlich D. Echocardiographic measurement of cardiac output in rats. American Journal of Physiology. 2003; 284:691-697.

Smith SH, Bishop SP. Selection criteria for drug-treated animals in two-kidney, one-clip renal hypertension. Hypertension. 1986; 8(8):700-705.

Smith SH, McCaslin M, Sreenan C, Bishop SP. Regional myocyte size in twokidney, one clip renal hypertension. Journal of Molecular and Cellular Cardiology. 1988; 20:1035-1042.

Stormark TA, Strommen K, Iversen BM, Matre K. Three-dimensional ultrasonography can detect the modulation of kidney volume in two-kidney, one-clip hypertensive rats. Ultrasound in Medicine and Biology. 2007 [EPUB]. 
Studer R, Reinecke H, Bilger J, Eschenhagen T, Bohm M, Hsenfuss G, Just H, Holtz J, Drexler $\mathrm{H}$. Gene expression of the cardiac $\mathrm{Na}^{+} / \mathrm{Ca}^{2+}$ exchanger in end-stage human heart failure. Circulation. 1994; 75:443-453.

Su DF, Chen L, Kong XB, Cheng Y. Determination of arterial baroreflex-bllod pressure control in conscious rats. Acta Pharmacologica Sinica. 2002; 23:103-109.

Su DF, Miao CY: Arterial baroreflex function in conscious rats. Acta Pharmacologica Sinica. 2002; 23:673-679.

Su DF, Miao CY. Blood pressure variability and organ damage. Clinical and Experimental Pharmacology and Physiologyl. 2001; 28:709-715.

Sumitani M, Krieger EM. Regression of the baroreceptor resetting in hypertension of long duration in rats. Clinical Science. 1981; 16 Suppl 7; $185 s-186 s$.

Swales JD, Thurston H, Queiroz FP, Medina A, Holland J. Dual mechanism for experimental hypertension. Lancet. 1971; ii: 1181-1184. 
Tanaka Y, Bernstein ML, Mecham RP, Patterson GA, Cooper JD, Botney MD. Site-specific responses to monocrotaline-induced vascular injury: evidence for two distinct mechanisms of remodeling. American Journal of Respiratory and Cellular Molecular Biology. 1996; 15(3):390-397.

Tei, C. New noninvasive index for combined systolic and diastolic ventricular function. Journal of Cardiology. 1995; 26:135-136.

Tei, C.; Nishimura, R.A.; Seward, J.B.; Tajik, A.J. Noninvasive Doppler-derived myocardial performance index: correlation with simultaneous measurements of cardiac catheterization measurements. Journal of the American Society of Echocardiography. 1997; 10:169-178.

Teichholz LE, Cohen MV, Sonnenblick EH, Gorlin R. Study of left ventricular geometry and function by B-scan ultrasonography in patients with and without asynergy. New England Journal of Medicine. 1974; 291:1220-1226.

Thurston H, Swales JD. Comparsion of angiotensin II antagonist and amtiserum with nephrectomy in the two kidney Goldblatt hypertensive rat. Circulation Research. 1974; 35: 325-329. 
Tigerstedt R, Bergmann PG. Niere and Kreislauf. Skandinar Archieves of Phisiology. 1898; 7-8: 223-271.

Van Vliet BN, Chafe LL, Montani JP: Contribution of baroreceptors and chemoreceptors to ventricular hypertrophy produced by sinoaortic denervation in rats. Journal of Physiology. 1999; 516:885-895.

Van Vliet BN, Hu L, Scott T, Chafe L, Montani JP: Cardiac hypertrophy and telemetered blood pressure 6 wk after baroreceptor denervation in normotensive rats. American Journal of Physiology. 1996; 271: R1758R1769.

Vasquez EC, Krieger EM. Decreased chronotropic responses to adrenergic stimulation following sinoaortic denervation in the rat. Brazilian Journal of Medical and Biological Research. 1982; 15:377-387.

Watson LE, Sheth M, Denyer R, Dostal DE. Baseline Echocardiographic Values For Adult Male Rats. Journal of the American Society of Echocardiography. $2004 ; 17: 161-167$ 
Wilson C, Byrom FB. Renal changes in malignant hypertension. Lancet.1939; i: 136-139.

Wright JW, Mizutani S, Harding JW. Pathways involved in the transition from hypertensive to hypertrophy to heart failure. Treatment strategies. Heart Failure Reviews. 2007. [EPUB]

Yamamoto J, Ogino K. Total venous capacity in two kidney one clip Goldblatt hypertensive rats. Japanese Circulation Journal. 1982; 46:21-26.

Ylitalo A, Airaksinen KE, Hautanen A, Kupari M, Carson M, Virolainen J, Savolainen M, Kauma H, Kesäniemi YA, White PC, Huikuri HV. Baroreflex sensitivity and variants of the renin angiotensin system genes. Journal of the American College of Cardiology. 2000; 35(1);194-200.

Zanchi A, Wiesel P, Aubert JF, Brunner HR, Hayoz D. Time course changes of the mechanical properties of the carotid artery in renal hypertensive rats. Hypertension. 1997; 29:1199-1203. 
Zaugg M, Schaub MC. Cellular mechanisms in sympatho-modulation of the heart. British Journal of Anaesthesia. 2004; 93:34-52. 